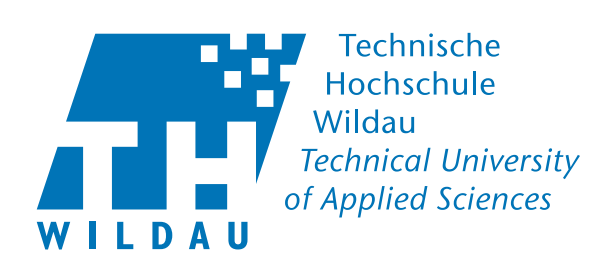

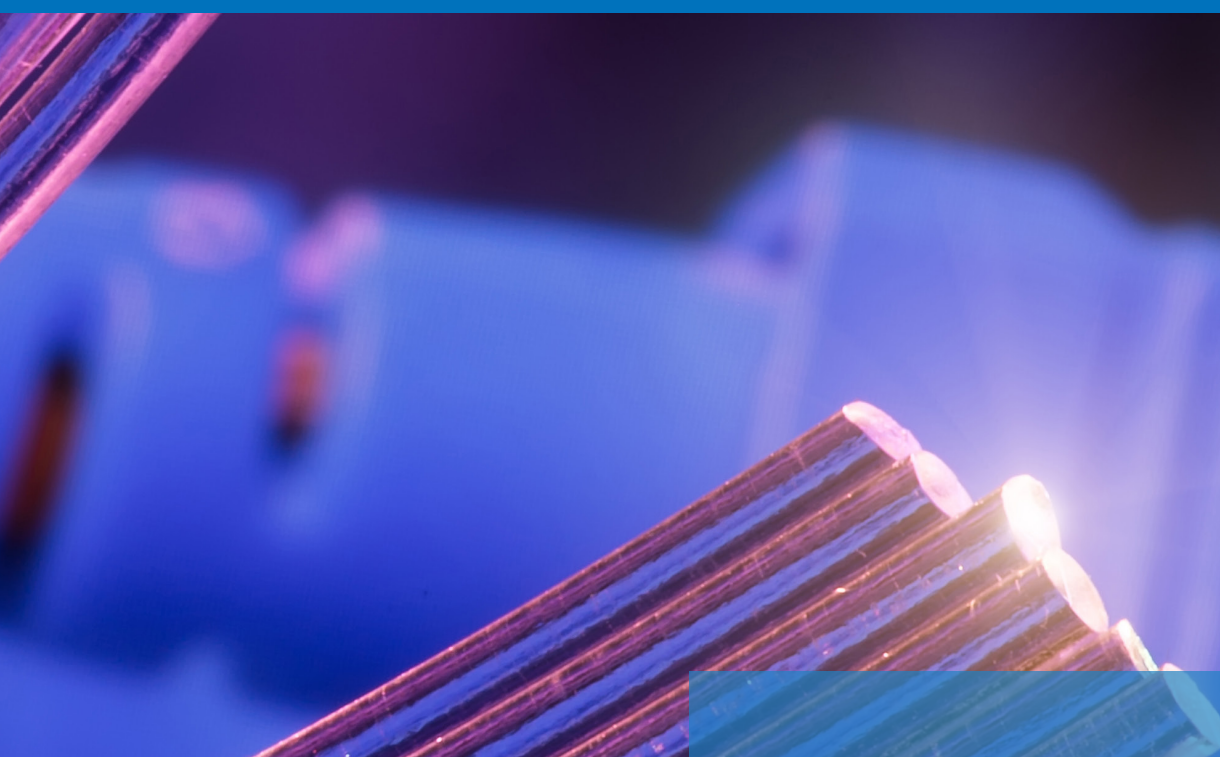

\title{
FORSCHUNGSBERICHT 2016
} FORSCHUNG | ENTWICKLUNG | LEHRE

Projekte und Publikationen der TH Wildau 


\title{
IMPRESSUM
}

\author{
HERAUSGEBER
}

Der Vizepräsident für Forschung und Unternehmenskontakte der Technischen Hochschule Wildau

Prof. Dr. Ralf Vandenhouten

Hochschulring 1

15745 Wildau

www.th-wildau.de

\section{REDAKTION}

Markus Vossel, Marianne Polkau

Telefon +49 (0) 3375 / 508-673

markus.vossel@th-wildau.de

\section{GESAMTHERSTELLUNC}

STÜRMER \& DRÄNGER - Visuelle Kommunikation GmbH

Richard-Sorge-Straße 24

10249 Berlin

Telefon (030) 48624764

kontakt@stuermer-draenger.de

www.stuermer-draenger.de

Titelfoto: asharkyu/Shutterstock.com

DOI: 10.15771/FB_2017_1

Der Forschungsbericht erscheint unter der Creative-Commons-Lizenz CC-BY-NC-ND.

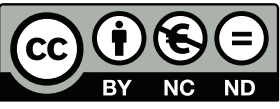

ERSCHEINUNGSDATUM

April 2017

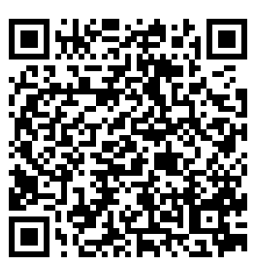

Hier finden Sie den Forschungsbericht zum kostenlosen Download. http://www.th-wildau.de/forschung/forschungsbericht.html 


\section{FORSCHUNGSBERICHT 2016}




\section{INHALTSVERZEICHNIS}

Forschungsbericht 2016

Grußwort des Präsidenten

Einführung in den Forschungsbericht

Übersicht über die laufenden Forschungsund Transferprojekte nach Forschungsbereichen der TH Wildau

FORSCHUNGSFELDER
9 Angewandte Biowissenschaften Applied Life Sciences

27 Informatik und Telematik Informatics and Telematics

41 Optische Technologien und Photonik Optical Technologies and Photonics

49 Produktion und Material Production and Materials

67 Verkehr und Logistik Transport and Logistics

75 Management und Recht Management and Law 


\section{GRUSSWORT \\ PROF. DR. LÁSZLÓ UNGVÁRI}

Die Technische Hochschule Wildau liegt vor den Toren Berlins im Land Brandenburg. Sie versteht sich als forschende Fachhochschule und ist als solche ein wichtiger Akteur in der Forschungslandschaft der Hauptstadtregion. Über die Forschungsaktivitäten zu berichten, gehört zu den Aufgaben einer mit Steuergeldern finanzierten Hochschule. Bereits zum achten Mal legt die TH Wildau den Forschungsbericht vor und informiert über die Projekte, die an der Hochschule 2016 bearbeitet wurden. Das Spektrum der Projektarten ist groß und reicht von kleineren Beratungs- und Forschungsprojekten bis zu mehrjährigen großen Verbundprojekten, die mit Partnern aus Wirtschaft und Wissenschaft bearbeitet werden. Die TH Wildau hat sich überregional einen sehr guten Ruf als kompetenter und verlässlicher Partner erarbeitet.

Kooperationsnetzwerke für den Wissens- und Technologietransfer verbinden unsere Hochschule mit international tätigen Großunternehmen der Industrie ebenso wie mit innovativen kleinen und mittleren Unternehmen in der Hauptstadtregion und darüber hinaus. Dabei bilden die angewandte Forschung und Entwicklung (F\&E) die Grundlage der Forschungsaktivitäten. Der deutsche Mittelstand ist ein enger Kooperationspartner, und so ist es nicht verwunderlich, dass 2016 allein 10 Vorhaben im Zentralen Innovationsprogramm des Mittelstands (ZIM) des Bundesministeriums für Wirtschaft und Technologie (BMWi) erfolgreich eingereicht werden konnten.
In Zukunft wollen die Technische Hochschule Wildau und die Brandenburgische Technische Universität Cottbus-Senftenberg intensiver zusammenarbeiten. So wurde im Herbst 2016 eine strategische Partnerschaft beschlossen, um gemeinsame Aktivitäten in den Bereichen Ausbildung, Forschung sowie Wissens- und Technologietransfer für die Wirkungsregion der beiden Hochschulen voranzutreiben. Die beiden Hochschulen sind überzeugt, dass durch eine gemeinsame Arbeit die Chancen der Region besser genutzt und Herausforderungen besser bewältigt werden können. Mit ihren Kompetenzen in der Grundlagen- und der angewandten Forschung werden die Hochschulen einen Beitrag zur Entwicklung der Region leisten. Im Zentrum der gemeinsamen Transferarbeit steht der systematische Austausch mit wichtigen regionalen Akteuren aus Wirtschaft, Forschung, Politik und Gesellschaft.

Erfolgreiche Projektarbeit ist ohne Zusammenarbeit mit Partnern nicht möglich. Im nationalen Kontext engagiert sich die Hochschule in über 30 Netzwerken und pflegt vielfältige Kooperationen mit Unternehmen, Hochschulen und Forschungseinrichtungen. Die TH Wildau pflegt Kontakte in den Bereichen Forschung und Lehre zu 148 ausländischen Partnern in 60 Ländern. Geographisch erstreckt sich die Zusammenarbeit dabei in den asiatischen Raum (z. B. Kasachstan, Pakistan, Indien, China) und den Mittleren Osten (Abu Dhabi) ebenso wie nach Mittel- und Südamerika und Ostafrika (Kenia).

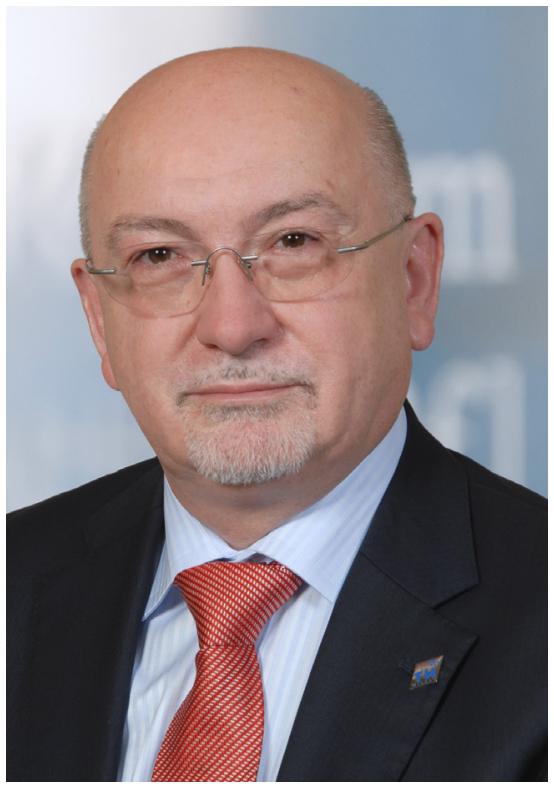

Ich lade Sie herzlich ein zu der Lektüre des vorliegenden Forschungsberichts, in dem Sie sich über die Jahresbilanz unserer Hochschule informieren können.

Alle Projekte finden Sie auch in der Projektdatenbank auf den Internetseiten der TH Wildau (http://www.th-wildau. de/forschung/projektdatenbank.html).

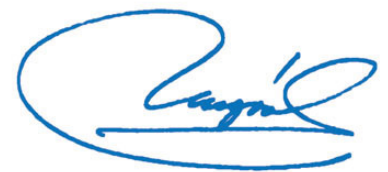

Prof. Dr. László Ungvári

Präsident der TH Wildau 


\section{EINLEITUNG}

\section{PROF. DR. RALF VANDENHOUTEN}

Angewandte Forschung und Entwicklung prägen den Charakter der $\mathrm{TH}$ Wildau, und Partner aus Wirtschaft, Politik und Verwaltung schätzen die Hochschule als verlässlichen Akteur. Auch 2016 konnte die TH Wildau ihren erfolgreichen Weg fortsetzen.

Drittmittel sind ein Indikator für erfolgreiche Forschungs- und Entwicklungsaktivitäten. Im Jahr 2016 lag das Drittmittelaufkommen der TH Wildau bei gut 10,5 Mio. Euro. Durch die eingeworbenen Drittmittel erhöhte sich der durch die Grundfinanzierung gedeckte Haushalt der Hochschule um fast zwei Drittel. Das ist bundesweit erneut ein Spitzenwert. Die Drittmitteleinnahmen lagen in den vergangenen 15 Jahren bei durchschnittlich 6,76 Mio. Euro, wobei es fast durchgängig einen Anstieg der Einnahmen pro Jahr gab. So konnte die Hochschule in den letzten fünf Jahren Drittmitteleinnahmen von durchschnittlich 10,86 Mio. Euro jährlich einwerben.

Die TH Wildau hat in den vergangenen Jahren die Interdisziplinarität in der Forschung auf verschiedene Weise gestärkt. Als ein Wegbereiter für disziplinübergreifende Projekte und Vorhaben hat die Digitalisierung in den vergangenen Jahren für die TH Wildau an Bedeutung gewonnen. Die moderne Arbeits- und Lebenswelt zeichnet sich dadurch aus, dass zunehmend Prozesse miteinander verknüpft und automatisiert werden. Die Informationsund Kommunikationstechnologien (IKT) sind der Treiber dieser Entwicklung. Die Verknüpfung und Automatisierung von Prozessen verschiedener Gewerke mittels IKT wird als digitale Integration verstanden. Sowohl die Hochschule als auch ihre Kooperationspartner stehen in diesem Bereich vor großen Herausforderungen. Für die TH Wildau ist es daher sinnvoll, die entsprechenden Aufgaben proaktiv anzugehen und Entwicklungen mitzugestalten.
Seit Oktober 2016 läuft beispielsweise unter der Koordination der Transferstellen der TH Wildau das „Pilotprojekt zur Vernetzung von Laboren und Entwicklung einer Testumgebung“. Die Idee dahinter ist, dass Labore an der TH Wildau vernetzt und so Prozesse der (digitalen) Integration sowohl intern als auch extern besser dargestellt und verstanden werden können. Im Rahmen der internen Zielvereinbarung sollen exemplarisch Labore aus den Bereichen Automatisierung, Wirtschaftsinformatik, Logistik und Telematik vernetzt und die Möglichkeiten der Interaktion der Bereiche erforscht und getestet werden. Es wird dabei ein skalierbares Modell entwickelt, das die digitale In-tegration von Laboren und Laboreinheiten sowie eine geringe Anschlusshürde weiterer Bereiche zum Ziel hat.

Zudem gibt es seit Juli 2016 eine Arbeitsgruppe zur Thematik der Digitalisierung, die sich aus Hochschulprofessorlnnen und MitarbeiterInnen zusammensetzt, die die Kompetenzen der einzelnen Forschungsfelder und -gruppen im Gebiet der digitalen Integration systematisch erfassen und in gemeinsamen hochschulweiten Umsetzungsprojekten weiterentwickeln.

Viele Forschungsarbeiten und Projekte befassen sich in ihrem Kern bereits mit der digitalen Integration. In dieser Ausgabe des Forschungsberichte kennzeichnen wir diese Vorhaben gesondert mit DII, um Ihnen eine Übersicht über die Spannweite der digitalen Integration zu geben.

Forschung bildet auch einen elementaren Bestandteil der praxisbezogenen Lehre, die ein Markenzeichen unserer Ausbildung ist. Für uns bilden Forschung und Lehre eine Einheit. Denn praxisorientierte Lehre muss sich durch die Forschungstätigkeit der Kolleginnen und Kollegen immer wieder erneuern und am aktuellen Stand der Wissenschaft ausrichten.

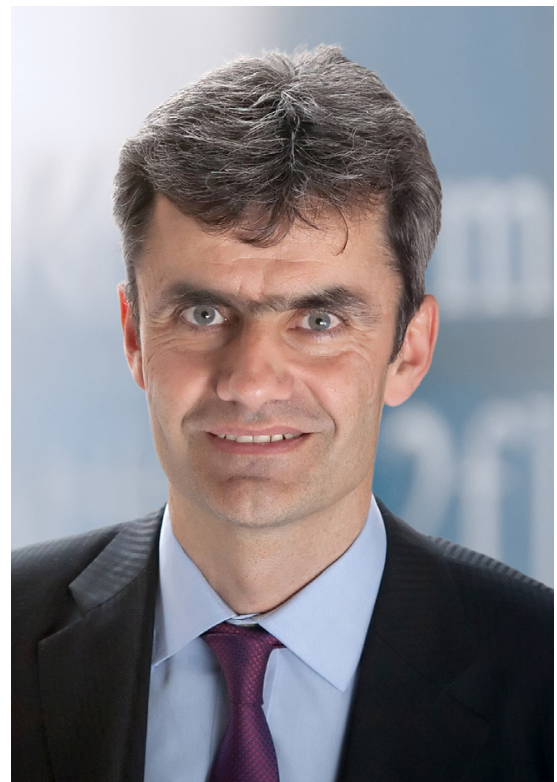

Die anwendungsorientierten Forschungsprojekte bereichern nicht nur Lehre und Studium durch anspruchsvolle Themen. Sie bieten Studierenden auch die Möglichkeit zur aktiven Mitwirkung bereits während des Studiums und stellen die zentrale Finanzquelle für die praxisnahe Forschung der Zukunft dar.

Wie die Lehre gehört an der TH Wildau zur Forschung auch der Wissens- und Technologietransfer. Angewandte Forschung und Entwicklung sind kein Selbstzweck, sondern sie leisten einen Beitrag zu unserem gesellschaftlichen Wohlstand.

Einem strategischen Prozess folgend wurden die Transfereinrichtungen der TH Wildau im Zentrum für Forschung und Transfer (ZFT) zusammengeschlossen. Bei der Beantragung und Realisierung der F\&E-Projekte ebenso wie bei den WTT-Aktivitäten werden die Professorinnen und Professoren vom Forschungsservice und dem Transferservice unterstützt. Während der Transferservice den Schwerpunkt auf Projekte der Hochschule mit brandenburgischen KMU legt, betreut der Forschungsservice F\&E-Anträge 


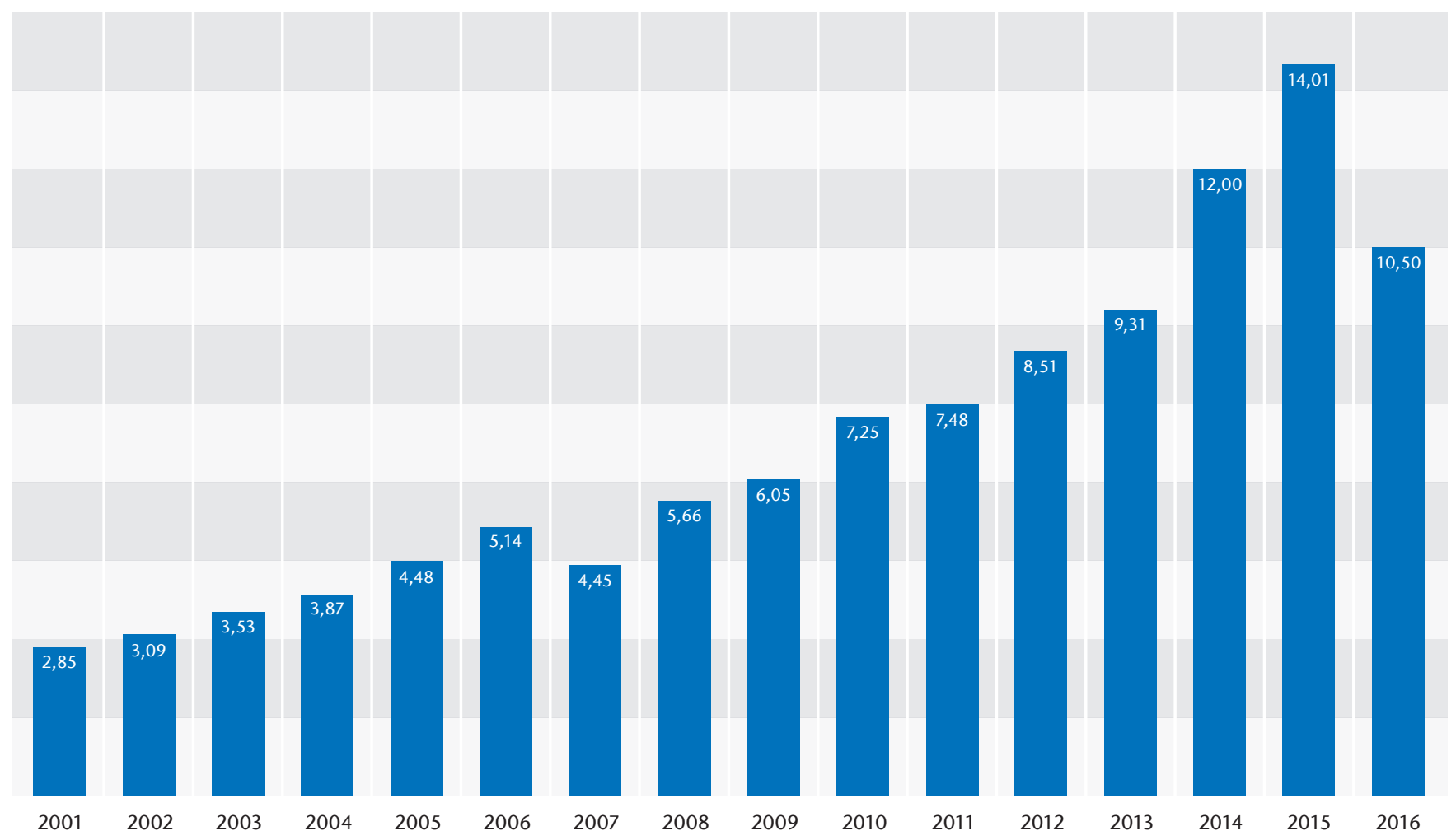

in Landes-, Bundes- und EU-Programmen. Der Wissens- und Technologietransfer wird zudem ergänzt durch den Gründungsservice sowie den Career Service der TH Wildau. Der Gründungsservice ist die zentrale Anlaufstelle für Studierende oder Wissenschaftler, wenn es um die Themen Unternehmensgründung und Entrepreneurship geht. Der Career Service hilft Studierenden und Absolventen bei Fragen zum Berufseinstieg und zur Karriereplanung und steht Unternehmen in allen Bereichen des Recruitings als kompetenter Partner zu Verfügung.

Mit der verstärkten Öffnung für Interessenten außerhalb der Hochschule festigt die TH Wildau entsprechend ihrem Leitbild ihre Rolle als gefragter und zuverlässiger Partner der Wirtschaft und als Wachstumsmotor der Region. Vor allem kleine und mittlere Unternehmen profitieren von der angewandten Forschung, können eigene Forschungskompetenzen entwickeln und so ihre Wettbewerbsfähigkeit sichern.
Das zentrale An-Institut Technologie- und Weiterbildungszentrum an der TH Wildau e.V. (TWZ e.V.) hat sich als Dach für die dort ansässigen Institute bewährt. Die Institute des TWZ e. V. führen vorwiegend Auftragsforschung und -entwicklung sowie Dienstleistungsprojekte durch, z.B. im Weiterbildungsbereich. Das TWZ e. V. besitzt wie die TH Wildau auch eine Zertifizierung nach ISO 9001:2008.

Die technische Ausstattung der Hochschule ist hervorragend, weil die $\mathrm{TH}$ Wildau in den vergangenen zwei Dekaden überdurchschnittlich erfolgreich Infrastrukturmittel einwerben konnte. Gerade die geräteintensiven Forschungsschwerpunkte, wie zum Beispiel Angewandte Biowissenschaften, Optische Technologien/ Photonik oder Informatik/Telematik, können eine national wie international wettbewerbsfähige Infrastruktur vorweisen. Dadurch existieren Rahmenbedingungen, in denen exzellente Forschungs- und Entwicklungsleistungen möglich sind. An dieser Stelle sei auch auf den Transferpass der TH
Wildau verwiesen (www.transferpass.de). Die Hochschule zeichnet ein forschungsfreundliches Klima aus, das den Forschergeist der Kolleginnen und Kollegen inspiriert und auch zunehmend zu disziplinübergreifenden Forschungsprojekten führt.

Der vorliegende Forschungsbericht 2016 gibt eine Übersicht über die laufenden Projekte aus dem Jahr 2016. Ausgewählte Projekte werden zudem ausführlicher dargestellt. Die Projekte sind geordnet nach den Forschungsfeldern. Ich wünsche Ihnen eine anregende Lektüre. Wir freuen uns über Ihre Kontaktaufnahme - wenn Sie Fragen oder Anregungen haben oder wenn Sie sich für eine Zusammenarbeit in bestimmten Bereichen interessieren.

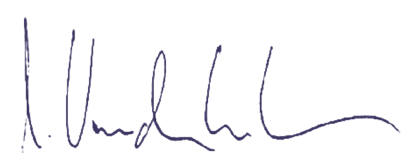

Prof. Dr. Ralf Vandenhouten

Vizepräsident für Forschung und Unternehmenskontakte 


\section{ÜBERSICHT ÜBER DIE LAUFEN- DEN FORSCHUNGS- UND TRANSFERPROJEKTE 2016}




\section{Angewandte Biowissenschaften Applied Life Sciences}




\title{
LipH Cycle: Lichtgesteuerte Nukleinsäurereaktionen für die Point-of-Care-Diagnostik
}

\author{
Prof. Dr. Marcus Frohme, Prof. Dr. Sigurd Schrader
}

PROJEKTMITARBEITER(INNEN) Heike Kagel, Dr. Jörn Glökler, Dr. Friedhelm Heinrich

PROJEKTVOLUMEN

MITTELGEBER

LAUFZEIT
$450.350 €$

Land Brandenburg | MWFK | EFRE

$01 / 2016-12 / 2018$
In diesem Projekt soll eine neue interdisziplinäre NukleinsäurereaktionsTechnologie entwickelt werden. Ziel ist es, darauf basierend neue Nachweissysteme für die Point-of-CareDiagnostik (POCD) zu ermöglichen. Für POCD ist es sehr vorteilhaft, Reaktionen ohne direkten Eingriff in die chemischen Bedingungen, also nichtinvasiv, steuern zu können. Für homogene Nachweisreaktionen eignet sich insbesondere die Steuerung durch Licht. Ein wichtiger Vorteil besteht dabei in der schnellen Umsetzung der Reaktion. Außerdem erlaubt der Einsatz von Lichtquellen vergleichsweise leicht eine Miniaturisierung der technischen Umgebung.

Für die Umsetzung von Licht in eine Reaktion sollen Farbstoffe verwendet werden, die nach Anregung die $\mathrm{pH}$ Bedingungen in der Reaktionslösung verändern können. Beispielsweise kann die Struktur der Nukleinsäuren oder auch die Aktivität von Enzymen über sogenannte Photobasen und Photosäuren gezielt manipuliert werden.
Zu diesem Zweck wurden mehrere Farbstoffe auf ihre Kompatibilität mit Enzymen untersucht. Als erste konnte die Photosäure HPTS (8-Hydroxypyrene-1,3,6-Trisulfonsäure) identifiziert werden, die unter Belichtung den $\mathrm{pH}$ Wert eines Puffers verändern kann. Als Lichtquelle wurden HochleistungsLEDs verwendet, um ausreichend Energie für die Reaktion in einem geeigneten Volumen bereitzustellen. HPTS kann durch Anregung eine starke Veränderung des $\mathrm{pH}$-Wertes bewirken, jedoch ist die Reaktion entgegen den Literaturangaben weitgehend irreversibel. Mittels HPTS konnte nachweislich die Aktivität der S1-Nuklease durch Ansäuerung des Puffers spezifisch angeschaltet werden, ohne dafür das Reaktionsgefäß zu öffnen. Damit konnte das grundlegende Prinzip der nicht-invasiven Steuerung von Nukleinsäurebasierten Reaktionen durch Licht erfolgreich bestätigt werden.

Im weiteren Projektverlauf soll das Prinzip mit Blick auf Energieeffizienz, Umkehrbarkeit und Übertragbarkeit

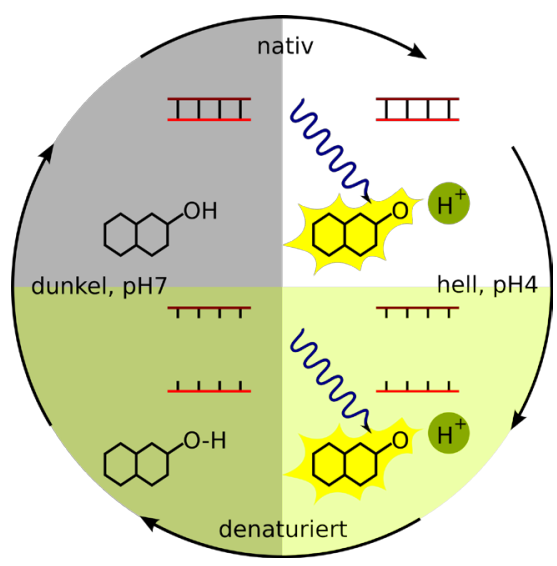

Abb. 1) Reversible Steuerung von Nukleinsäurestrukturen durch Lichteinwirkung

auf andere Reaktionen genauer untersucht werden. Ziel ist es, auf der Grundlage des Projekts ein neuartiges Verfahren zu entwickeln, das patentierbar und damit auch kommerziell einsetzbar ist.

\section{KONTAKT}

marcus.frohme@th-wildau.de

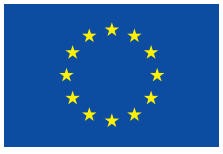

EUROPÄISCHE UNION

Europäischer Fonds für Regionale Entwicklung Investition in Ihre Zukunft!

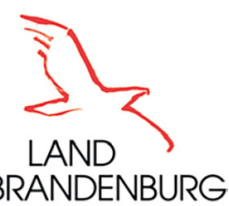

Ministerium für Wissenschaft, Forschung und Kultur 


\section{MALDI-Coffee: Verfahren zur Analyse und Optimierung von Reifungsprozessen in Rohkaffee auf der Basis von MALDI-TOF-Massenspektrometrie}

Prof. Dr. Marcus Frohme

PROJEKTMITARBEITER

KOOPERATIONSPARTNER

PROJEKTVOLUMEN

MITTELGEBER

LAUFZEIT
Dr. Oliver Brödel

The Coffee Store $\mathrm{GmbH}$, Mannheim

$190.000 €$

Bund | BMWi | ZIM

$03 / 2016-05 / 2018$
Rohkaffee ist eines der wichtigsten Agrarhandelsprodukte der Welt, wird allerdings vorwiegend als Massenprodukt gehandelt, mit negativen Folgen für die Umwelt und unter Benachteiligung der Erzeuger. Es gibt jedoch einen wachsenden Markt für fair gehandelte und hochwertige Spezialitäten- bzw. Lagenkaffees; Ziel ist dabei, für unterschiedliche Rohkaffees (z.B. Sorten oder Lagen) charakteristische Geschmacksprofile herauszuarbeiten. Direkte Handelsbeziehungen zu den Kaffeefarmern erlauben die Verfolgung und Beeinflussung von Produktionsprozessen und machen die Beteiligten weitgehend unabhängig von Schwankungen an den Warenbörsen.

Kaffeesamen weisen keine Samenruhe auf, daher können Keimungsprozesse schon unmittelbar nach Ernte der Kaffeekirschen beginnen. Bekannt sind metabolische Prozesse während der Prozessierung, des Transports und der Lagerung, die die Qualität des Röstkaffees beeinflussen können. Dies reicht von Keimungsprozessen über Stressreaktionen bis hin zu Post-mortem-Effekten nach Absterben des Keimlings.

Der Industriepartner im Projekt konnte durch eine einjährige Lagerung des Rohkaffees in der Pergamenthülle auf der Kaffeefarm die Tassenqualität des Röstkaffees sowie die Lagerfähigkeit des Rohkaffees wesentlich verbessern. Das Ergebnis dieser Reifungsphase kann bislang jedoch nur nach dem Rös-

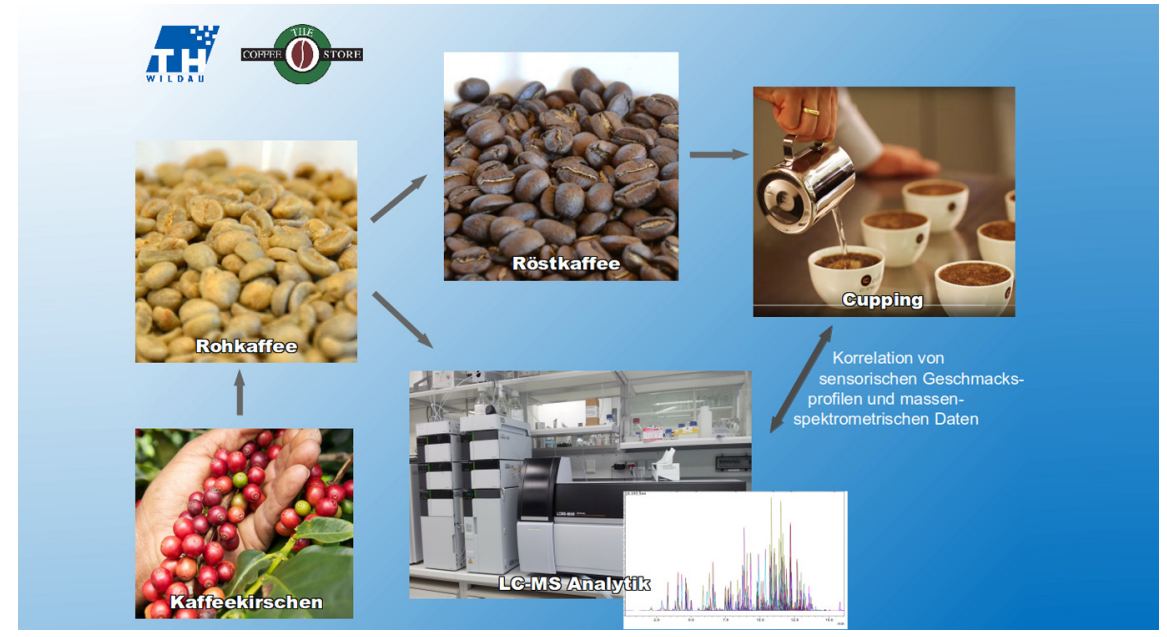

Abb. 1) Identifizierung von Markersubstanzen für Reifungsprozesse in grünen Kaffeebohnen. Für die sensorischen Geschmacksprofile muss der Rohkaffee zunächst geröstet werden. Durch Korrelation der Geschmacksprofile mit den massenspektrometrischen Daten aus grünen Kaffeebohnen lassen sich Marker identifizieren.

ten durch Erstellung von sensorischen Geschmacksprofilen beurteilt werden.

Ziele des Projekts sind die Entwicklung eines analytischen Verfahrens zur Charakterisierung von Reifungsprozessen in Rohkaffee auf der Basis der MALDITOF-Massenspektrometrie sowie anschließend die Optimierung und Verkürzung der Reifungsphase.

Zunächst werden relevante Inhaltsstoffe mittels LC-ESI-Massenspektrometrie quantifiziert; das sind neben Aromavorstufen (reduzierende Zucker, Aminosäuren, Kaffeesäuren und Lipide) auch Metaboliten aus Keimungsprozessen und Stressreaktionen. Über die Korrelation mit sensorischen Geschmacksprofilen sollen einzelne
Markersubstanzen identifiziert werden, die es ermöglichen, den Verlauf und den Abschluss der Reifungsphase sowie Keimungs- und Stressreaktionen zu detektieren. Für diese Marker soll dann ein schnelles und unkompliziertes MALDITOF-Messverfahren entwickelt werden.

Mit dem Verfahren können anschließend verschiedene Einflussfaktoren auf die Kaffeequalität bzw. das Geschmacksprofil untersucht werden. Geplant ist, die Wirkung von Gasgemischen auf den Rohkaffee sowie den Einfluss der Lage, des Bodens und der allelopathischen Effekte benachbarter Pflanzen in den Blick zu nehmen.

\section{KONTAKT}

marcus.frohme@th-wildau.de 
Gefördert durch:

你 Bundesministerium für Wirtschaft und Energie

aufgrund eines Beschlusses des Deutschen Bundestages 


\section{Companion Diagnostics von Wachstumshormon- störungen basierend auf dem SOCS2-Komplex (SOCS2 CompDiag)}

Prof. Dr. Marcus Frohme

PROJEKTMITARBEITER

KOOPERATIONSPARTNER

PROJEKTVOLUMEN

MITTELGEBER

LAUFZEIT
Wilhelm Gossing, Lars Radke

Ipsen, Pfizer, Novartis

$397.000 €$

Land Brandenburg | MWFK | EFRE

01/2016-12/2018
SOCS2 CompDiag zielt auf die Validierung neuer Biomarker im Bereich seltener Wachstumshormonstörungen.

Das Wachstumshormon (GH) ist nicht nur während der Pubertät für das Körperwachstum zuständig, sondern reguliert im adulten Organismus wichtige Funktionen wie bspw. Muskel- und Knochenwachstum, Energieund Fettstoffwechsel etc. Irreguläre $\mathrm{GH}$-Spiegel werden oft durch gutartige Hypophysenadenome verursacht und wirken sich, bei erhöhter Mortalität, nachteilig auf die Leistungsfähigkeit und Lebensqualität aus.

Hintergrund dieses Projekts ist der derzeit verwendete Biomarker Insulin-like growth factor 1, der in der Diagnostik als ungenau und unzuverlässig gilt.

Mithilfe eines neuen Biomarkers sollen die Diagnostik und somit auch die medikamentöse Therapie der Wachstumshormondefizienz und Akromegalie verbessert werden, um Fehldiagnosen und Nebenwirkungen zu minimieren und außerdem Möglichkeiten zur Früherkennung zu erforschen.

Der von uns untersuchte potentielle Biomarker ECS-Komplex besteht aus fünf Proteinen, die gemeinsam die aktivierten GH-Rezeptoren über einen negativen Feedback-Mechanismus abbauen. Diese fünf Komponenten des Markers sollen im Blut von GH-Patienten auf mRNA- und Proteinebene gemessen

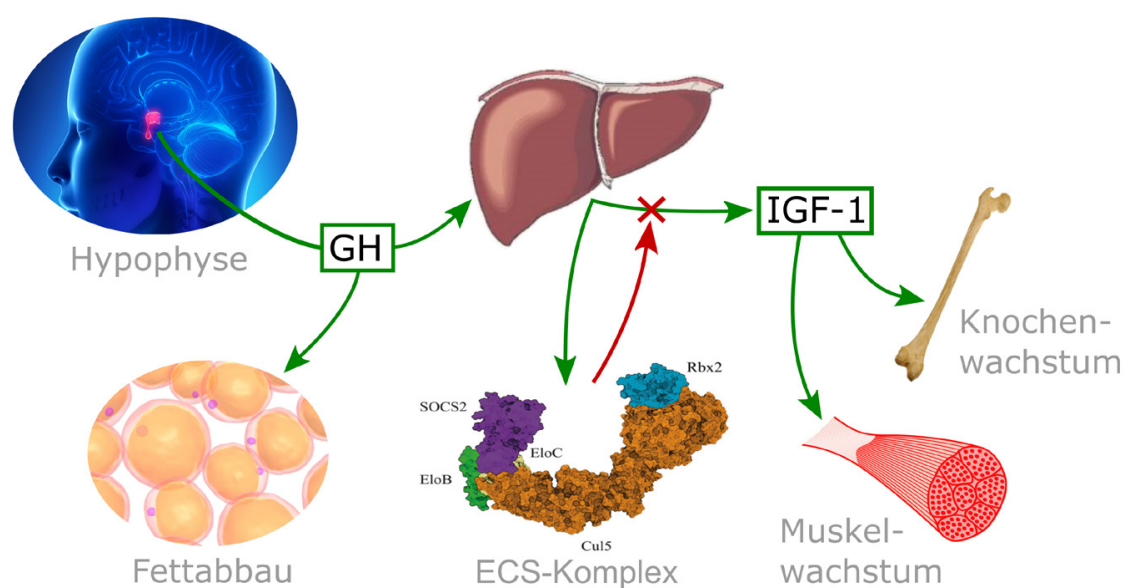

Abb. 1) Wirkungskreislauf des Wachstumshormons (GH) im Körper und die Rolle des ECS-Komplexes

werden, um eine mögliche Korrelation zur bestehenden Medikamentendosis und damit zum Therapiestatus nachzuweisen.

Im zweiten Projektteil geht es um die Untersuchung und Charakterisierung der für Wachstumshormonstörungen ursächlichen Hypophysenadenome. Durch die Entwicklung hochsensitiver DNA-Nachweismethoden (z. B. digitale Droplet-PCR) ist es möglich, im Blut zellfreie zirkulierende Tumor-DNA nachzuweisen. Durch diese nichtinvasive Methode soll die Diagnostik bei Patienten verbessert und der Erfolg nach Bestrahlung oder operativer Entfernung erhöht werden.

Letztendlich kann eine verbesserte Analytik für Patienten mit Wachstums- hormonstörungen entwickelt werden, die auf einer validierten Korrelation zwischen neuem Biomarker und präzise diagnostiziertem Krankheitsbild beruht. Erste positive Resultate mit dem neuen Biomarker konnten bereits an einem kleineren Patientenkontingent beobachtet werden und sollen in diesem Projekt mit größerer Fallzahl und erweiterter Analytik bestätigt werden. Bei vielversprechenden Ergebnissen folgt die Implementierung des Biomarkernachweises als biosensorischer Schnelltest zur praxisnahen Auswertung der Blutparameter in einem Point-of-CareFormat.

KONTAKT

marcus.frohme@th-wildau.de 
Gefördert durch das Ministerium für Wissenschaft, Forschung und Kultur aus

Mitteln des Europäischen Fonds für regionale Entwicklung und des Landes Brandenburg.

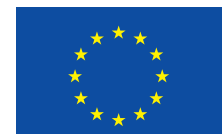

EUROPÄISCHE UNION

Europäischer Fonds für Regionale Entwicklung Investition in Ihre Zukunft

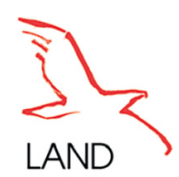

BRANDENBURG

Ministerium für Wissenschaft, Forschung und Kultur 


\title{
CDN-Parkinson - Fluidisches System zur Detektion von bei der Parkinson-Erkrankung relevanten Enzymen und Medikamenten
}

\author{
Prof. Dr. Fred Lisdat
}

$\begin{array}{ll}\text { PROJEKTMITARBEITER(INNEN) } & \text { Dipl.-Biotechnol. G. Göbel } \\ \text { KOOPERATIONSPARTNER } & \text { BioTeZ Berlin-Buch GmbH, UP TRANSFER GmbH Potsdam } \\ \text { PROJEKTVOLUMEN } & 190.000 € \\ \text { MITTELGEBER } & \text { Bund | BMWi | ZIM } \\ \text { LAUFZEIT } & 03 / 2016-08 / 2018\end{array}$

Für eine individuelle Behandlung und Diagnose bei Parkinson-Patienten sollen im Rahmen einer personalisierten Medizin neue diagnostische Systeme entwickelt werden.

Ziel des Kooperationsprojekts ist es, Analyseverfahren zu entwickeln, die eine Bestimmung der Wirkeffizienz von Parkinsonmedikamenten ermöglichen und dadurch eine auf den Patienten maßgeschneiderte Therapie erlauben. Dabei sollen insbesondere Medikamente detektiert werden, die die Wirkung von Enzymen des Katecholaminstoffwechsels (z.B. der Dopamin-Decarboxylase) inhibieren. Die BioTeZ Berlin-Buch GmbH möchte hierfür einen Recovery-ELISA zur Bestimmung der Enzymkonzentration und der Wirkstoffeffizienz etablieren. Dieser neuartige Verdrängungsassay stellt an die von der UP TRANSFER $\mathrm{GmbH}$ Potsdam herzustellenden Antikörper besondere Anforderungen.

Die Aufgaben des Teilprojekts der TH Wildau liegen zum einen in der Anti-

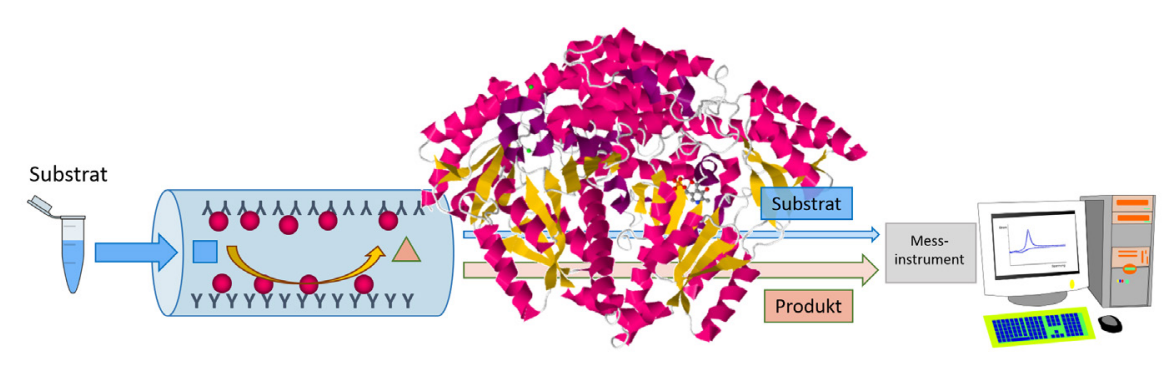

Abb. 1) Nachweisprinzip der Wirksamkeit von Parkinsonmedikamenten

körpercharakterisierung für den Einsatz in den Funktionsassays der Biotez $\mathrm{GmbH}$ sowie in Immunaffinitätssäulen mittels Oberflächenplasmonresonanzspektroskopie (SPR) und in enzymatischen Tests und zum anderen in der Entwicklung eines fluidischen Analysesystems für die oben genannten Enzyme. Das analytische Verfahren soll eine immunaffine Extraktion der Enzyme direkt aus Realproben mit anschließender Detektion erlauben und so auch eine Validierung des Immunoassays ermöglichen. Dafür ist sowohl die Erarbeitung eines selektiven elektrochemischen Nachweises für die Substrate bzw. Produkte der
Enzymreaktionen erforderlich als auch die Kombination mit der chromatographischen Trennung in einem zu entwickelnden fluidischen System. Dies soll einen schnellen Nachweis und einen guten Probendurchsatz gewährleisten. Mit dem System soll die Aktivität der ausgewählten Enzyme auch nach entsprechender Hemmung charakterisiert werden. Eine weitere Entwicklungsaufgabe besteht in der direkten Detektion von Parkinsonmedikamenten wie Selegilin, Carbidopa oder Tolcapon.

\section{KONTAKT}

gero.goebel@th-wildau.de
Gefördert durch:

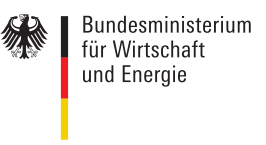

aufgrund eines Beschlusses des Deutschen Bundestages

\section{ZIM}

Zentrales Innovationsprogramm 


\title{
TABELLARISCHE ÜBERSICHT LAUFENDER PROJEKTE
}

\author{
Philips-NGS-2016: Sequenz-Datenanalyse Prostata-Krebs

\begin{tabular}{l|l}
$\begin{array}{l}\text { Projektleiter } \\
\text { Mittelgeber }\end{array}$ & Prof. Dr. rer. nat. Peter Beyerlein \\
\hline $\begin{array}{l}\text { Laufzeit } \\
\text { 10/2016-12/2017 }\end{array}$ \\
\hline $\begin{array}{l}\text { Die Philips Forschung beauftragt die Forschungsgruppe Diagnostische Bioinformatik von Prof. Dr. Beyerlein mit der } \\
\text { Datenanalyse von ca. } 500 \text { Patientenprobenzum Aufbau von diagnostischen und therapiebegleitenden Tests. Der Fokus } \\
\text { liegt dabei auf Transkritomen, Genomen und Fusionen. }\end{array}$
\end{tabular}

Biomarkers in Leishmania spp. - a hybrid based strategy

\begin{tabular}{|c|c|}
\hline Projektleiter & Prof. Dr. sc. hum. Marcus Frohme \\
\hline Mitarbeiter & Dr. Katrin Kuhls, Dr. Sofia Cortes \\
\hline Mittelgeber & Land Brandenburg | MWFK | BRAIN (EU Cofund) \\
\hline Projektvolumen & $140.000 €$ \\
\hline Laufzeit & $12 / 2014-11 / 2016$ \\
\hline \multicolumn{2}{|c|}{$\begin{array}{l}\text { The main goals of this proposal are the search for virulence markers within Leishmania spp. by assessment of in vitro } \\
\text { virulence phenotypes of L. infantum/L. major hybrid clones with post-selection of the ones bearing distinct phenotypes } \\
\text { as well as identification of putative protein virulence markers. Virulence markers can be identified at DNA sequence level, } \\
\text { reflecting variations in the protein sequence or at the level of protein expression. }\end{array}$} \\
\hline
\end{tabular}

\section{CyanoScreen - Entwicklung von Microcystin als Wirkstoffkandidaten gegen Tumore}

\begin{tabular}{|c|c|}
\hline Projektleiter & Prof. Dr. sc. hum. Marcus Frohme \\
\hline Mittelgeber & Bund | BMWi | ZIM \\
\hline Projektvolumen & $175.000 €$ \\
\hline Laufzeit & $07 / 2015-09 / 2017$ \\
\hline \multicolumn{2}{|c|}{$\begin{array}{l}\text { Cyanobakterien werden auf neue Microcystine (Toxine) im Hochdurchsatz untersucht. Hierzu wird eine an der TH Wildau } \\
\text { entwickelte Screeningplattform weiterentwickelt und eingesetzt. Zusätzliche Variabilität wird über Fütterung gesonder- } \\
\text { ter Aminosäuren und genetische Manipulation erzeugt. Ziel ist die Identifikation eines auf den OATP1B3-Transporter } \\
\text { spezifischen Toxins für den potenziellen Einsatz als Tumortherapeutikum. }\end{array}$} \\
\hline
\end{tabular}


GHECS - Theranostics

Projektleiter

Kooperationspartner

Mittelgeber

Laufzeit

Prof. Dr. sc. hum. Marcus Frohme

Ipsen Pharma GmbH

Wirtschaft

$09 / 2015-12 / 2016$

Dieses Projekt befasst sich mit der Entwicklung neuartiger Companion Diagnostics im Bereich seltener Wachstumshormonstörungen. Diese sollen die medikamentöse Therapierung der Wachstumshormonsdefizienz und Akromegalie verbessern und so Fehldiagnosen verhindern und Nebenwirkungen minimieren. Zu diesem Zweck soll durch Messung der Genexpression und Proteinkonzentration in Blutporben von Patienten und gesunden Kontrollen der Nutzen eines neuen Biomarkers für die Krankheiten validiert werden.

\section{Kopplung von TCR-Ketten: Verknüpfung der einzelnen Ketten der T-Zell Rezeptoren aus T-Zelllinien}

Projektleiter

Prof. Dr. sc. hum. Marcus Frohme

Mittelgeber

$$
\text { HS Diagnomics GmbH }
$$

Laufzeit

$10 / 2016-01 / 2017$

Im Rahmen des Projektes sollen bekannten Sequenzen der einzelnen Ketten von T-Zell Rezeptoren aus verschiedenen T-Zelllinien verknüpft werden. Die Verknüpfung soll in einem Rasterformat und ggf. in Tröpfchen einer Emulsion erreicht werden. Die Verknüpfung soll auf der Ebene von RNA und auch der genomischen DNA getestet werden.

ImmuMagMALDI - Erregeridentifizierung über Immunisolation (magnetic beads) und MALDI-TOF profiling

Projektleiter

Kooperationspartner

Mittelgeber

Laufzeit
Prof. Dr. sc. hum. Marcus Frohme

Seramun Diagnostica $\mathrm{GmbH}$

Wirtschaft

$09 / 2013-02 / 2016$

Zusammen mit der Firma Seramun wird ein diagnostisches Verfahren zum Nachweis von Parasiten und Viren direkt aus primärem Probenmaterial entwickelt. Erreger sollten über spezifische Antikörper an Magnetpartikel gebunden und aus der Probenmatrix isoliert werden. Anschließend werden im Massenspektrometer erregerspezifische Proteinprofile gemessen, die über einen Datenbankabgleich eindeutig zugeordnet werden können. Das neue Verfahren könnte die Diagnose wesentlich vereinfachen und beschleunigen.

\section{LipH Cycle: Lichtgesteuerte Nukleinsäurereaktionen für die Point-of-Care Diagnostik}

Projektleiter

Mittelgeber

Projektvolumen

Laufzeit
Prof. Dr. sc. hum. Marcus Frohme

Land Brandenburg | MWFK | EFRE

$450.350 €$

$01 / 2016-12 / 2018$

In diesem Projekt soll eine neue, patentierbare und interdisziplinäre Technologie von Nukleinsäurereaktionen entwickelt werden. Diese arbeiten anders als klassische PCR statt mit Temperatur mit Lichtsteuerung. Sie können als Nachweissysteme für die Point-of-Care Diagnostik genutzt werden. 
MALDI Blast - MALDI-TOF Massenspektrometrie Analytik zur Untersuchung von spreng- und

explosivstoffbelasteten Liegenschaften und Gebäuden

Projektleiter

Kooperationspartner

Mittelgeber

Projektvolumen

Laufzeit

Prof. Dr. sc. hum. Marcus Frohme

terracon Laboratorium für Umwelt- und Pestizidanalytik GmbH,

Prof. Dr. Machholz Umweltprojekte $\mathrm{GmbH}$

Bund | BMWi | ZIM

$193.072 €$

$10 / 2014-03 / 2017$

Das Projekt hat die Etablierung einer innovativen Technik zum Nachweis von Spreng-/Explosivstoffverbindungen sowie deren Abbauprodukten in Boden-/Grundwasserproben zum Ziel. Hierfür wird die MALDI-TOF-MS als Hochdurchsatzmethode eingesetzt. Mit der zu entwickelnden Vor-Ort-Extraktion und -Probenvorbereitung werden die labilen Verbindungen direkt am Probenentnahmeort konserviert. Zusätzlich wird der Einfluss der Bindung an Huminsäuren und die Auswirkungen auf die Bioverfügbarkeit untersucht.

MALDI on-site-Prep - MALDI-Messmethodik zum Nachweis von Mikroorganismen in sprengstoffbelasteten Böden

Projektleiter

Prof. Dr. sc. hum. Marcus Frohme

Mittelgeber Bund | BMWi | ZIM

Laufzeit

$10 / 2014-03 / 2017$

Entwicklung eines Hochdurchsatz-Nachweisverfahrens für Mikroorganismen in sprengstoffkontaminierten Böden. Mit Hilfe des MALDI-TOF Intact Protein Profiling werden die Zeigerorganismen für Sprengstoffkombinationen bestimmt. Zur schonenden Probengewinnung aus verschiedenen Bodenschichten wird ein neues Probenentnahmegerät (Multikapillarer-Mikroorganismen-Sampler) konstruiert. Zudem wird die Möglichkeit untersucht, intrazelluläre Sprengstoffverbindungen nachzuweisen.

\section{MALDI-Coffee}

\begin{tabular}{|c|c|}
\hline Projektleiter & Prof. Dr. sc. hum. Marcus Frohme \\
\hline Mittelgeber & Bund | BMWi | ZIM \\
\hline Projektvolumen & $189.836 €$ \\
\hline Laufzeit & $03 / 2016-05 / 2018$ \\
\hline
\end{tabular}

Entscheidend für die Qualität von Röstkaffee ist die etwa einjährige Phase vor der Röstung. Ziel des Projekts ist die Charakterisierung dieser Reifungsprozesse. Dazu werden massenspektrometrische Analysemethoden entwickelt und mit sensorischen Geschmacksprofilen des Röstkaffees korreliert. Zur Optimierung der Reifungsprozesse wird eine Apparatur zur Begasung von Kaffeebohen konstruiert. Unterschiedliche Einflussfaktoren sollen untersucht und optimiert werden. 
Projektleiter

Mittelgeber

Projektvolumen

Laufzeit
Prof. Dr. sc. hum. Marcus Frohme

Land Brandenburg | MWFK | EFRE

$397.000 €$

$03 / 2016-05 / 2018$

In diesem Projekt soll ein potenzieller Biomarker für Companion Diagnostics bei Wachstumshormondefizienz (GHD) oder Akromegalie validiert werden,d.h., eine Untersuchung von Veränderungen in der Gen- und Proteinexpression des SOCS2-Komplexes. Im Anschluss soll dies als Lab-on-a-Chip-System implementiert werden durch Messung von zirkulierender zellfreier DNA im Blut.

\section{Theranostics of GH-metabolism dysfunctions based on the SOCS2-Complex}

Projektleiter

Kooperationspartner

Mittelgeber

Laufzeit
Prof. Dr. sc. hum. Marcus Frohme

PFIZER Pharma GmbH

Wirtschaft

$11 / 2014-11 / 2016$

In diesem Projekt soll ein potentieller Biomarker für die Diagnostik und Therapiekontrolle von Wachstumshormonkrankheiten beim Menschen untersucht werden. Dazu werden Genexpressionen von fünf Markergenen mittels Real-Time PCR und die Konzentrationen der zugehörigen Proteine durch Immunoassay im Blut von Patienten gemessen und mit Werten von gesunden Probanden verglichen. Zusätzlich werden die entsprechenden Gene sequenziert, um mögliche pathogene Mutationen aufzudecken.

\section{MolEpiArm: Molecular epidemiology and diagnostics of Leishmaniasis in Armenia}

Projektleiter

Kooperationspartner

Mittelgeber

Projektvolumen

Laufzeit

\section{Dr. Katrin Kuhls}

Alexsanyan Institute, Jerewan, Armenia; Trakia University, Stara Zagora, Bulgaria

DAAD

$1.000 €$

$10 / 2016-07 / 2017$

In the scientific focus are epidemiological screening studies on prevalence/distribution of Leishmaniasis in Armenia and its neighboring countries and sampling from infected humans and animals. The samples will be used for genotyping of the parasites. The results will help to understand the transmission cycles, the dynamics, origin and the way of spread of the disease including also neighboring countries and the prediction of risk factors. Training will be provided in molecular techniques. 
ZACaLeish - Molekulare Epidemiologie und Diagnostik der Infektionskrankheit Leishmaniose

in Ländern des Südkaukasus und Zentralasiens

\begin{tabular}{|c|c|}
\hline Projektleiter & Dr. Katrin Kuhls \\
\hline Mittelgeber & Bund | BMBF | Internationales Büro \\
\hline Projektvolumen & $136.000 €$ \\
\hline Laufzeit & $10 / 2014-06 / 2016$ \\
\hline \multicolumn{2}{|c|}{$\begin{array}{l}\text { Molekulare Epidemiologie und Diagnostik der Infektionskrankheit Leishmaniose in Ländern des Südkaukasus und Zen- } \\
\text { tralasiens. Ein Beitrag zur Entwicklung lokaler Monitoring-und Kontrollsysteme. Das Projekt umfasst die Förderung von } \\
\text { Personal und Sachmitteln für Labor-und Feldarbeit,sowie den Austausch von Wissenschaftlern und Doktoranden in bei- } \\
\text { den Richtungen. }\end{array}$} \\
\hline
\end{tabular}

Bioelektrokatalyse 2020+- Nutzung von Sonnenenergie für die Bioelektrokatalyse

\begin{tabular}{l|l}
\hline Projektleiter & Prof. Dr. rer. nat. \\
\hline Mittelgeber & Bund / BMBF \\
\hline Projektvolumen & $836.760 €$ \\
\hline Laufzeit & $11 / 2012-10 / 2017$
\end{tabular}

Im Rahmen des Tandemvorhabens sollen lichtaktivierbare Elektroaufbauten für die biokatalytische Synthese entwickelt werden. Hierzu sollen zunächst Photosysteme oder Photosystemkomponenten mit Elektroden derart kombiniert werden, dass ein effektiver Photoelektronentransfer möglich wird. Durch die Kopplung unterschiedlicher Enzymsysteme mit photoaktivierbaren Elektroden soll dann der generierte Photostrom für die biokatalysierte Synthese wichtiger chemnischer Verbindungen genutzt werden.

CDN-Parkinson; Fluidisches System zur Detektion von bei der Parkinson-Erkrankung

relevanten Enzymen und Medikamenten

\begin{tabular}{|c|c|}
\hline Projektleiter & Prof. Dr. rer. nat. habil. Fred Lisdat \\
\hline Mitarbeiter & Dipl.-Biotechnol. Gero Göbel \\
\hline Kooperationspartner & BioTeZ Berlin-Buch GmbH, UP TRANSFER GmbH Potsdam \\
\hline Mittelgeber & Bund | BMWi | ZIM \\
\hline Projektvolumen & $190.000 €$ \\
\hline Laufzeit & $03 / 2016-08 / 2018$ \\
\hline \multicolumn{2}{|c|}{$\begin{array}{l}\text { Für eine individuelle Behandlung und Diagnose bei Parkinson-Patienten sollen im Rahmen einer personalisierten Medizin } \\
\text { neue diagnostische Systeme entwickelt werden. Ziel des Kooperationsprojektes ist es Analyseverfahren zu entwickeln, } \\
\text { die eine Bestimmung der Wirkeffizienz von Parkinsonmedikamenten ermöglichen und dadurch eine auf den Patienten } \\
\text { maßgeschneiderte Therapie erlauben. }\end{array}$} \\
\hline
\end{tabular}


EDS Detektor: Detektor zur energiedispersiven Röntgenspektroskopie EDS

Projektleiter

Prof. Dr. rer. nat. habil. Fred Lisdat

Mittelgeber

Land Brandenburg | MWFK | EFRE

Projektvolumen

$99.500 €$

Laufzeit

$11 / 2016-12 / 2017$

Bei der im Rahmen dieses Projektes beabsichtigten Beschaffung eines Detektors zur energiedispersiven Röntgenspektroskopie (EDS) sollen die bestehenden Fähigkeiten eines bereits etablierten Rasterelektronenmikroskops zur strukturellen Charakterisierung von Oberflächen im Mirko- und Nanometerbereich um die Fähigkeit zur Elementanalyse erweitert werden. Dies ist für zahlreiche Fragestellungen von Interesse, da es hier oft um die sinnvolle Kombination von verschiedenen Materialien geht.

MikroNanoRob: Etablierung eines Mikro-Handling Systems zur Untersuchung von Mikro- und Nanostruktur

\begin{tabular}{l|l|}
$\begin{array}{l}\text { Projektleiter } \\
\text { Mittelgeber }\end{array}$ & Prof. Dr. rer. nat. habil. Fred Lisdat \\
\hline Projektvolumen & $76.800 €$ \\
\hline Laufzeit & $02 / 2016-09 / 2016$ \\
\hline
\end{tabular}

Es soll eine Methode zur Kontaktierung und elektrischen Untersuchung von Mikro- und Nanostrukturen etabliert werden, die aus einer Messplattform aus Mikromanipulatoren besteht und mit bspw. elekronenmikroskopischen Untersuchungen gekoppelt werden kann. Damit sollen sowohl biologische Strukturen als auch technische Bauelemente charakterisiert werden.

\section{NaWiTex - naturwissenschaftlich und technische Schülerlabore der TH Wildau}

\begin{tabular}{l|l}
$\begin{array}{l}\text { Projektleiter } \\
\text { Mittelgeber }\end{array}$ & Prof. Dr. rer. nat. habil. Fred Lisdat \\
\hline $\begin{array}{l}\text { Projektvolumen } \\
\text { Laufzeit }\end{array}$ & $505.140 €$ \\
\hline
\end{tabular}

NaWiTex dient der Studienvorbereitung der TH Wildau und soll den Übergang an die Hochschule speziell in den MINT-Studiengängen erleichtern. Es beinhaltet den Auf-/Ausbau von 4 Schülerlaboren im Fachbereich INW, die mit einer einheitlichen Koordination und Außendarstellung versehen werden. Zielgruppen sind Schülerinnen und Schüler der Sekundarstufe II (u.a. weibliche TN und TN aus bildungsfernen Haushalten). Des Weiteren soll das Schnupperstudium auf Berufsqualifizierende erweitert werden. Ziel ist eine Teilnehmerzahl von 4200.

\section{SimLED: Optimierung einer Software zur Simulation von Summenspektren mehrerer LEDs}

Projektleiter Prof. Dr. rer. nat. Heike Pospil

Mittelgeber Optotransmitter-Umweltschutz-Technologie e.V.
Laufzeit
$09 / 2016-10 / 2016$

Es wird eine Software zur Simulation von Summenspektren mehrerer LEDs erstellt. Ziel ist die Entwicklung eines Programms zur zeiteffizienten Berechnung dieser Summenspektren durch Multithreading. 


\begin{tabular}{|c|c|}
\hline Projektleiter & Dr. Anke Renger \\
\hline Kooperationspartner & Fond der Chemischen Industrie \\
\hline Mittelgeber & Wirtschaft \\
\hline Laufzeit & $10 / 2016-03 / 2018$ \\
\hline \multicolumn{2}{|c|}{$\begin{array}{l}\text { Mit dem vorliegenden Projekt sollen Schülern naturwissenschaftlich-technische Arbeitsmethoden vermittelt werden. Dies } \\
\text { soll dazu führen, dass die Schüler ersten eigenen Ideen in den modernen Chemiewissenschaften nachgehen. Diese individu- } \\
\text { elle Förderung von MINT-interessierten Schülern und die Einbindung von Experimenten in das wissenschaftliche Arbeiten } \\
\text { soll nach der Schule außerdem eine authentische Perspektive für einen Beruf oder ein Studium aufzeigen. Darüber hinaus } \\
\text { gibt es Workshops für Lehrer. }\end{array}$} \\
\hline
\end{tabular}

Oculyze - eine kombinierte Lösung für mobile Mikroskopie und Bildauswertung

\begin{tabular}{l|l|}
\hline $\begin{array}{l}\text { Projektleiter } \\
\text { Mittelgeber }\end{array}$ & Dr. rer. nat. Katja Schulze \\
\hline Projektvolumen & $131.000 €$ \\
\hline Laufzeit & $08 / 2015-07 / 2016$ \\
\hline
\end{tabular}

Ziel ist es, ein System zur mobilen Bildverarbeitung aufzubauen, um die Analyse von Bierhefen zu vereinfachen. Dabei liegt der Fokus auf der automatisierten Auswertung von mirkoskopischen Bildern, die mit Hilfe eines optischen Aufsatzes für moderne Endgeräte wie Tablet-PCs oder Mobilfunktelefone aufgenommen werden. 


\section{TABELLARISCHE ÜBERSICHT PUBLIKATIONEN}

Böhme A, Radke L, Schütze F, Schneider S, Liebscher T, Sauer S, Santo L, Quadrini F, Hummel M, Giese C, Frohme M, Foitzik A (2016)

Bortz B, Marczok S, Pospisil H (2016)

Duscharla D, Bhumireddy SR, Lakshetti S, Pospisil H, Murthy PVLN, Walther R, Sripadi P, Ummanni R (2016)

Feifel SC, Stieger KR, Kapp A, Weber D, Allegrozzi M, Piccioli M, Turano P, Lisdat F (2016)

Franke P, Frohme M, Glökler JF, Endrullat C (2016)

Gladisch J, Sarauli D, Schäfer D, Dietzel B, Schulz B, Lisdat F (2016)

Gladisch J, Sarauli D, Schäfer D, Dietzel B, Schulz B, Lisdat F (2016)

Göbel G, Beltran ML, Mundhenk J, Heinlein T, Schneider JJ, Lisdat F (2016)

Göbel G, Lange R, Hollidt J-M, Lisdat F (2016)

Gossing W, Radke L, Frohme M, Biering H (2016)

Janowski S, Gross I, Sauer-Gürth H, Tietze DT, Grohme MA, Frohme M, Becker P, Wink M (2016)
Miniaturized Flow-Through Bioreactor for Processing and Testing in Pharmacology. In: Materials Science Forum (Volume 879), pp 236-243. doi: 10.4028/www.scientific.net/MSF.879.236

Genomweite Identifizierung von chromosomalen Bruchpunkten bei Tumoren unterschiedlicher Gewebe. Wissenschaftliche Beiträge 2016 20:7-14. doi: 10.15771/0949-8214_2016_1_1

Prostate Cancer Associated Lipid Signatures in Serum Studied by ESITandem Mass Spectrometryas Potential New Biomarkers. PLoS one 11(3):Artikel e0150253. doi: 10.1371/journal.pone.0150253

Insights into Interprotein Electron Transfer of Human Cytochrome c Variants Arranged in Multilayer Architectures by Means of an Artificial Silica Nanoparticle Matrix. ACS omega 1(6):1058-1066. doi: 10.1021/ acsomega.6b00213

Standardization and quality management in next-generation sequencing. Applied and Translational Genomics July:2-9. doi: 10.1016/j. atg.2016.06.001

Elektrogesponnene Polymerfasern als neuartiges Material für die Bioelektrokatalyse des Enzyms Pyrrolochinolinchinon-abhängige Glucosedehydrogenase. Wissenschaftliche Beiträge 2016 20:15-21. doi: 10.15771/0949-8214_2016_1_2

Towards a novel bioelectrocatalytic platform based on "wiring" of pyrroloquinoline quinone-dependent glucose dehydrogenase with an electrospun conductive polymeric fiber architecture. Scientific Reports 6:Article number: 19858. doi: 10.1038/srep19858

Operation of a carbon nanotube-based glucose/oxygen biofuel cell in human body liquids-Performance factors and characteristics. Electrochimica Acta 218(10):278-284. doi: 10.1016/j.electacta.2016.09.128

Development of a fast and simple test system for the semiquantitative protein detection in cerebrospinal liquids based on gold nanoparticles. Talanta 146:49-54. doi: 10.1016/j.talanta.2015.08.016

ECS-Komplex - ein neuer Biomarker bei Wachstumshormonstörungen? Wissenschaftliche Beiträge 2016 20:23-29. doi: 10.15771/09498214_2016_1_3

New Microsatellite Markers for the Common Tern (Sterna hirundo) Developed with 454 Shot-Gun Pyrosequencing. The Open Ornithology Journal 9:50-59. doi: 10.2174/1874453201609010050 
Karamian M, Kuhls K, Hemmati M, Ghatee MA (2016)

Kosztyła P, Stec D, Morek W, Frohme M, Gąsiorek P, Zawierucha K, Michno K, Ufir K, Małek D, Hlebowicz K, Laska A, Dudziak M, Prokop ZM, Kaczmarek $Ł$, Michalczyk $Ł$ (2016)

Kuhls K, Akhoundi M, Cannet A, Votýpka J, Marty P, Delaunay P, Sereno D (2016)

Kuhls K, Al-Jawabreh A, Mahnaz T, Mauricio IL, Schönian G, Farajnia S, Alimohammadian MH (2016)

Lisdat F, Molinnus D, Sorich M, Bartz A, Siegert P, Willenberg HS, Poghossian A, Keusgen M, Schoening MJ (2016)

Marczok S, Bortz B, Wang C, Pospisil H (2016)

Sarauli D, Borowski A, Peters K, Schulz B, Fattakhova-Rohlfing D, Leimkühler S, Lisdat F (2016)

Stern D, Pauly D, Zydek M, Lisdat F, Dorner M, Dorner BG, Nitsche A, Miller L, Piesker J, Laue M (2016)

Stern D, Pauly D, Zydek M, Müller C, Avondet MA, Worbs S, Lisdat F, Dorner MB, Dorner BG (2016)

Stieger KR, Ciornii D, Kölsch A, Hejazi M, Lokstein H, Feifel SC, Zouni A, Lisdat F (2016)

Stieger KR, Feifel SC, Lokstein H, Hejazi M, Zouni A, Lisdat F (2016)

Wettstein C, Kano K, Schäfer D, Wollenberger U, Lisdat F (2016)
Phylogenetic structure of Leishmania tropica in the new endemic focus Birjand in East Iran in comparison to other Iranian endemic regions. Acta Tropica 158:68-76. doi: 10.1016/j.actatropica.2016.02.010

Experimental taxonomy confirms the environmental stability of morphometric traits in a taxonomically challenging group of microinvertebrates. Zoological Journal of the Linnean Society 178(4):765-775. doi: 10.1111/zoj.12409

A Historical Overview of the Classification, Evolution, and Dispersion of Leishmania Parasites and Sandflies. PLoS Neglected Tropical Diseases 10(3):e0004770. doi: 10.1371/journal.pntd.0004349

Leishmania major: Genetic heterogeneity of Iranian isolates by single-strand conformation polymorphism and sequence analysis of ribosomal DNA internal transcribed spacer. Acta Tropica 98(1):52-58. doi: 10.1016/j.actatropica.2006.01.010

Towards an adrenaline biosensor based on substrate recycling amplification in combination with an enzyme logic gate. Sensors and Actuators B: Chemical 237:190-195. doi: 10.1016/j.snb.2016.06.064

Comprehensive Analysis of Genome Rearrangements in Eight Human Malignant Tumor Tissues. PLoS one 11(7):e0158995. doi: 10.1371/ journal.pone.0158995

Investigation of the $\mathrm{pH}$-Dependent Impact of Sulfonated Polyaniline on Bioelectrocatalytic Activity of Xanthine Dehydrogenase. ACS Catalysis 6(10):7152-7159. doi: 10.1021/acscatal.6b02011

Development of a Genus-Specific Antigen Capture ELISA for Orthopoxviruses - Target Selection and Optimized Screening. PLoS one 11(3):e0150110. doi: 10.1371/journal.pone.0150110

Simultaneous differentiation and quantification of ricin and agglutinin by an antibody-sandwich surface plasmon resonance sensor. Biosens Bioelectron 78:111-117. doi: 10.1016/j.bios.2015.11.020

Engineering of supramolecular photoactive protein architectures: the defined co-assembly of photosystem I and cytochrome c using a nanoscaled DNA-matrix. Nanoscale 8:10695-10705. doi: 10.1039/ C6NR00097E

Biohybrid architectures for efficient light-to-current conversion based on photosystem I within scalable 3D mesoporous electrodes. Journal of materials chemistry 43(4):17009-17017. doi: 10.1039/C6TA07141D

Interaction of Flavin-Dependent Fructose Dehydrogenase with Cytochrome $\mathrm{c}$ as Basis for the Construction of Biomacromolecular Architectures on Electrodes. Anal Chem 88(12):6382-6389. doi: 10.1021/acs.analchem.6b00815 


\section{FORSCHUNGSPREISE}

Forschungsprofessur 2014-2019 der TH Wildau
„Molekulare Biotechnologie und Funktionelle Genomik“ 


\section{Informatik und Telematik Informatics and Telematics}




\section{AM@Ferrari: Optimierung des Anforderungsmanage- ments in der Elektronik-Entwicklung bei Ferrari S. p. A.}

Prof. Dr.-Ing. Stefan Kubica

KOOPERATIONSPARTNER

LAUFZEIT
Ferrari S.p.A.

$12 / 2015-02 / 2017$
Ziel dieses Projekts ist es, die Digitalisierung im Bereich des Anforderungsmanagements elektrischer/elektronischer Fahrzeugfunktionen bei Ferrari S. p. A. zu steigern. Im Fokus steht hierbei eine exemplarische Migration ausgewählter existierender Lastenhefte im MS-Of-

fice-Format in ein datenbankorientier- tes Anforderungsmanagementsystem (IBM DOORS) sowie die Entwicklung dazugehöriger Prozesse.

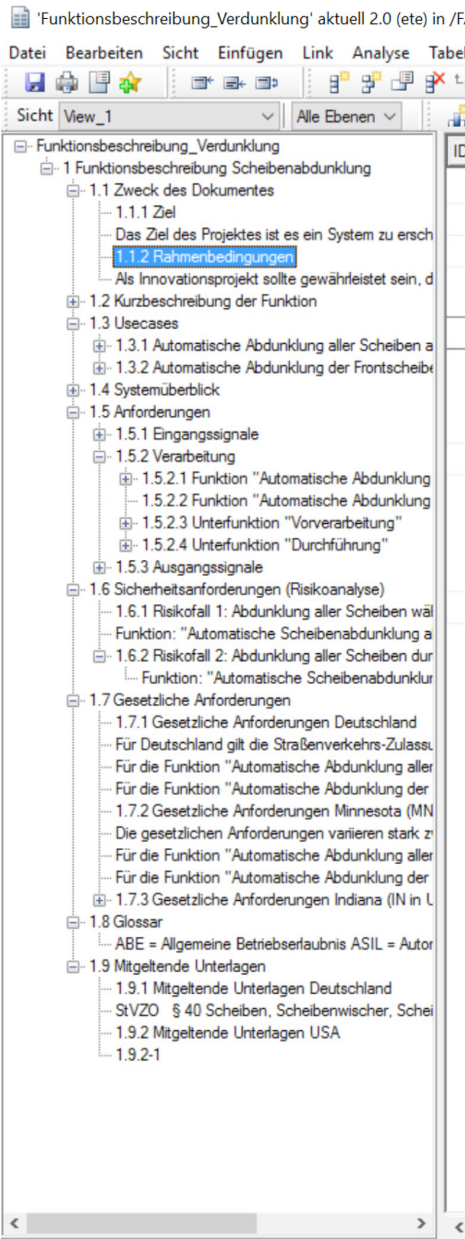

/FAS_WS16 (Formal Modul) - DOORS

\begin{tabular}{|c|c|c|c|}
\hline & & a Avitorderungstatus & \\
\hline 1 & 1 Funktionsbeschreibung Scheibenabdunklung & abgestimmt & Struktur \\
\hline 2 & 1.1 Zweck des Dokumentes & abgestimmt & Struktur \\
\hline 161 & 1.1.1 Ziel & abgestimmt & Struktur \\
\hline 158 & $\begin{array}{l}\text { Das Ziel des Projektes ist es ein System zu erschaffen, welches es ermöglicht die Scheiben des } \\
\text { Fahrzeuges je nach Situation vollständig oder nur zum Teil automatisch abzudunkeln. }\end{array}$ & abgestimmt & Information \\
\hline 157 & 1.1.2 Rahmenbedingungen & abgestimmt & Struktur \\
\hline 3 & $\begin{array}{l}\text { Als Innovationsprojekt sollte gewährleistet sein, dass die Funktionalität zum ersten Start im } \\
\text { vollen Umfang zur Verfügung steht. Daher ist ausgiebiges Testen an der Tagesordnung. Die } \\
\text { dadurch verursachten Mehrkosten machen es unabdingbar, dass die Zielgruppe im höheren } \\
\text { Preissegment bei WW liegt, wie zum Beispiel dem WW Passat und CC. }\end{array}$ & abgestimmt & Information \\
\hline 4 & 1.2 Kurzbeschreibung der Funktion & abgestimmt & Struktur \\
\hline 243 & $\begin{array}{l}\text { Die Funktion blendet zum Einen beim Verschließen des Fahrzeuges alle Scheiben ab, bis eine } \\
\text { vollständige Abdunklung erreicht ist. Zum Anderen werden während der Fahrt der obere Teil der } \\
\text { Frontscheibe je nach Sonneneinfall und ausgewähltem Lichtempfindlichkeitsprofil abgedunkelt. } \\
\text { Je nach Land können auch Seitenscheiben abgedunkelt werden. Immer zur Auswahl während } \\
\text { der Fahrt steht die Abdunklung der hinteren Seitenscheiben. }\end{array}$ & abgestimmt & Information \\
\hline 163 & 1.2.1 Innovationsskizze & abgestimmt & Struktur \\
\hline 168 & $<$ Bild $>$ & abgestimmt & Information \\
\hline
\end{tabular}

\section{Teilabdunklung}

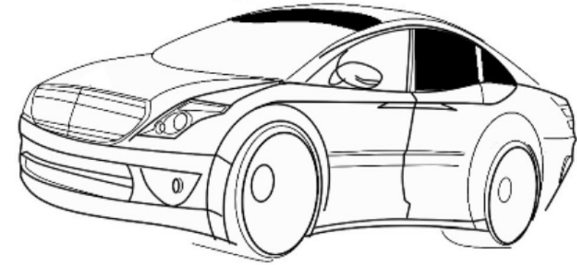

\section{Vollabdunklung}

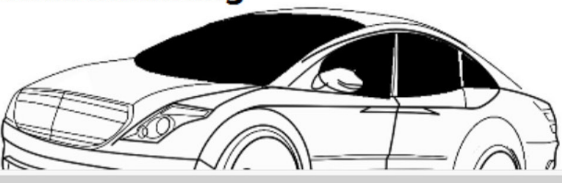


Zu den hierbei adressierten Punkten gehörte u. a.

- Export mehrerer Funktionslastenhefte in eine entsprechend angepasste Struktur nach DOORS

- Erstellung einer Signal- und Glossardatenbank in DOORS sowie Implementierung von Algorithmen zur automatischen Verlinkung von Entitäten zwischen Lastenheftmodulen und der zentralen Signal- und Glossardatenbank
- Integration von Prozessattributen zur Darstellung von Review- und Anforderungslebenszykluseigenschaften

- Sammlung von Fallbeispielen, um an den migrierten Lastenheften die Vorteile von DOORS aufzuzeigen (Änderungshistorie, Rechte- und Rollensystem, Baseline-Management, Filterfunktionen, eindeutige IDs für Anforderungen etc.)

- Erstellung umfangreicher Programme zur automatischen Migration weiterer Original-Lastenhefte nach DOORS unter Beibehaltung der bisher gelebten Kommentierungsphilosophie

- Begleitende Anleitungen und Handbücher

- Planung und Durchführung eines Mitarbeiter-trainings vor Ort in Maranello (Italien)

KONTAKT

stefan.kubica@th-wildau.de 


\section{Initialisierung einer Machbarkeitsanalyse zur Auslegung von Crashsensoren auf RFID-Basis für die Volkswagen AG}

Prof. Dr.-Ing. Stefan Kubica

KOOPERATIONSPARTNER

LAUFZEIT
Volkswagen AG

$01 / 2016-03 / 2017$
Durch stetig steigende Anforderungen und komplexer werdende Unfallszenarien wird permanent nach neuen Sensortechnologien zur Unfallsensierung in puncto Leistungsvermögen und Kosten gesucht. Neben den bekannten Technologien (Druck- und Beschleunigungsmessung) haben sich in anderen Bereichen diverse Technologien etabliert.

Das vorliegende Projekt untersucht die Potentiale von Funk-technologien für den Einsatz in der Unfallsensierung. Hierzu werden beispielsweise diverse Testszenarien bezüglich Performance, Robustheit und weiterer fahrzeugrelevanter Einflüsse entworfen und in prototypischen Hardware-Aufbauten durchgeführt und ausgewertet.

\section{KONTAKT}

stefan.kubica@th-wildau.de

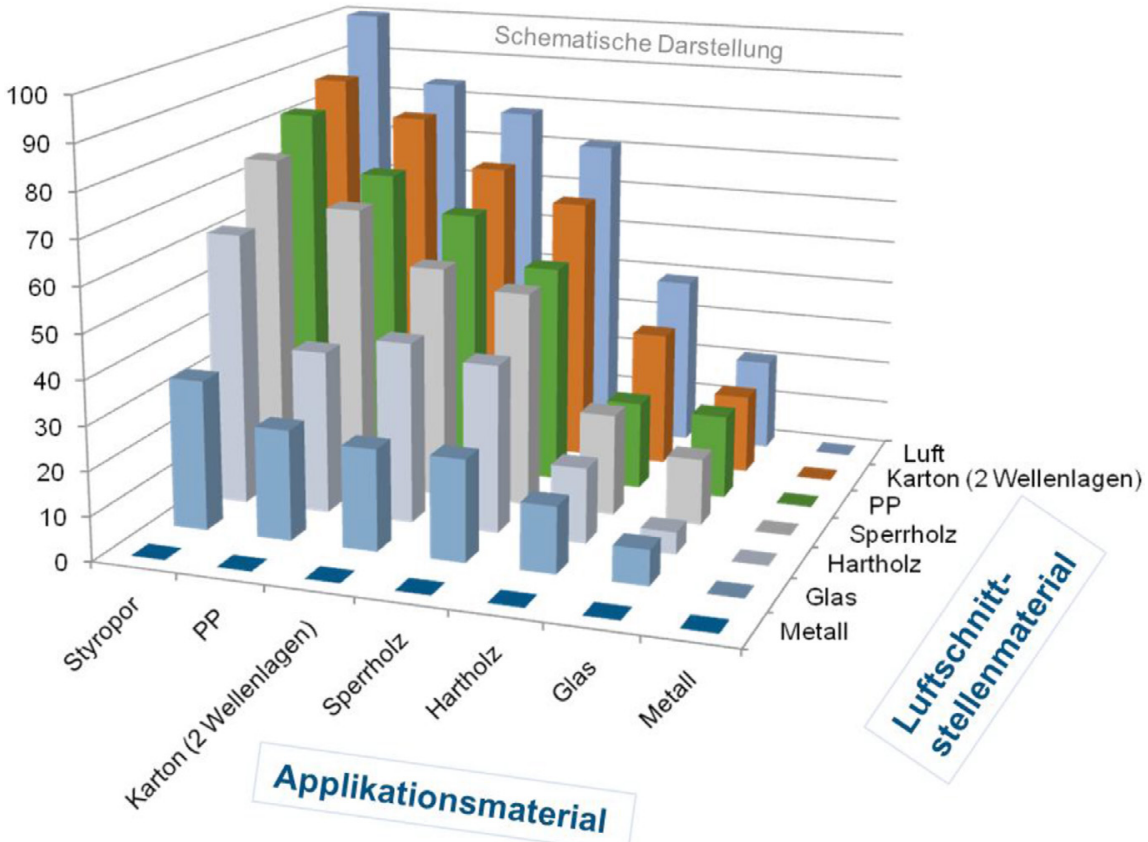

Abb. 1) Beispiel für materialabhängige Beeinflussung der RFID-Reichweite 


\section{IHSITOP (Innovation hybrid strategy of IT-outsourcing partnership with enterprises)}

Prof. Dr. rer. nat. Günter-Ulrich Tolkiehn (Emeritus)

PROJEKTMITARBEITER(INNEN) Jörg Peter, Olga Rösch, Bertram Meimbresse, Susanne Koczoh

KOOPERATIONSPARTNER

PROJEKTVOLUMEN

MITTELGEBER

LAUFZEIT
Alpen-Adria-Universität Klagenfurt

Chernihiv National University of Technology

Institute for Applied System Analysis (Kiew)

Kharkiv Chamber of Commerce and Industry

Kharkiv National University of Radio-Technology

Malibu Sport Ltd. (Kharkiv)

Óbuda University (Budapest)

Odessa National Polytechnic University

Stollmann Entwicklungs-und Vertriebs-GmbH (Hamburg)

$728.431 €$

EU | EACEA | Tempus IV

10/2012-02/2016
Ziel des von der ukrainischen Kollegin Nataliya Bilous initiierten Projekts war die Verstärkung des Praxisbezugs im Informatikstudium in der Ukraine durch eine hybride Kooperationsstrategie, durch die Studierende in Nebentätigkeit oder in praktischen Studienabschnitten unter der Leitung von Hochschulmitarbeitern an IT-Projekten in Wirtschaft und Verwaltung mitarbeiten können. Konzeption und Aufbau von Technologietransfer-Agenturen an den vier ukrainischen Partnerhochschulen in Charkiv, Chernihiv, Kiew und Odessa für die Akquisition und Durchführung geeigneter IT-Projekte bauten auf dem Erfahrungshintergrund der beteiligten EU-Partner auf. Die erforderlichen Anpassungen an Bedarf, Kultur und Rechtssystem in der Ukraine waren erheblich, dennoch konnten die langjährigen bestehenden Erfahrungen der EU-Partner mit Industriekooperationen und ihre bestehenden Vorgehensmodelle als Ausgangspunkte der Diskussion dienen. Ein ukrainischer Mittelständler und eine ukrainische Industrie- und Handelskammer waren als Pilotkunde bzw. Berater am Projekt beteiligt Die

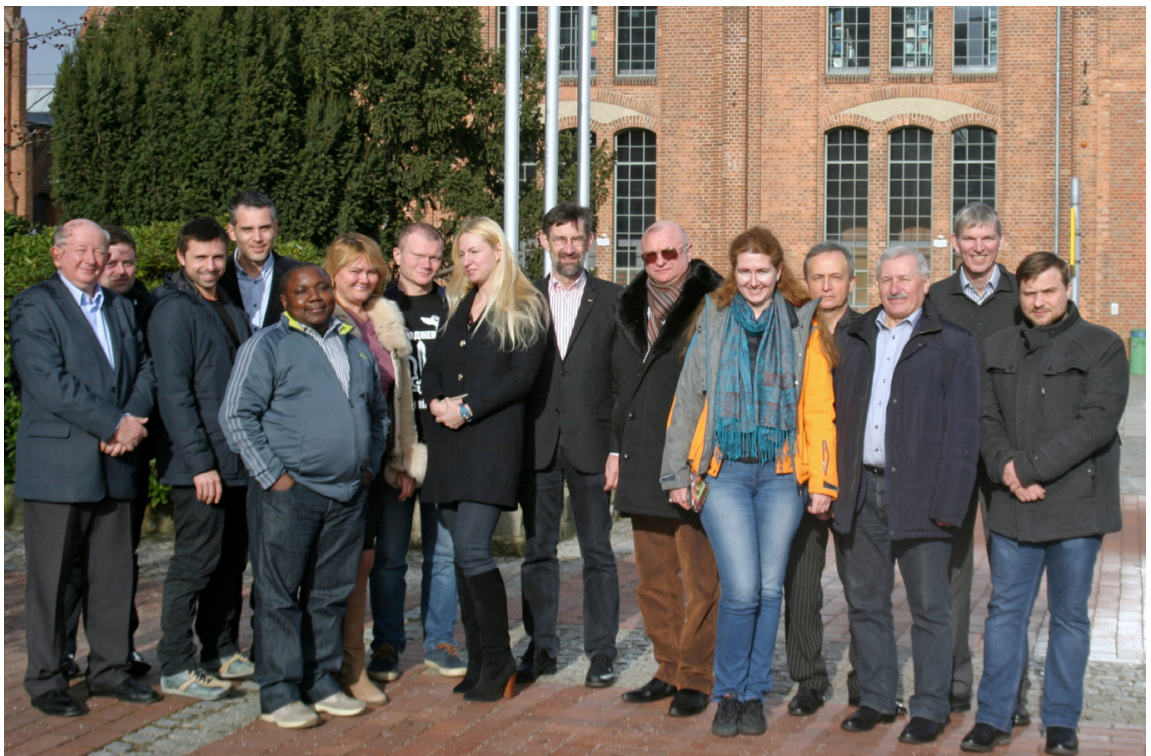

Abb. 1) Abschluss-Meeting in Wildau, v. I.: Iózsef Tick, András Kiss, Igor Ivanisenko, Tamás Kersánszki, Kyandoghere Kyamakya, Nataliya Bilous, Dmytro Chornyi, Tetiana Chorna, Günter Tolkiehn, Mykola Slipchenko, Maryna Didkovska, Yury Timoshenko, Volodymyr Kazymyr, Christian Lührs, Mykola Hodovychenko

ukrainischen Partner (sowohl Mitarbeiter als auch ausgewählte Studierende) hatten auch Gelegenheit, die Verhältnisse bei IT-Hochschulkooperationen mit der Wirtschaft in den drei EU-Partnerländern aus erster Hand kennenzulernen.
Wegen der nach Projektbeginn eingetretenen Unruhen in der Ukraine konnten nicht alle Reisen dorthin planmäßig durchgeführt werden, was u. a. eine budgetneutrale Verlängerung der Projektlaufzeit bis 29.2. 2016 erforderlich machte. 
Alle vier ukrainischen Hochschulpartner haben in der Laufzeit Infrastrukturen aufgebaut, die eine erhebliche Anzahl an IT-Outsourcing-Projekten akquiriert, begonnen und zum Teil auch bereits abgeschlossen haben. Dies wurde auch von Unternehmensvertretern, Studierenden, Hochschulleitungen sowie der ukrainischen Wissenschaftspolitik und Presse gewürdigt. Das Projekt gab auch Anlass zu zahlreichen Publikationen der Partner.

Sowohl was Nutzen und Nachhaltigkeit der Ergebnisse als auch die trotz erheblicher "Korruptionskultur" in der Ukraine sehr korrekte und aufgabenangemessene wirtschaftliche Abwicklung betrifft, bekam das Projekt vom Fördergeber EACEA und den von ihm hinzugezogenen MonitoringPartnern hervorragende Bewertungen, was auch der Selbsteinschätzung der Partner entsprach. Der von der EU auferlegte bürokratische Aufwand wurde jedoch als belastend und teilweise als unangemessen empfunden.

PROJEKTWEBSEITE

https://ostpcen.wordpress.com/

\section{KONTAKT}

joerg.peter@th-wildau.de 


\section{TABELLARISCHE ÜBERSICHT LAUFENDER PROJEKTE}

\begin{tabular}{|l|l|}
\hline $\begin{array}{l}\text { Coronect } \\
\text { Projektleiter }\end{array}$ & Dipl.-Kauffrau Babette Grothe \\
\hline Mitarbeiter & André Reincke, Norman Krüger, Hieronymus Deutsch \\
\hline Mittelgeber & Bund / BMWi / ESF | EXIST \\
\hline Projektvolumen & $125.000 €$ \\
\hline Laufzeit & $06 / 2015-05 / 2016$ \\
\hline Projekthomepage & http://www.coronect.de \\
\hline $\begin{array}{l}\text { Coronect entwickelt ein hochwertiges Medizinprodukt, das Vitalparameter (EKG, Blutdruck, etc.) und Stürze erkennt. Mit } \\
\text { einer cloudbasierten Lösung werden im Notfall, z. B. bei Herzinfarkten, automatisch Helfer alarmiert. }\end{array}$ \\
\hline
\end{tabular}

\section{ARES: Ablaufumgebung für einen Regelenergie-Leitstand}

Projektleiter

Mittelgeber

Kooperationspartner

Laufzeit
Prof. Dr.-Ing. Michael Hendrix

\section{WWF Solar GmbH}

Wirtschaft

$11 / 2016-08 / 2018$

Inhalt dieses Projektes ist die Konzeption und Entwicklung einer Hard- und Software als Ablaufumgebung für den operativen Betrieb eines Leitstandes zur Überwachung, Steuerung und Abrechnung eines Netzwerkes von Regelenergieanlagen.

\section{KIS-NI - Kampfmittelinformationssystem Niedersachsen}

Projektleiter

Prof. Dr.-Ing. Michael Hendrix

Mittelgeber

Landesamt für Geoinformation und Landvermessung Niedersachsen

Projektvolumen $409.735 €$

Laufzeit

$$
12 / 2015-05 / 2020
$$

Inhalt dieses Projektes ist die Erstellung einer Anwendungssoftware „Kampfmittelinformationssystem Niedersachsen (KIS$\mathrm{NI}$ “ zur digitalen Bearbeitung aller wesentlichen Geschäftsprozesse für den Kampfmittelbeseitigungsdienst Niedersachsen (KBD) in folgenden Leistungsstellen: - Auftragsverwaltung - Luftbildauswertung - Räumstellendokumentation - Kampfmittelfund und -entsorgung - Berichtwesen - Datenhaltung in einer Kampfmitteldatenbank - Kampfmittelwebdienste. 
KMBD- FIS 6. Modul: Kampfmittelbeseitigung Fachinformationssystem 6. Modul - 2016

\begin{tabular}{l|l} 
Projektleiter Prof. Dr.-Ing. Michael Hendrix & Prix
\end{tabular}

Mittelgeber Land Brandenburg I Zentraldienst der Polizei

Projektvolumen $\quad 125.300 €$

Laufzeit $\quad 11 / 2016-10 / 2017$

Die Bearbeitung des Projektes zur Implementierung des Fachinformationssystems für den Kampfmittelbeseitigungsdienst (KMBD-FIS) soll mit der Entwicklung eines sechsten Moduls zzgl. der Entwicklung einer App (KMBD-FIS Touch) und Durchführung eines Langzeitfeldversuches bezüglich des praktischen Einsatzes von KMBD-FIS Touch fortgesetzt werden.

MI4G-Navigator: Bewertung der mobilen Datenverbindung

\begin{tabular}{|l|l|}
\hline Projektleiter & Prof. Dr.-Ing. Michael Hendrix \\
\hline Mittelgeber & Bund | BMWi | ZIM \\
\hline Projektvolumen & $169.543 €$ \\
\hline Laufzeit & $09 / 2016-12 / 2017$ \\
\hline
\end{tabular}

Inhalt des Projektes ist die Entwicklung einer Messmethode zur Nutzung semiprofessioneller Endgeräte (Smartphones) für die automatisierte Messung und Bewertung von Netz-, System- und Geräteperformance in Mobilfunknetzwerken mit dem Ziel der Ermittlung von Leistungsindizes und leichtverständlicher Darstellung der Reports in Form Nutzer-spezifischer Interpretationsmatrizen unter Berücksichtigung der relevanten Einflüsse.

SensoSphere: Mobiler sensorbasierter Kugelroboter zur spontanen Aufklärung sicherheitskritischer Situationen

\begin{tabular}{|l|l|}
\hline Projektleiter & Prof. Dr.-Ing. Michael Hendrix \\
\hline Mittelgeber & Bund / BMWi / ZIM \\
\hline Projektvolumen & $190.000 €$ \\
\hline Laufzeit & $08 / 2016-07 / 2018$ \\
\hline
\end{tabular}

Ziel dieses Projektes ist die Entwicklung eines mobilen, fernsteuerbaren, mit Kameras und Sensoren ausgestatteten KugelRoboters, der mittels Wurf oder Luftdruck-Schussgerät in ein Beobachtungsgebiet verbracht werden kann, ohne dass ein Operator in dieses Gerät eindringen kann. SensoSphere soll als jederzeit einsetzbares und einfach zu handhabendes System zur spontanen Feldaufklärung bei Großschadensereignissen und Gefährungslagen sowohl indoor als auch outdoor verwendbar sein. Die Sensorik und die Kommunikationsmöglichkeiten des Systems sind modular konzipiert und lassen sich damit spontan an die Erfordernisse des jeweiligen Einsatzszenarios vor Ort anpassen.

AM@Ferrari: Optimierung des Anforderungsmanagements in der Elektronik-Entwicklung bei Ferrari S. p. A.

Projektleiter Prof. Dr.-Ing. Stefan Kubica

\begin{tabular}{l|l} 
Mittelgeber $\quad$ Ferrari S.p.A.
\end{tabular}

Laufzeit $\quad 12 / 2015-02 / 2017$

Ziel dieses Projektes ist es, die Digitalisierung im Bereich des Anforderungsmanagements elektrischer/elektronischer Fahrzeugfunktionen bei Ferrari S.p.A. zu steigern. Hierbei geht es u.a. um die Einführung entwicklungsbegleitender Kennzahlen, datenbankorientiertem Anforderungsmanagement und dazugehörigen Prozessbeschreibungen.(CVision:Lab) sollen in diesem Investitionsvorhaben beschafft werden: Hochfrequenz-Spezialspindel zur Erstellung von Kleinteilen, Messwerkzeug zur flexiblen Einstellung von Fräskoordinaten, Vakuumplatte zur sicheren Befestigung von kleinen Modellobjekten, Spezialfräswerkzeug mit Wechselmagazin. 
Projektleiter

Prof. Dr.-Ing. Stefan Kubica

Kooperationspartner

Mittelgeber

Wirtschaft

Volkswagen AG

Laufzeit

$10 / 2016-02 / 2017$

Durch stetig steigende Anforderungen und komplexer werdende Unfallszenarien wird permanent nach neuen Sensortechnologien zur Unfallsensierung in punkto Leistungsvermögen und Kosten gesucht. Neben den bekannten Technologien (Druck- und Beschleunigungsmessung) haben sich in anderen Bereichen diverse Technologien etabliert. Das vorliegende Projekt untersucht die Potentiale von RFID-Technologie für den Einsatz in der Unfallsensierung.

\section{SecAware4job - Informationssicherheitsbewusstsein/Information Security Awareness für den Berufseinstieg}

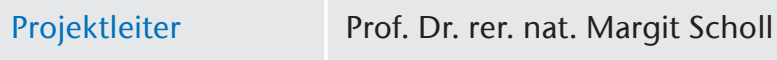

Mitarbeiter Frauke Fuhrmann, Denis Edich, Peter Ehrlich, Peter Koppatz

Kooperationspartner known_sense

Mittelgeber

Horst Görtz Stiftung

Projektvolumen $199.805 €$

Laufzeit

09/2015-08/2017

SecAware4job verfolgt das Ziel, Studierende nicht-technischer Studiengänge als zukünftige Mitarbeiter/innen für die alltäglichen Herausforderungen des Schutzes der Informationssicherheit und der digitalen Infrastruktur zu sensibilisieren und ihr IT-Sicherheitsbewusstsein fundiert zu fördern. Zur Erreichung dieses Ziels wird eine berufsorientierte Zusatzqualifikation für Studierende in Form einer innovativen Weiterbildung zur Stärkung des Bewusstseins und der Kompetenzen bzgl. Informations- und insbesondere IT-Sicherheit entwickelt. Diese Zusatzqualifikation soll zielgruppenspezifisch aufgebaut und vor allem in den nicht-technischen Studiengängen der TH Wildau direkt integriert werden. Die Studierenden erhalten die Möglichkeit, ein vierstufiges Zertifikat zu erwerben: vom einfachen Teilnahme- bzw. Moderationszertifikat, über den Europäischen Computerführerschein (ECDL) in den Modulen IT-Sicherheit und/oder Datenschutz bis hin zum fünf Jahre gültigen Zertifikat IT-Sicherheitsbeauftragte/r (IT-SiBe). Um das abstrakte und komplexe Thema Informationssicherheit mit all seinen Facetten (z. B. rechtliche Rahmenbedingungen, Normen \& Standards, Schutzmaßnahmen, Konzepte) verständlich sowie greif- und erlebbar zu vermitteln, werden kreative Lehr- und Lernmethoden, u. a. analoge und digitale simulierte Szenarien, entwickelt und erprobt. 
Projektleiter

Mitarbeiter

Mittelgeber

Projektvolumen

Laufzeit
Kooperationspartner

Prof. Dr. rer. nat. Margit Scholl

\section{Frauke Fuhrmann}

Fundacio Per A La Universitat Oberta De Catalunya (Uoc) (Federführung), Institut Obert De Catalunya (loc), Stockholms Universitet (Su), Hochschule Der Bundesagentur Für Arbeit (Hdba), Fundació Factor Humá

EU | Erasmus+ | KA2 Strategic Partnerships

$18.000 €$

09/2016-02/2019

Das Ziel des Projektes ist die bessere Vorbereitung von Hochschulabsolventen auf ihren Berufseinstieg und somit die Verbesserung ihrer Beschäftigungsfähigkeit und ihres beruflichen Erfolgs. Durch authentische Lernszenarien und -umgebungen und moderne Lehr- und Lernmethoden sollen die Studierenden die notwendigen auf dem Arbeitsmarkt geforderten Fähigkeiten (Hard- und Softskills) für ihren Berufseinstieg erlangen. Zur Erreichung des Ziels wurde eine länderübergreifende Kooperation, bestehend aus sechs Partnern (Hochschulen mit verschiedenen Ausrichtungen, Einrichtung für die berufliche Bildung sowie Arbeitgebervertreter) aus Spanien, Schweden und Deutschland ins Leben gerufen.

\section{TechPedia: European Virtual Learning Platform for Electrical and Information Engineering}

Projektleiter

Prof. Dr. rer. nat. Margit Scholl

Mittelgeber

Projektvolumen

Laufzeit

Projekthomepage

\section{EU | Erasmus+}

\section{$28.543 €$}

$$
\text { 09/2014-08/2017 }
$$

http://www.techpedia.eu

Im Projekt erstellen jeweils eine Hochschule und ein Ausbildungsbetrieb in jeweils fünf Partnerländern Lernmaterialien für den technischen \& IT-Bereich. Alle Lernmaterialien werden auf einem Bildungsportal und für Lernplattformen (z. B. Moodle), als PDFs, für eBook-Reader und Smartphones zur Verfügung stehen. Auf internationaler Ebene soll zudem ein großer Wettbewerb durchgeführt werden, die Technische Olympiade.

BERMUDA - Bilderkennung multiperspektivischer Daten zur intelligenten

Analyse von Gesten und Aktionsmustern

Projektleiter

Mittelgeber

Projektvolumen

Laufzeit
Prof. Dr. rer. nat. Ralf Vandenhouten

Bund | BMBF | FHprofUnt

Ein Bedarfsfeld der Hightech-Strategie 2020 ist die Sicherheit der Bürgerinnen und Bürger der Gesellschaft. Zum Bedarfsfeld der Sicherheit zählt u.A. der Schutz der Gesellschaft vor Terrorismus und Kriminalität. Dieses Forschungsprojekt widmet sich der Fragestellung des Einsatzes von stereo- und multiperspektiven Kameras zur Erkennung von Delikten des öffentlichen Personennahverkehrs (ÖPNV) sowie auf öffentlichen Plätzen (z. B. Bahnhöfe, Flughäfen). 
Projektleiter

Kooperationspartner

Mittelgeber

Projektvolumen

Laufzeit
Prof. Dr. rer. nat. Ralf Vandenhouten

Condat AG, DFKI, BVG

Bund | BMBF

$363.546 €$

$01 / 2013-05 / 2016$

Thema des Projekts ist die IT-gestützte und multimediale Wissenskollaboration älterer und erfahrener mit neuen und jungen Mitarbeitern. Schwerpunkt ist die Sicherung und Weitergabe episodischen Wissens im konkreten Arbeitsprozess mittels mobiler Assistenten und strukturoffener Wissensdatenbanken. Die "Portable Lern- und Wissensplattform zum Transfer episodischen Wissens in Organisationen" (PLUTO) unterstützt die Wissenssicherung und Wissensvermittlung mit mobilen Arbeitsplätzen im demografischen Wandel von großen Unternehmen und Organisationen. Das Projekt PLuTO wurde 2016 mit dem Maintainer Award ausgezeichnet (siehe https://www.tm.th-wildau.de/maintainer-award-fuer-verbundprojekt-pluto/).

\section{WErKiB: Werkzeuge zur Erstellung von Kleinprototypen in der Bildberarbeitung}

\begin{tabular}{l|l} 
Projektleiter $\quad$ Prof. Dr. rer. nat. Ralf Vandenhouten \\
\hline
\end{tabular}

Mittelgeber $\quad$ Land Brandenburg I MWFK | EFRE

Projektvolumen $\quad 40.000 €$

Laufzeit $\quad$ 07/2015-06/2016

Folgende Geräte zur Erweiterung einer bestehenden CNC-Fräse im Innovationszentrum für Bild- und Videoverarbeitung (CVision:Lab) sollen in diesem Investitionsvorhaben beschafft werden: Hochfrequenz-Spezialspindel zur Erstellung von Kleinteilen, Messwerkzeug zur flexiblen Einstellung von Fräskoordinaten, Vakuumplatte zur sicheren Befestigung von kleinen Modellobjekten, Spezialfräswerkzeug mit Wechselmagazin

PSM - Power-Selekt-Managementsystem

Projektleiter

Prof. Dipl.-Inf. Birgit Wilkes

Mittelgeber

Bund | BMWi | ZIM

Projektvolumen

$173.890 €$

Laufzeit

$04 / 2015-12 / 2016$

Ein Verbund innovativer, regenerativer Energiesysteme soll durch ein PSM in die Lage versetzt werden, für autarke Nutzergemeinschaften z.B. mittelständische Unternehmen, großflächige Freizeiteinrichtungen oder ganze Quartiere, eine Management- und Abrechnungsbasis für eigenerzeugte, regenerative Energie zu schaffen. Die Entwicklungsarbeit liegt dabei in einem eingliedrigen, diffenrenzierten Regelstreckenalogrithmus. Der Schwerpunkt des Projektes ist geprägt von einem aktiven Verbrauchermanagement. 


\section{TABELLARISCHE ÜBERSICHT PUBLIKATIONEN}

Azmitia A, Mohnke J, Wiechers H (2016)

Azmitia A, Mohnke J, Wiechers H (2016)

Barton T, Herrmann F, Meister VG, Müller C, Seel C (2016)

Brüggemann R, Koopatz P, Fuhrmann F, Scholl M (2016)

Eylert B (2016)

Keist N-K, Benisch S, Müller C (2016)

Kubica S, Jacob T (2016)

Sandoval-Almazan R, Scholl M, Kavanaugh A (2016)

Schmalenberg F, Vandenhouten R (2016)

Schmalenberg F, Vandenhouten R (2016)

Scholl M (2016)
Campus App Unidos Wildau - ein ständiger Begleiter für den Alltag an der Technischen Hochschule Wildau. In: Barton T, Müller C, Seel C (eds) Mobile Anwendungen in Unternehmen. Springer Fachmedien, Wiesbaden, ISBN: 978-3-658-12009-2, pp 227-242. doi: 10.1007/978-3-658-12010-8_15

Wo bin ich? iBeacons im Einsatz in der Bibliothek der TH Wildau. Bibliothek Forschung und Praxis 40(3):395-404. doi: 10.1515/bfp-2016-0050

Prozesse, Technologie, Anwendungen, Systeme und Management 2016. Tagungsband zur 29. AKWI-Jahrestagung vom 11.09.2016 bis 14.09.2016 an der Technischen Hochschule Brandenburg. doi: 10.15771/978-3944330-54-9

A matching problem, partial order and an analysis applying the Copeland index. In: Bruggemann, M, Fattore R (eds) Partial Order Concepts in Applied Sciences, Springer, New York

Sicherheit bei Smartphones und Tablets. In: Barton T, Müller C, Seel C (eds) Mobile Anwendungen in Unternehmen. Springer Fachmedien, Wiesbaden, ISBN: 978-3-658-12009-2, pp 123-138. doi: 10.1007/978-3658-12010-8_9

Möglichkeiten und Grenzen der plattformübergreifenden App-Entwicklung. In: Barton T, Müller C, Seel C (eds) Mobile Anwendungen in Unternehmen. Springer Fachmedien, Wiesbaden, ISBN: 978-3-658-12009-2, pp 109-119. doi: 10.1007/978-3-658-12010-8_8

Data-Mining-Methoden zur frühzeitigen Erkennung bedrohlicher Situationen im Fahrzeug. In: Kubica S, Ringshausen H, Reiff-Stephan J, Schlingelhoff M (eds) 1. Automobil Symposium Wildau. Technische Hochschule Wildau, Wildau, pp 59-63

Introduction to the Social Media in Government Minitrack. In: IEEE, p 2990. doi: 10.1109/HICSS.2016.374

A DFD Based Approach to Model Data Processing Solutions. Wissenschaftliche Beiträge 2016 20:31-36. doi: 10.15771/0949-8214_2016_1_4

An advanced data processing environment based on data flow diagrams with a flexible triggering and execution model. In: IEEE, ISBN: 978-14673-8739-2, pp 159-164. doi: 10.1109/SAMI.2016.7423000

Forschendes Lernen aus der Perspektive der Fachhochschulen. In: Mieg HA, Lehmann J (eds) Forschendes Lernen: Wie die Lehre in Universität und Fachhochschule erneuert werden kann. Campus, Frankfurt, ISBN: 978-3-5935-0140-6 
How usable and clear are the websites of European capitals from the point of view of German students adopting an E-Government perspective? In: IEEE, pp 2893-2902. doi: 10.1109/HICSS.2016.363

What Lessons Can We Learn for "Good E-Government" From a User-Centred Evaluation of the Websites of European Capitals? Research-Based

Scholl M (2016) and Genetic Learning in the Study of Administration and Law. International Journal of E-Planning Research 5(4):16-40. doi: 10.4018/ IJEPR.2016100102

Information Security Awareness 3.0 for Job Beginners. In: Quintela Varajão JE (ed). Proceedings of Conference on ENTERprise Information Systems/International Conference on Project MANagement/Conference on Health and Social Care Information Systems and Technologies, Porto, Portugal, ISBN: 978-989-97433-7-3, pp 433-436

The Human Factor: How Can Information Security Awareness Be Sustainably Achieved in E-Government? In: Scholl HJ, Glassey O, Janssen MFWHA (eds) Electronic government and electronic participation. Joint proceedings of ongoing research, PhD papers, posters and workshops of IFIP EGOV and ePart 2016. Innovation and the Public Sector, vol 23. IOS Press, Netherlands, ISBN: 1614996709, pp 403-404

CMPLServer - An open source approach for distributed and grid optimisation. Anwendungen und Konzepte der Wirtschaftsinformatik 4:9-22

Logistik-Entscheidungen, 2. aktualis. und kompl. überarb. De Gruyter Studium. De Gruyter, Berlin und Boston. ISBN: 978-3-11-043984-7

Simultaneous differentiation and quantification of ricin and agglutinin by an antibody-sandwich surface plasmon resonance sensor. Biosens Bioelectron 78:111-117. doi: 10.1016/j.bios.2015.11.020

Forschungsbericht 2015. Forschung, Entwicklung, Lehre. Technische Hochschule Wildau, Wildau. doi: 10.15771/FB_2016_1

A Modular Mobile Device for Real-Time 3D Streaming. Wissenschaftliche Beiträge 2016 20:37-43. doi: 10.15771/0949-8214_2016_1_5 


\section{Optische Technologien und Photonik Optical Technologies and Photonics}




\section{TABELLARISCHE ÜBERSICHT LAUFENDER PROJEKTE}

\section{Speculum2 - Chrom- und Goldbeschichtung von Spiegeloberflächen und Referenzproben}

\begin{tabular}{|c|c|}
\hline Projektleiter & Dipl.-Physiker Harald Beyer \\
\hline Kooperationspartner & SENTECH Instruments $\mathrm{GmbH}$ \\
\hline Mittelgeber & Wirtschaft \\
\hline Laufzeit & $01 / 2015-06 / 2016$ \\
\hline
\end{tabular}

\section{DeepView - Optisches Messsystem zur Charakterisierung von Deep Silicon Vias}

\begin{tabular}{|c|c|}
\hline Projektleiter & Prof. Dr. rer. nat. habil. Sigurd Schrader \\
\hline Mittelgeber & Bund | BMWi | ZIM \\
\hline Projektvolumen & $175.000 €$ \\
\hline Laufzeit & $01 / 2015-06 / 2016$ \\
\hline \multicolumn{2}{|c|}{$\begin{array}{l}\text { Ziel des Vorhabens ist die Entwicklung eines optischen Verfahrens und Aufbaus zur Vermessung von Kontaktlöchern } \\
\text { (deep silicon vias) für die 3D-Chip-Technologie und anderer Strukturen mit extrem hohen Aspektverhältnissen bis 1:25. } \\
\text { Das Verfahren basiert auf einem neuartigen, an der TH Wildau entwickelten Ansatz. Die Konzeption des Verfahrens sieht } \\
\text { eine Einsetzbarkeit zur Echtzeit-Tiefenkontrolle an SENTECH-Plasmaätzanlagen vor. }\end{array}$} \\
\hline
\end{tabular}

\section{DiaS: Erweiterung eines Beschichtungssystems zur Herstellung diamantartiger Schichten}

\begin{tabular}{l|l}
\hline $\begin{array}{l}\text { Projektleiter } \\
\text { Mittelgeber }\end{array}$ & Prof. Dr. rer. nat. habil. Sigurd Schrader \\
\hline Projektvolumen & $74.527 €$ \\
\hline Laufzeit & $10 / 2016-09 / 2017$ \\
\hline
\end{tabular}

Im vorliegenden Vorhaben soll ein vorhandenes Plasmabeschichtungssystem technisch erweitert werden. Die Erweiterung dient der Herstellung diamantähnlicher Kohlenstoffschichten für den Schutz und zur gezielten Funktionalisierung von Oberflächen hauptsächlich im Bereich der Sensorik. Damit sollen Oberflächen einerseits gegenüber äußeren Umwelteinflüssen wie zum Beispiel Feuchtigkeit und chemischen Angriffen unempfindlich werden. 
EEP-S: Entwicklung eines endoskopischen Messkopfes mit Schrägsicht

Projektleiter

Prof. Dr. rer. nat. habil. Sigurd Schrader

Kooperationspartner Rolls-Royce Deutschland Ltd. \& Co KG

Mittelgeber

Wirtschaft

Laufzeit

03/2016-12/2016

Das geplante Vorhaben beinhaltet die "Entwicklung eines endoskopischen Messkopfes mit Schrägsicht" als Bestandteil des LuFoV-Projketes "Reparatur- und Inspektionstechnologien für effizientes Fliegen" und wird in das Arbeitspaket 1.2 "Endoskopische Inspektion kleiner Oberflächenbeschädigungen" eingeordnet. Die Aufgabe der TH Wildau besteht darin, einen miniaturisierten Prüfkopf mit Schrägsicht-Optik auf Grundlage photonischer Verfahren zu entwicklen.

EOFP: Entwicklung elektro-optisch abstimmbarer Fabry-Perot Ultraschallsensoren für biomedizinische photoakustische Bildgebung mit hoher Bildrate

Projektleiter

Prof. Dr. rer. nat. habil. Sigurd Schrader

Mittelgeber

DFG

Projektvolumen

$211.300 €$

Laufzeit

$03 / 2016-02 / 2019$

Ziel des interdisziplinären Projektes ist die Entwicklung elektro-optisch abstimmbarer Fabry-Perot-Ultraschallsensoren für biomedizinische photoakustische Bildgebung mit hohen Bildraten. Das Projekt wird in Kooperation mit der TU Berlin durchgeführt. Es umfasst Entwicklugnsarbeiten in den Bereichen der nichtlinearen Optik, Polymerchemie, optischen Beschichtungstechnologie, optischen Ultraschallmessung und photoakustischen Bildgebung.

EVD: Schichtbildung durch elektronenaktivierte Vakuum-Deposition

\begin{tabular}{|l|l|}
\hline $\begin{array}{l}\text { Projektleiter } \\
\text { Mittelgeber }\end{array}$ & Prof. Dr. rer. nat. habil. Sigurd Schrader \\
\hline Projektvolumen & $703.574 €$ \\
\hline Laufzeit & $04 / 2016-03 / 2018$ \\
\hline
\end{tabular}

Ziel dieses Vorhabens ist es, Forschungsergebnisse der TH Wildau auf dem Gebiet der Vakuum-Gasphasen-Abscheidung kohlenstoffbasierter Funktionsmaterialien als Grundlage neuer Beschichtungstechnologien zu nutzen. Der Projektverbund strebt die Etablierung einer regionalen Entwicklungs- und Technologieplattform an, welche neue Polymer- bzw. Kohlenstoffbeschichtungsverfahren wie den EVD-Prozess und damit herstellbare Funktionsschichten ins Zentrum der gemeinsamen F\&E-Aktivitäten stellt. 


\section{FAEROS - Fasern mit extrem rechteckigen Querschnitten für optische Sensorik}

Projektleiter

Kooperationspartner

Mittelgeber

Projektvolumen

Laufzeit
Prof. Dr. rer. nat. habil. Sigurd Schrader

F\&T Fibers and Technology GmbH

Bund | BMWi | ZIM

$174.970 €$

05/2014-09/2016

F\&T Fibers and Technology GmbH beabsichtigt in Kooperation mit der TH Wildau die Entwicklung der Herstellungstechnologie neuartiger optischer Sensorfasern, welche sich durch 1) ein extrem hohes Verhältnis der äußeren Oberfläche zum Volumen, 2) Kerne oder Kern-Mantel-Strukturen aus synthetischem Quarzglas und 3) sensitive Beschichtungen auf Basis funktioneller Gruppen dotierter Polymere auszeichnen.

\section{FibrOLED: Faserförmige Organische Leutdioden}

Projektleiter

Prof. Dr. rer. nat. habil. Sigurd Schrader

Mittelgeber

OSRAM GmbH

Laufzeit

$12 / 2016-03 / 2017$

Das Projekt dient der Entwicklung neuartiger organischer Leuchtdioden auf nichtplanaren Substraten und eines neuartigen Herstellungsverfahrens, welches Chemisorptionsprozesse aus der Flüssigphase nutzt.

\section{HOLMES: Systematische Untersuchung des nicht ordnungsgemäßen Betriebs von PIDs}

Projektleiter

Mittelgeber

Laufzeit

Prof. Dr. rer. nat. habil. Sigurd Schrader

Analytic Control Instruments $\mathrm{GmbH}$

$08 / 2016-02 / 2017$

Ziel des vorliegenden Projektes ist es, durch systematische Untersuchungen des nicht ordnungsgemäßen Betriebs von PIDs für verschiedene Umweltbedingungen im Hinblick auf die Abhängigkeit des Messsignals von der Transmission des Lampenfensters Schwachstellen und Ursachen im Aufbau der PIDs zu lokalisieren und durch geeignete Maßnahmen die Problematiken zu beheben.

\section{LAGER - Laser-assistierte Beschichtungstechnologie für Gleitlager als effizienter Ersatz des Schleudergussverfahrens}

Projektleiter

Kooperationspartner

Mittelgeber

Projektvolumen

Laufzeit
Prof. Dr. rer. nat. habil. Sigurd Schrader

\section{ADMOS Gleitlager $\mathrm{GmbH}$}

Deutsche Bundesstiftung Umwelt

\section{$21.500 €$}

$11 / 2015-11 / 2016$

Ziel des Projektes ist die Entwicklung eines wirtschaftlichen, laserbasierten Beschichtungsprozesses mit einem vorzugsweise pulverförmigen Ausgangsmaterial zum Aufbrigen von Gleitschichten für Hochleistungslager auf der Basis von Kupfer oder Weißmetalllegierungen. Dabei kann eine energeitsche Einsparung von bis zu 80\% im Vergleich zur herkömmlichen Fertigungstechnologie des Gießens, bezogen auf die Gesamtleistungen, erzielt werden. 
Pro-STELLA - Prototyp-Entwicklung eines optischen Strahlungsmoduls mit elektrodenloser Entladungslampe und Verfahren zur Herstellung

Projektleiter

Kooperationspartner

Mittelgeber

Projektvolumen

Laufzeit
Prof. Dr. rer. nat. habil. Sigurd Schrader

Analytical Control Instruments $\mathrm{GmbH}$

Bund | BMWi | ZIM

$175.000 €$

07/2014-06/2016

Ziel des Vorhabens ist die Entwicklung des neuartigen Prototyps eines Strahlungsmoduls mit einer elektrodenlosen Entladungslampe im Niederdruckbereich für die Anwendung in photometrischen Messgeräten der industriellen Analysenmesstechnik mit gesteigerter Stabilität der Strahlungsausgangsleistung (Spektrallinien stabilisiert) für verschiedene spektrale Mess-Referenzlinien und reproduzierbaren Einsatzzeiten von bis zu 20.000 Betriebsstunden. Durch gezielte, zu evaluierende Prinzipien und Fertigungstechnische Maßnahmen soll der Anteil der Einbrennzeit, der momentan die Lebensdauer entscheidend verringert, auf ein Minimum reduziert werden, um die geforderte stabile Betriebszeit zu gewährleisten.

Pro-ZyLiMa: Entwicklung von nicht-planen strukturierten Masken für die Verwendung in lithographischen Prozessen

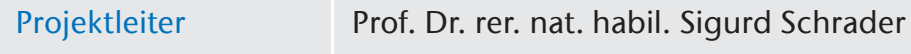

Mittelgeber Bund | BMWi

Projektvolumen $\quad 41.598 €$

Laufzeit $\quad 01 / 2016-12 / 2016$

Ziel des Projektes ist die Entwicklung von nicht-planen und insbesondere zylinderförmigen oder elliptischen Strukturierungsmasken für die Verwendung in lithographischen Prozessen. Teil des Projektes ist Herstellung und Verwendung von Mikro- und Makrostrukturierungen von nicht-planen, runden Oberflächen bzw. zylindrischen Körpern. Ein Teil der Idee betrifft einen innovativen Verfahrensansatz, der Beugungsinterferenzeffekte für die Lithographie und insbesondere für Mikrostrukturen bereinigt.

SVO-NALA - Entwicklung neuartiger Hochleistungs-Absorberschichten für lasertechnische Anwendungen

Projektleiter

Mittelgeber

Projektvolumen

Laufzeit

Projekthomepage
Prof. Dr. rer. nat. habil. Sigurd Schrader

Bund | BMWi | ZIM

$174.946 €$

$09 / 2014-08 / 2016$

In dem Netzwerkprojekt (Entwicklung neuartiger Hochleistungs-Absorberschichten für lasertechnische Anwendungen) (SVO-NALA) soll ein prototypischer Lasersensor für hohe Leistungsdichten mit kurzen Zeitkonstanten entwickelt und erprobt werden. Dazu ist beabsichtigt, den Reflexionsgrad von Kupfer, Nickel und Edelstahl durch eine gezielte Strukturierung der Oberfläche im Mikrometerbereich so anzupassen, dass diese Materialen als Absorberschichten in Laserleistungsmessköpfen eingesetzt werden können. 
SVO-Graphen: Graphene and Anti-reflective Coatings using Pulsed High-Current Arc Evaporation

\begin{tabular}{|c|c|}
\hline Projektleiter & Prof. Dr. rer. nat. habil. Sigurd Schrader \\
\hline Mittelgeber & Bund | BMWi | ZIM \\
\hline Projektvolumen & $188.914 €$ \\
\hline Laufzeit & 08/2016-07/2018 \\
\hline \multicolumn{2}{|c|}{$\begin{array}{l}\text { Ziel des hier skizzierten Vorhabens ist die Entwicklung eines neuartigen Verfahrens zur Abscheidung von schwarzen koh- } \\
\text { lenstoffbasierten Schichten und Graphen. Die prototypische Labormusteranlage soll in der Lage sein, Proben unterschied- } \\
\text { licher Größe und Beschaffenheit zu schwärzen, so dass sowohl die direkte als auch diffuse Reflexion deutlich vermindert } \\
\text { wird. Ferner soll durch geeignete Modifikation der Anlage die Beschichtung von unterschiedlichen Substraten (Metalle, } \\
\text { Isolatoren) mit Graphen untersucht werden. }\end{array}$} \\
\hline
\end{tabular}

\section{ZIEHGE - Optische Vermessung von Ziehsteingeometrien für die Drahtindustrie}

\begin{tabular}{|c|c|}
\hline Projektleiter & Prof. Dr. rer. nat. habil. Sigurd Schrader \\
\hline Mittelgeber & Bund | BMWi | ZIM \\
\hline Projektvolumen & $175.000 €$ \\
\hline Laufzeit & $02 / 2015-07 / 2016$ \\
\hline \multicolumn{2}{|c|}{$\begin{array}{l}\text { Ziel des hier skizzierten Projektes ist die Entwicklung eines optischen Messverfahrens zur Charakterisierung von Ziehstei- } \\
\text { nen mit Lochdurchmessern von } 10 \mu \mathrm{m} \text { bis } 8 \mathrm{~mm} \text {. Mit dem neuen Verfahren sollen fünf grundlegende Geometrieeigen- } \\
\text { schaften von Ziehsteinen (Innendurchmesser, Länge des inneren Segments bzw. Zylinderlänge, Einlaufwinkel, Ziehwinkel } \\
\text { und Auslaufwinkel) zerstörungsfrei gemessen werden. }\end{array}$} \\
\hline
\end{tabular}




\section{TABELLARISCHE ÜBERSICHT PUBLIKATIONEN}

Buchmann J, Zhang E, Scharfenorth C, Spannekrebs B, Villringer C, Laufer J (2016)

Fursenko O, Bauer JM, Marschmeyer S (2016)

Klingsporn M, Kirner S, Villringer C, Abou-Ras D, Costina I, Lehmann M, Stannowski B (2016)

Lux H, Siemroth P, Schrader SK (2016)

Padilla-Michel Y, Pulwer S, Saffari P, Ksianzou V, Schrader SK (2016)

Prosposito P, Melino S, Ciocci M, Francini R, Mochi F, Matteis F de, Di Nardo P, Ksenzov S, Schrader SK, Casalboni M (2016)

Pulwer S, Steglich P, Villringer C, Bauer JM, Burger M, Franz M, Grieshober K, Wirth F, Blondeau J, Rautenberg J, Mouti S, Schrader SK (2016)

Steglich P, Mai C, Stolarek D, Lischke S, Kupijai S, Villringer C, Pulwer S, Heinrich F, Bauer J, Meister S, Knoll D, Casalboni M, Schrader S (2016)

Steglich P, Pulwer S, Villringer C, Bauer JM, Heinrich F, Dietzel B, Mai A, Schrader SK (2016)

Steglich P, Pulwer S, Villringer C, Bauer JM, Heinrich F, Dietzel B, Mai A, Schrader SK (2016)

Steglich P, Villringer C, Pulwer S, Bauer J, Heinrich F, Casalboni M, Schrader S (2016)
Evaluation of Fabry-Perot polymer film sensors made using hard dielectric mirror deposition. Proceedings of SPIE 9708:art. no. 970856. doi: $10.1117 / 12.2234698$

3D through silicon via profile metrology based on spectroscopic reflectometry for SOI applications. In: Proc. SPIE 9890, Optical Microand Nanometrology VI, 989015 (April 26, 2016). SPIE Proceedings. doi: $10.1117 / 12.2227651$

Resolving the nanostructure of plasma-enhanced chemical vapor deposited nanocrystalline SiOx layers for application in solar cells. Journal of Applied Physics 119(22):k.A. doi: 10.1063/1.4953566

Ultra-fast synthesis of Graphene on poly-crystalline metal foils and insulators. In: EnFi 2016 - 9th Meeting "Engineering of Functional Interfaces", 03.-05.07.2016, Wildau

On the origin and removal of interference patterns in coated multimode fibres. In: Proc. SPIE 9912, Advances in Optical and Mechanical Technologies for Telescopes and Instrumentation II, 991255 (22 July 2016). doi: $10.1117 / 12.2233676$

Photolithography of 3D Scaffolds for Artificial Tissue. Materials Science Forum 879:1519-1523. doi: 10.4028/www.scientific.net/MSF.879.1519

Triangulation-based 3D surveying borescope. In: Proc. SPIE 9890, Optical Micro- and Nanometrology VI, 989009 (April 26, 2016). SPIE Proceedings. doi: 10.1117/12.2225203

Partially slotted silicon ring resonator covered with electro-optical polymer. In: Vivien L, Pavesi L, Pelli S (eds), Sunday 3 April 2016, Brussels, Belgium. SPIE Proceedings. SPIE, 98910R. doi: 10.1117/12.2217725

Photonic devices for future chip-integrated biosensors. GIT laboratory journal Europe

Vor-Ort-Analytik. Photonische Bauelemente für Chip-integrierte Biosensoren. GIT : Labor-Fachzeitschrift k.A:k.A

Advanced Nanophotonics: Silicon-Organic Hybrid Technology. Wiss Beitr TH Wildau 20:45-48. doi: 10.15771/0949-8214_2016_1_6 
Steglich P, Villringer C, Pulwer S, Casalboni M, Schrader S (2016)

Buchmann J, Zhang E, Scharfenorth C, Spannekrebs B, Villringer C, Laufer J (2016)

Fursenko O, Bauer JM, Marschmeyer S (2016)
Design Optimization of Silicon-on-Insulator Slot-Waveguides for Electrooptical Modulators and Biosensors. In: Ribeiro PA, Raposo M (eds) Photoptics 2015. Proceedings of the 3rd International Conference on Photonics, Optics and Laser Technology, 1st ed. 2016. Springer Proceedings in Physics, vol 181. Springer International Publishing; Springer, Cham, ISBN: 3319301357, pp 173-187

Evaluation of Fabry-Perot polymer film sensors made using hard dielectric mirror deposition. Proceedings of SPIE 9708:art. no. 970856. doi: $10.1117 / 12.2234698$

3D through silicon via profile metrology based on spectroscopic reflectometry for SOI applications. In: Proc. SPIE 9890, Optical Microand Nanometrology VI, 989015 (April 26, 2016). SPIE Proceedings. doi: $10.1117 / 12.2227651$

\section{FORSCHUNGSPREISE}

Forschungsprofessur 2014-2019 der TH Wildau

1. Preis beim »Best Student Paper Award« der SPIE Photonics Europe 2016 in Brüssel
Prof. Dr. rer. nat. habil. Sigurd Schrader

Patrick Steglich M. Eng.
„Photonik, Laser-und Plasmatechnologien“

„Partially slotted silicon ring resonator covered with electro-optical polymer" 


\section{Produktion und Material Production and Materials}




\section{TelhydrA: Entwicklung eines teleskophydraulischen Aufzugsystems. Teilprojekt: Entwicklung des hydraulischen Steuerungssystems}

Prof. Dr.-Ing. Jörg Reiff-Stephan

$\begin{array}{ll}\text { PROJEKTMITARBEITER } & \text { Uwe Düsterhaus M. Eng.; } \\ \text { KOOPERATIONSPARTNER } & \text { Grädler Fördertechnik GmbH } \\ \text { PROJEKTVOLUMEN } & 188.632 € \\ \text { MITTELGEBER } & \text { Bund | BMWi | ZIM } \\ \text { LAUFZEIT } & 04 / 2016-03 / 2018\end{array}$

Aufgrund der demographischen Entwicklung in Deutschland und Europa, die eine immer weiter alternde Bevölkerung prognostiziert, sowie des wachsenden Wunsches nach erhöhtem Wohnkomfort steigt besonders bei bestehenden niedriggeschossigen Wohnhäusern die Nachfrage nach kostengünstigen und effizienten Aufzugssystemen, die nachträglich an die Gebäudeaußenseite eingebaut werden können. Die heute angebotenen Personenaufzüge, die diesen Zweck erfüllen sollen, weisen jedoch teilweise sehr hohe Anschaffungs- und/ oder Betriebskosten auf und bewirken, bedingt durch ihre Bauform, eine hohe Verschattung der Hausfläche/ Fassade. Diese zusätzliche Verschattung am Gebäude betrifft vor allem Bewohner und Nutzer der unteren
Etagen, die den Aufzug nicht benötigen. Folglich sinkt aufgrund dieser Einschränkungen und der oft hohen Investitions- sowie Betriebskosten die Akzeptanz der Mieter gegenüber dem Einbau eines Aufzugsystems. Da jedoch bei einem nachträglichen Einbau deren Zustimmung erforderlich ist, wird eine Nachrüstung oftmals durch diesen Umstand verhindert. Angesichts des Ziels einer Steigerung des Immobilienwerts, einer Erhöhung des Wohnkomforts und einer langfristigen Anpassung an den demographischen Wandel besteht daher eine profitable Marktnische für kostengünstige, kompakte und weitestgehend verschattungsfreie Aufzugsysteme.

Ziel des Projekts ist die Entwicklung einer neuen Antriebstechnik für hyd- raulische Aufzugsysteme samt integrierter Zylinderführung und minimiertem Bauraum. Das System soll die im vorherigen Punkt adressierten Problemstellungen aufgreifen und durch einen innovativen Lösungsansatz die Verschattung der Gesamtanlage möglichst gering halten. Aufgabe der TH Wildau ist die Entwicklung des hydraulischen Antriebssystems sowie der Hydrauliksteuerung.

\section{PROJEKTWEBSEITE}

http://www.th-wildau.de/im-studium/fachbereiche/inw/inw-studiengaenge/automatisierungstechnik0/ at-forschung/at-telhydra.html

\section{KONTAKT}

joerg.reiff-stephan@th-wildau.de
Gefördert durch:

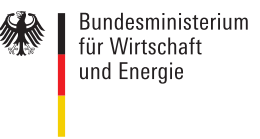

aufgrund eines Beschlusses des Deutschen Bundestages 


\section{Togo: Mensch und Technik - mobile regenerative Energiesysteme in der Savanne für Leben und Bildung}

Prof. Dr.-Ing. Jörg Reiff-Stephan

PROJEKTMITARBEITER

KOOPERATIONSPARTNER

MITTELGEBER

LAUFZEIT
Uwe Düsterhaus, M. Eng. René von Lipinski M. Eng., Sebastian Schulz M. Eng.

Deutsch-Afrikanische Zusammenarbeit e. V.

Bund | BMZ

06/2016-12/2016
Ein Großteil des afrikanischen Kontinents ist noch immer von Armut betroffen. Im besonderen Maße ist dieser Zustand prägend für die westafrikanische Republik Togo. Kennzeichnend für die Region ist das sehr schlecht ausgebaute Energie- und Infrastrukturnetz, das die Entwicklung sowohl im wirtschaftlichen als auch im bildungspolitischen Bereich hindert. Um die Weiterentwicklung des Landes zu fördern, wird die Nutzbarmachung regenerativer Energien mit dem vorliegenden Projekt unterstützt und so ein Beitrag zur „Hilfe zur Selbsthilfe“ geleistet. Hierfür wird eine Analyse der Savannenregion hinsichtlich der klimatischen und kulturellen Bedingungen durchgeführt. Die Analyseergebnisse dienen als Basis für die Ableitung möglicher regenerativer Energieträger und die Erstellung von Konzepten zu deren dezentraler Nutzung. Am Fallbeispiel einer Lehmsteinpresse wird gezeigt, inwieweit der für die Region optimale regenerative Energieträger sinnvoll in mechanische Leistung überführt werden kann. Eine Berechnungsgrundlage zur Auslegung entsprechender Leistungsbedarfe wird abgeleitet. Ein weiterer Teilaspekt behandelt die Entwicklung eines den rauen Umwelt-

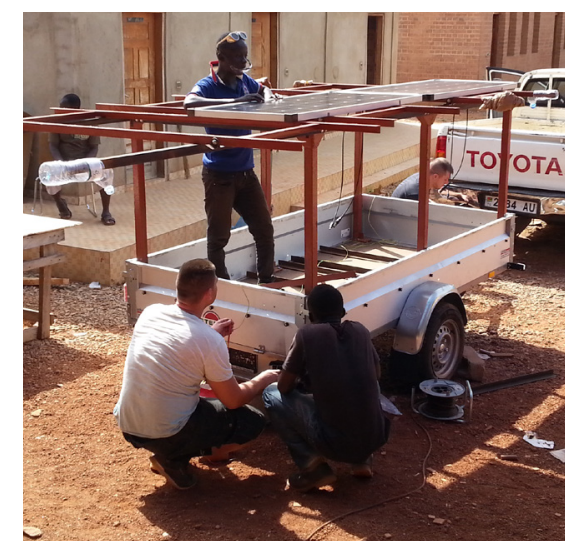

bedingungen gewachsenen mobilen Handyladesystems, um die Energieversorgung der weitläufig vorhandenen Mobiltelefone zu gewährleisten. Ergänzend wird im Rahmen eines Nutzenkonzepts ein denkbares Betätigungsfeld aufgezeigt und durchgespielt. Ausführend wurde nach umfassendem Vergleich das solartechnische Energieträgersystem als Leistungslieferant herangezogen. Bei der konstruktiven Umsetzung, in dessen Verlauf ein mobiler PV-Generator erarbeitet und aufgebaut wurde, gab es verschiedene Faktoren zu berücksichtigen. Die Bedienbarkeit und Wartung der Systeme sollten ohne Kenntnis der Amtssprache Französisch durch nichtqualifiziertes Personal bei

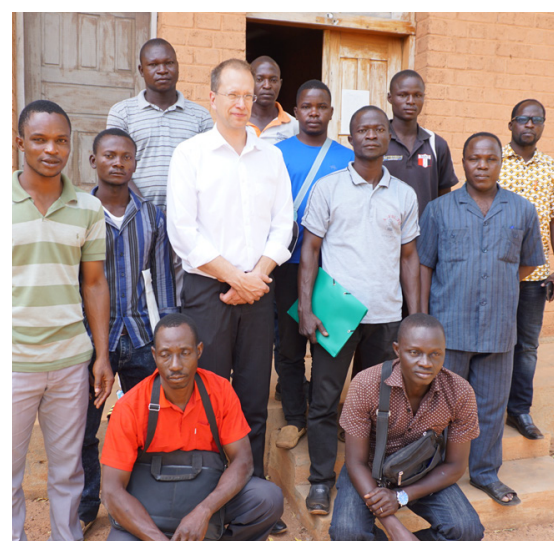

Minimierung von Störanfälligkeit und Wartungsaufwand möglich sein. Da die Versorgung mit Ersatzteilen nicht gewährleistet werden kann, musste zudem die Ausfallwahrscheinlichkeit durch eine robuste Bauweise gesenkt werden. Im Sinne der Hilfe zur Selbsthilfe soll die Bevölkerung motiviert werden, derartige Systeme zu kopieren, um diese dann vielfältig anzuwenden und die Entwicklung des Landes langfristig eigenständig voranzutreiben.

\section{PROJEKTWEBSEITE \\ www.daz-eu.de}

\section{KONTAKT}

joerg.reiff-stephan@th-wildau.de 


\section{HASA-Hocheffiziente-Adsorptionswärmepumpe mit skalierbarem Adsorbens}

Prof. Dr. rer. nat. Franz-Xaver Wildenauer

PROJEKTMITARBEITER

KOOPERATIONSPARTNER

PROJEKTVOLUMEN

MITTELGEBER

LAUFZEIT
Thomas Herzog, Bastian Hutschenreuter

BTU Cottbus-Senftenberg, InvenSor $\mathrm{GmbH}$

$273,000 €$

Bund | BMBF

$11 / 2016-10 / 2019$
Das Ziel ist die Entwicklung einer hocheffizienten Adsorptionswärmepumpe mit dem skalierbaren Sorptionsmaterial DAY- (dealuminierter Y-) Zeolith, der für die Kälte- und Wärmebereitstellung in Industrie und Wirtschaft optimiert ist. Die Investitionskosten in ein Adsorptionssystem sollen um $30 \%$ gesenkt, die Stromaufnahme um $35 \%$ und die benötigte Antriebsenergie um $25 \%$ reduziert werden. Damit lassen sich bei $5 \%$ Marktanteil (DE, IT, FR, GB, TUE, ESP) jährlich ca. 32 Mio. MWh Strom einsparen und ca. 18 Mio. $\mathrm{t} \mathrm{CO}_{2}$ Ausstoß gegenüber der marktbeherrschenden Kompressionsklimatisierung reduzieren. Für das Adsorptionsmaterial ist die Entwicklung eines Herstellungsprozesses im Drehrohrofen für kurze Durchlaufzeiten vorzunehmen. Hierbei sollen die Materialparameter erzielt werden, die einer passgenauen Einstellung auf das neue Anlagenkonzept der Adsorptionswärmepumpe entsprechen. Weitere Aufmerksamkeit gilt dabei dem Aufbau einer Porenhierarchie im Kristall, die eine leichte Desorption und kurze Desorptionswege für das Betriebsmittel Wasser gewährleistet.

\section{KONTAKT}

thomas.herzog@th-wildau.de

GEFÖRDERT VOM

Bundesministerium

für Bildung

und Forschung

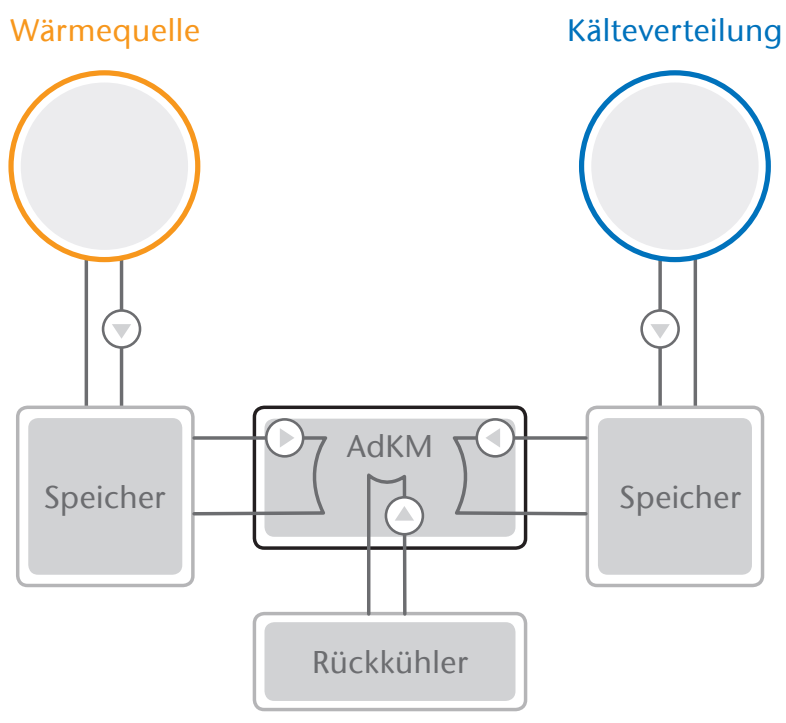

Abb. 1) Vergleich Entwicklung Adsorptionswärmepumpe: links: klassische Entwicklung, rechts: Zielentwicklung
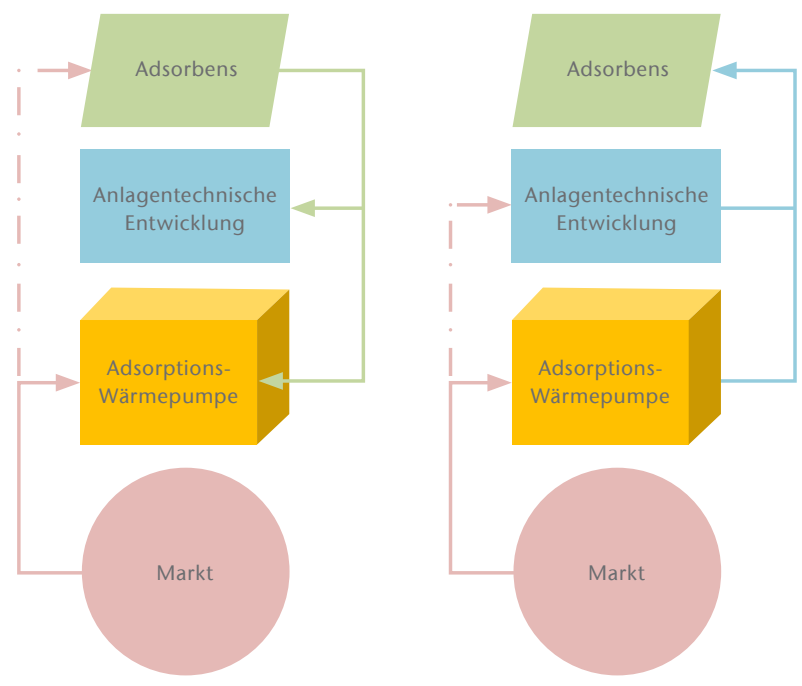


\section{TABELLARISCHE ÜBERSICHT LAUFENDER PROJEKTE}

BIP - Bremsbelag Impedanz Test

\begin{tabular}{|l|l|}
\hline Projektleiter & Prof. Dr. Peter Blaschke \\
\hline Mittelgeber & Bund | BMWi | ZIM \\
\hline Projektvolumen & $193.224 €$ \\
\hline Laufzeit & $04 / 2015-03 / 2017$ \\
\hline
\end{tabular}

Ziel des Projekts ist die Entwicklung eines neuartigen Messverfahrens einschließlich der zugehörigen Gerätetechnik für die Bestimmung der dynamischen Eigenschaften von Bremsbelägen in Abhängigkeit von Bremsdruck und Kolbenposition. Zum Projekt gehören Konzeption, Simulation und Sensitivitätsanalyse eines Bremsbelag Impedanz Tests (BIP) mit spezifischer Messprozedur und eingehender Validierungsergebnisse.

ViKProQuO - Vibroakustische Composit-Prozesskontrolle für Qualitätssicherung und Optimierung

\begin{tabular}{|l|l|}
\hline Projektleiter & Prof. Dr. Peter Blaschke \\
\hline Mittelgeber & Land Brandenburg I MWFK | EFRE \\
\hline Projektvolumen & $325.277 €$ \\
\hline Laufzeit & $07 / 2015-06 / 2018$ \\
\hline
\end{tabular}

Das Ziel des Vorhabens ist die Entwicklung von praxisgerechten vibroakustischen Prüfverfahren für die strukturdynamische Charakterisierung von Compositen. Durch diese innovativen Prüfverfahren können in der Herstellung von Leichtbauprodukten Material, Energie und Ausschuss nachhaltig eingespart werden. Durch die Kooperation der Projektpartner TH Wildau und Fraunhofer Pyco wird die technologische und anwendungsnahe Forschung am Standort Wildau insgesamt nachhaltig gestärkt.

ViTaMinB: Vibroakustikoptimierung mit der Transferpfadanalyse-Methode in Brandenburg

\begin{tabular}{|c|c|}
\hline Projektleiter & Prof. Dr. Peter Blaschke \\
\hline Mittelgeber & Land Brandenburg | MWFK | EFRE \\
\hline Projektvolumen & $46.400 €$ \\
\hline Laufzeit & $02 / 2016-04 / 2017$ \\
\hline \multicolumn{2}{|c|}{$\begin{array}{l}\text { Das Ziel des ViTaMinB-Projektes ist es, messtechnische Grundlagen für die strukturdynamische Charakterisierung von } \\
\text { Composite-Materialien an Maschinen sowie Kraft-, Flug- und Schienenfahrzeugen zu schaffen. Für die Geräuschiden- } \\
\text { tifikation ist es wichtig, die genauen Geräuschquellen und Klangursachen zu kennen und zusätzlich die Tranferpfade } \\
\text { (Körper- bzw. Luftschall)zum Hörohr zu analysieren. Für diese Analyse wird die Transferpfadanalyse und -synthesetechnik } \\
\text { (TPA/TPS) angewendet. }\end{array}$} \\
\hline
\end{tabular}


8sens: Universelles Lesegerät für Schnelltestsysteme (IBA-IVD)

Projektleiter

Prof. Dr. rer. nat. Andreas Foitzik

Kooperationspartner

8sens.biognostic $\mathrm{GmbH}$

Mittelgeber

VDI | VDE

Projektvolumen

$153.248 €$

Laufzeit

01/2016-12/2017

Projekthomepage

http://www.th-wildau.de/im-studium/fachbereiche/igw/igw-studiengaenge/bb-forschung/ mikrosystemtechnik0/mst-forschung.html

Ziel ist die Entwicklung eines Low-Cost-Messsystems für Smartphones zur qualitativen und quantitativen Bestimmung von biologischen Analyten mittels Lateral Flow Assay-Teststreifen. Das Messsystem soll aus einem blickdichten Messgehäuse mit einer Teststreifenaufnahme, einer Weißlichtquelle und einer Fluoreszenz-Lichtquelle bestehen. Kernstück des Gehäuses ist eine Smartphoneaufname im Messgehäuse sowie einer App für Smartphones zur visuellen Aufnahme und Auswertung der Testergebnisse von Lateral.

\section{Designstudie für ein Blutentnahmesystem}

Projektleiter

Mittelgeber

Laufzeit

Prof. Dr. rer. nat. Andreas Foitzik

Midge medical UG

$11 / 2016-01 / 2017$

Die Entwicklung eines mobilen Sytems zur Entnahme von Blut durch einen einfachen Auslösemechanismus ist Ziel dieses Projektes. Abgenommenes Blut wird in ein Reservoir geleitet und dort für weitere analytische Schritte vorbereitet.

\section{Einweg Kühlwärmesystem}

Projektleiter

Mittelgeber

Laufzeit

Prof. Dr. rer. nat. Andreas Foitzik

Wirtschaft

$11 / 2016-01 / 2017$

Dieses Projekt beinhaltet eine Konstruktionsstudie eines Einweg Heiz- und Kühlsystems für eine Herz-Lungen-Maschine auf Basis von 3D CAD-Daten zur Visualisierung des Wärme- und Flusskonzeptes.

\section{Entwicklung technologischer Lösungsansätze zur Umsetzung einer Kunststoff- und Kautschuk-Mikrodichtung}

Projektleiter

Mittelgeber

Laufzeit
Prof. Dr. rer. nat. Andreas Foitzik

Bund | BMWi | ZIM

$09 / 2014-08 / 2016$

Im Rahmen des Projektes wird die Entwicklung einer neuartigen Mikrodichtung als Mikrospritzgußbauteil zur Applikation in Produkten für die Bereiche Life-Science, Medizintechnik und im Maschinenbau angestrebt. Ziel ist hierbei, eine Dichtung zu entwickeln, die in einem geschlossenen bzw. automatisierten Prozess als Massenprodukt reproduzierbar gefertigt werden kann. 
MACIC - Mikro-Absorber für Combustion-Ionenchromatographie

Projektleiter

Prof. Dr. rer. nat. Andreas Foitzik

Mittelgeber

Bund | BMWi | ZIM

Projektvolumen

$194.085 €$

Laufzeit

$05 / 2015-04 / 2017$

Ziel des zu beantragenden Projekts ist die Entwicklung eines miniaturisierten und mikrostrukturierten Absorbers, der einer Verbrennungseinheit nachgestellt und einer Messeinheit für lonenchromatographie vorgeschaltet ist. Mit diesem Absorber sollen kleinste Volumina an Ausgangsstoffen einer dennoch präzisen chemischen Analyse für Halogene und Schwefel zugeführt werden.

MBTK - Entwicklung des Prototyps eines vollautomatischen zellbiologischen Multi BenchTop

\begin{tabular}{|l|l|}
\hline Projektleiter & Prof. Dr. rer. nat. Andreas Foitzik \\
\hline Mittelgeber & Bund | BMWi | ZIM \\
\hline Projektvolumen & $194.292 €$ \\
\hline Laufzeit & $02 / 2015-01 / 2017$ \\
\hline
\end{tabular}

Das angestrebte Projekt verfolgt als Ziel die Realsisierung eines Multi BenchTop Kultivators (MBTK) mit integrierter Sensorik, einem Heiz- und Kühlkreislauf inklusive externen und internen Versorgunsmodulen. Dies soll letztlich die autarke und vor allem vollautomatische Kultivierung von (i) Organoiden, (ii) 3D-Zellkulturen ohne organähnliche Eigenschaften und (iii) 2D-Zellkulturen in Mikroreaktoren ( $\mu$ l-Volumina) ermöglichen.

\section{Orthopädische Unterlagen}

Projektleiter

Prof. Dr. rer. nat. Andreas Foitzik

Kooperationspartner

\section{GRAVIMENS GmbH}

Mittelgeber

\section{Wirtschaft}

Laufzeit

09/2015-03/2016

Ziel des Projektes ist die Optimierung des Designs der orthopädischen Hilfe und die Herstellung eines Prototypen. Hierbei sollen Redesigns der orthopädischen Hilfe auf Basis der vorhandenen Daten erfolgen und berücksichtigen, dass das Produkt auf die Serienproduktion überführbar ist. Des Weiteren muss das Design den optischen Ansprüchen gegenüber dem Patienten gerecht werden. Abschließend werden die Komponenten des Prototypen mit Hilfe von 3D-Druck oder Fräszentren hergestellt. 
PolyMed: Polymere für die Medizintechnik

Projektleiter

Mittelgeber

Projektvolumen

Laufzeit

Prof. Dr. rer. nat. Andreas Foitzik

Bund | BMWi | ZIM

$59.862 €$

$03 / 2016-02 / 2018$

Es ist eine Innovationsplattform auf dem Gebiet der Medizintechnik, insbesonere im Bereich der Kunststoffverarbeitung entstanden. Das strategische Ziel der im Netzwerk zusammengeschlossenen Unternehmen besteht in der Entwicklung, Realisierung und Vermarktung innovativer Kunststoffprodukte sowie die Vernetzung dieser mit elektronischen Komponenten für die Medizinbranche, um langfristig die Innovationskraft der regionalen Wirtschaft zu stärken. Die Grundidee besteht darin, Problemstellungen in Zusammenarbeit zu lösen.

\section{B-Watch - Entwicklung eines sensorbasierten Bewegungsanalysesystems}

Projektleiter

Kooperationspartner

Mittelgeber

Projektvolumen

Laufzeit
Prof. Dr. rer. nat. Thomas Goldmann, Prof. Dr. phil. Bertil Haack

Charité Berlin, DreiF Informationstechnologie GmbH, SATIS INFORMATION GmbH

Bund | BMWi | ZIM

$174.221 €$

$07 / 2014-06 / 2017$

Im Rahmen der sensormotorischen Behandlung von Patienten mit Parkinson-Syndromen, Schlaganfall und anderen neurologischen Erkrankungen ist es erforderlich, Bewegungen präzise, objektiv und ohne hohen technischen bzw. zeitlichen Aufwand zu untersuchen. Beabsichtigt ist die Entwicklung eines sensorbasierten Systems zur Bewegungsanalyse im Prototypen insbesondere für die klinische Anwendung bei Parkinson- und Schlaganfall-Patienten, jedoch mit der Erweiterungsoption auf weitere Anwendungsbereiche.

\section{COMTES - Combined development of compact thermal energy storage technologies}

Projektleiter

Mitarbeiter

Kooperationspartner

Mittelgeber

Projektvolumen

Laufzeit

Projekthomepage
Prof. Dr.-Ing. Udo Hellwig

Dr. Jochen Jänchen

11 Partner aus 5 Staaten (D, DK, CH, AT, GB)

EU | FP 7

$200.000 €$

01/2012-03/2016

http://www.bastianweiss.at/COMTES/comtes-project/

COMTES hat zum Ziel, drei neuartige kompakte Systeme für die saisonale Speicherung von thermischer Solarenergie zu entwickeln und in je einer Demonstrationsanlage zu testen. Dabei soll eine deutlich höhere Speicherdichte als mit Wasser als Speichermedium erreicht werden. In drei parallelen Entwicklungslinien sind als Speichertechnologien die Adsorption in Feststoffen (Zeolithe), der Absorption in Flüssigkeiten (Natronlauge) sowie der Speicherung in einem unterkühlten Latentspeichermaterial (Natriumacetat) vorgesehen. Der Vorteil dreier paralleler Entwicklungslinien besteht in der gemeinsamen Nutzung von Analysen, Methoden und Technologien, die für alle drei Speicherarten gleich sind. Die TH Wildau ist wegen der langjährigen Erfahrungen in der Entwicklung thermischer Adsorptionsspeichermedien für die Auswahl, Charakterisierung, Tests und Beurteilung der festen Adsorbentien eingeladen worden. 


\section{Bio Fitting}

Projektleiter

Mittelgeber

Laufzeit
Prof. Dr. rer. nat. Michael Herzog

Wirtschaft

$11 / 2015-06 / 2016$

Thermische Analyse

BridG iT! - Bridging the Gap through Intercultural Engineering Transposition!

\begin{tabular}{|l|l|}
\hline Projektleiter & Prof. Dr. rer. nat. Michael Herzog \\
\hline Mittelgeber & DAAD \\
\hline Projektvolumen & $200.000 €$ \\
\hline Laufzeit & $01 / 2014-12 / 2017$ \\
\hline
\end{tabular}

Das Projekt Bridging the Gap through Intercultural Engineering Transposition! wird im Rahmen des Programms „Fachbezogene Partnerschaften mit Hochschulen in Entwicklungsländern“ vom DAAD gefördert. Ausgangspunkt ist eine Hochschulkooperation zwischen der Dedan Kimathy University of Technology in Nyeri, Keniy, und der TH Wildau. Ziel des vierjährigen Projekts ist es unter anderem, einen Doppelabschluss Master im Maschinenbau zu etablieren sowie den Studentaustausch zu initiieren.

Entwicklung von UV-beständigen elastischen Vergussmassen mit guter Reparaturfähigkeit

\begin{tabular}{|l|l|}
\hline Projektleiter & Prof. Dr. rer. nat. Michael Herzog \\
\hline Mittelgeber & Bund | BMWi | ZIM \\
\hline Projektvolumen & $174.000 €$ \\
\hline Laufzeit & $01 / 2014-06 / 2017$ \\
\hline
\end{tabular}

Das Ziel dieses Vorhabens ist die Entwicklung neuartiger UV-beständiger Vergussmassen hoher Elastizität für die Anwendung in elektrischen Komponenten wie Verteilern, Schalter Kabelverbindern, Kabelmuffen etc., die im Falle einer Reparatur der betreffenden Komponente leicht entfernt werden können, d. h. dass sie trotz einer hohen Elastizität, die zur Aufnahme der Kabel und/oder Leitungen erforderlich ist, nur in geringem Maße an den verwendeten Materialien haften.

ERA Fellow Sofia: Komptenzaufbau im Wirtschaftssegment mit der Universität für chemische Technologie und Metallurgie in Sofia und Vernetzung der EU 13

\begin{tabular}{|c|c|}
\hline Projektleiter & Prof. Dr. rer. nat. Michael Herzog \\
\hline Mittelgeber & Bund | BMBF | ERA Fellowships 2016 \\
\hline Projektvolumen & $10.830 €$ \\
\hline Laufzeit & $08 / 2016-11 / 2016$ \\
\hline \multicolumn{2}{|c|}{$\begin{array}{l}\text { Aufbauend auf der überdurchschnittlich erfolgreichen Drittmittelakquise der TH Wildau sollen für den ERA-Fellow von der } \\
\text { Universität für Chemische Technologie und Metallurgie Sofia wesentliche Aspekte von Wissenschaftsmanagement und } \\
\text {-administration in einem 3-monatigen Aufenthalt als ERA Fellow an der TH Wildau und in } 2 \text { Campuswochen vermittelt } \\
\text { und aktiv gestaltet werden. Durch die Vernetzung mit weiteren Wissenschafts-Managern und -Einrichtungen bzW. - } \\
\text { Organisationen der EU } 13 \text { Staaten wird die Wettbewerbsfähigkeit im internationalen Wissenschaftsbetrieb, insbesondere } \\
\text { im Rahmen europäischer Ausschreibung, deutlich erhöht. }\end{array}$} \\
\hline
\end{tabular}


Projektleiter

Mittelgeber

Projektvolumen

Laufzeit

Prof. Dr. rer. nat. Michael Herzog

Bund | BMWi | ZIM

$174.660 €$

$12 / 2014-12 / 2016$

Es ist das Ziel dieses Vorhabens, ein Verfahren und eine Anlage zur kontinuierlichen doppelten Beschichtung von kleinen Spritzgussteilen ohne Verwendung von organsichen Lösungsmitteln zu entwickeln. Es soll ein Beschichtungssystem ermittelt und für die speziellen Anforderungen der Kleinteilebeschichtung formuliert und eingestellt werden, wobei die Beschichtung in zwei Schritten erfolgen soll. Der Vorgang erfolgt mit einer speziell metallic eingefärbten ersten und einer hochglänzenden schützenden zweiten Schicht.

\section{In-lining - Entwicklung eines neuen Materials und Verfahrens zum In-lining}

\begin{tabular}{|c|c|}
\hline Projektleiter & Prof. Dr. rer. nat. Michael Herzog \\
\hline Mittelgeber & Bund | BMWi | ZIM \\
\hline Projektvolumen & $190.000 €$ \\
\hline Laufzeit & $07 / 2015-12 / 2016$ \\
\hline
\end{tabular}

Ziel des Vorhabens ist es, durch Kombination von positiv gelisteten Komponenten Formulierungen für den kalten und warmen Trinkwasserbereich auf der Basis von aminhärtenden Epoxydsystemen zu entwickeln und die Anforderungen an die Beschichtungspraxis in Bezug auf die Viskosität der Komponenten, die Topfzeit der Systeme und die Härtungszeit bei Umgebungstemperatur sowie die Eigenschaften der Schichten in Bezug auf Wasseraufnahme, Sauerstoffdiffusion, Festigkeit und Temeraturbeständigkeit zu erreichen.

\section{Mauerwerk Fitting}

Projektleiter

Mittelgeber

Laufzeit
Prof. Dr. rer. nat. Michael Herzog

\section{Wirtschaft}

12/2015-06/2016

In diesem Projekt sollen Altersuntersuchungen in der Klimakammer und mit Mikrotitrierplatten durchgeführt werden.

\section{METALCOAT: Steel products protected by Corrosion inhibiting, self-healing, solvent- and primer-less}

Projektleiter

Mittelgeber

Projektvolumen

Laufzeit
Prof. Dr. rer. nat. Michael Herzog

EU | EUREKA

$182.972 €$

07/2016-12/2018

The project is directed to an new process to coat steel products including galvanized or metal coated steel products by solvent-less coating using a polymer coating material without the application of a primer made by rotational spray coating technology an immediately following a UV curing process to receive metal products smoothly coated by an elastic layer to be chemically bonded to the metal and showing extremely low water and oxygen penetration to avoid corrosion over a log time range. 
Nanonetz - Netzwerkabbildung durch nanoskalige anorganische Verbindungen

Projektleiter

Prof. Dr. rer. nat. Michael Herzog

Kooperationspartner NK Neuhäuser Kunststoff GmbH

Mittelgeber

Wirtschaft

Laufzeit

$03 / 2014-03 / 2016$

Untersuchung der Netzwerkabbildung durch nanoskalige anorganische Verbindungen anhand der mechanischen Parameter Speicher- und Verlustmodul durch DMA (Automatisches Messpendel) Bestimmung der thermischen Eigenschaften (DSC) und der Verteilung nanoskaliger Teilchen in einer Kunststoff-matrix durch AFM

\section{STIBET - Förderung ausländischer Doktoranden aus Partnerhochschulen}

Projektleiter

Prof. Dr. rer. nat. Michael Herzog

Mittelgeber

DAAD

Projektvolumen

$15.600 €$

Laufzeit

$01 / 2016-12 / 2018$

Dieses Projekt dient der Betreuung ausländischer Doktoranden an der TH Wildau.

\section{Untersuchung neuartiger Gele und Hartschalenmaterialien}

Projektleiter

Prof. Dr. rer. nat. Michael Herzog

Mittelgeber

Bund | BMBF

Projektvolumen

$120.850 €$

Laufzeit

$10 / 2015-03 / 2018$

Bei diesem Projekt handelt es sich um ein Teilprojekt des Verbundprojektes zur „Entwicklung von zweilagig isolierend und leitenden Kabelverbindungen, Verzweigungen und Anschlüssen“. Es sollen für diesen Zweck neuartige Gele und Hartschalenmaterialien untersucht werden.

\section{Untersuchungen an Kunststoffmischungen}

Projektleiter

Prof. Dr. rer. nat. Michael Herzog

Kooperationspartner Richter Recycling $\mathrm{GmbH}$

Mittelgeber

Wirtschaft

Laufzeit

03/2014-03/2016

Es sollen spektroskopische (vorzugsweise IR) und thermische (vorzugsweise DSC) Untersuchungen an Kunststoffen bzw. Kunststoffmischungen durchgeführt werden. Diese beinhalten Untersuchungen zu anorganischen nanoskaligen Partikeln in Kunststoffen mittels mikroskopischer (vorzugsweise AFM bzw. REM) und mechanischer (DMA) Verfahren einschließlich der Auswertung und Interpretation der Messwerte. 


\section{UP Harz: Entwicklung UP-Harz Recycling}

Projektleiter

Mittelgeber

Projektvolumen

Laufzeit

Prof. Dr. rer. nat. Michael Herzog

Bund | BMWi | ZIM

$190.000 €$

$12 / 2016-12 / 2018$

Ziel des Vorhabens ist ein Verfahren und eine Anlage zum chemischen Recycling auf der Basis gefüllter ungesättigter Polyesterharze zu entwickeln. Bei der Herstellung von Formteilen auf der Basis von UP-Harzen, die mit parikulären Verstärkungsstoffen gefüllt sind, fallen zwangsläufig Abfälle in Form von Angüssen, Graten oder Ausschussteilen an. Beim Partner GTK liegen die Mengen im Bereich von 8 \% bis $12 \%$ des Produktionsvolumens. Diese Mengen werden zur Zeit nicht wiederverwertet.

\section{Zugproben}

Projektleiter

Prof. Dr. rer. nat. Michael Herzog

Mittelgeber

Wirtschaft

Laufzeit

$11 / 2015-01 / 2016$

Bestimmung mechanischer Eigenschaften: Durchführung von Zugversuchen an Kunststoff-Standardflachproben inkl. grafischer Auswertung.

\section{RevDop: Entwicklung strömungsoptimierter Bauteile im Automotivebereich}

\begin{tabular}{l|l|}
\hline $\begin{array}{l}\text { Projektleiter } \\
\text { Mittelgeber }\end{array}$ & Prof. Dr.-Ing. Stefan Kubica \\
\hline Projektvolumen & $138.600 €$ \\
\hline Laufzeit & $08 / 2016-07 / 2017$
\end{tabular}

RevDop führt Technologieoptimierungen von Strömungsbauteilen für Verbrennungsmotoren durch, um eine Erhöhung des Wirkungsgrades zu erzielen. Somit wird gleichzeitig die Motorleistung gesteigert, der Kraftstoffverbrauch gesenkt und darüber hinaus der Schadstoffausstoß minimiert. Es werden also Zielstellungen für Kosteneinsparungen, nachhaltige Ökologie und Leistungssteigerungen gleichzietig erreicht.

\section{CFD - Simulationstechnik/CFD/FEM}

Projektleiter

Laufzeit
Prof. Dipl.-Ing. Thomas Mirre

$$
09 / 2015-08 / 2018
$$

Das Projekt ermöglicht in verschiedenen Bereichen mit ingenieurmäßigen Methoden der CFD und FEM Bauteil- und Prozesssimulationen durchzuführen, um erforderliche Berechnungen zu Festigkeit, Strömungen, Wärmeübertragungen u. ä. umzusetzen. 
eManag - Technologieprüfung eines Energiemanagementsystems

Projektleiter

Prof. Dr.-Ing. Jörg Reiff-Stephan

Mitarbeiter

René von Lipinski

Mittelgeber

Wirtschaft

Laufzeit

$11 / 2015-02 / 2016$

Im Rahmen des Projektes wird geprüft, ob ein Energiemanagement über industrielle Steuerungstechnik ermöglicht werden kann. Hierbei wird insbesondere auf Steuerungssysteme der Firmen SIEMENS und Beckhoff abgestellt. Die Anforderungen werden hierbei nutzwertanalytisch nach verschiedene Kriterien bewertet und experimentell verifiziert. Als Fallbeispiel wird die Vakuumlötanlage VS320 herangezogen.

MetamoFAB - Metamorphose zur intelligenten und vernetzten Fabrik

Projektleiter Prof. Dr.-Ing. Jörg Reiff-Stephan

Kooperationspartner budatec, Festo, Fraunhofer IPK, Infineon, Pickert \& Partner, Universität Potsdam, Universität Stuttgart

Mittelgeber $\quad$ Bund | BMBF

\begin{tabular}{l|l} 
Laufzeit & $11 / 2013-01 / 2016$
\end{tabular}

Projekthomepage http://metamofab.de

Im Rahmen des Verbundprojektes Metamorphose zur intelligenten und vernetzten Fabrik erfolgt die Bearbeitung verschiedener Ziele: Zum einen die Entwicklung von fallspezifischen Referenzmodellen und zum anderen die Ableitung von erforderlichen Fähigkeiten der beteiligten Entitäten, sowie neuer Regeln für deren Zusammenwirken. Ein weiterer Schwerpunkt des Projektes ist die Entwicklung eines Transformationscockpits, um Entscheidungen, welche in stark vernetzten Systemen getroffen werden, vor der Realsisierung virtuell absichern zu können.

\section{TelhydrA: Entwicklung eines teleskophydraulischen Aufzugsystems}

Projektleiter Prof. Dr.-Ing. Jörg Reiff-Stephan

Kooperationspartner Grädler Fördertechnik GmbH

Mittelgeber $\quad$ Bund | BMWi | ZIM

\begin{tabular}{l|l} 
Projektvolumen & $188.632 €$
\end{tabular}

Laufzeit $\quad 01 / 2016-12 / 2017$

Ziel des geplanten FuE-Kooperationsprojektes zwischen der Grädler Fördertechnik GmbH (GFT) und der TH Wildau ist die Entwicklung eines innovativen hydraulischen Aufzugsystems. Innerhalb des Projektes wird GFT die Hydraulikzylinder, das Führungssystem sowie die Aufzugssteuerung entwicklen. Aufgabe der TH Wildau ist die Entwicklung des hydraulischen Antriebssystems sowie der Hydrauliksteuerung. 


\begin{tabular}{|c|c|}
\hline Projektleiter & Prof. Dr.-Ing. Jörg Reiff-Stephan \\
\hline Mittelgeber & Land Brandenburg | MWFK | EFRE \\
\hline Projektvolumen & $31.064 €$ \\
\hline Laufzeit & 02/2016-10/2017 \\
\hline
\end{tabular}

Mit der Entwicklung der Forschungsstrategie „Industrie 4.0“ wird es wesentlich werden, Produktionsprozesse intelligent zu führen und stetig einen Überblick über die Produktionsentwicklung zu haben. Forschungsaufgaben in diesem Umfeld zielen auf die Weiterentwicklung von SCADA Systemen, um eine selbstanalysierende und -optimierende Produktion zu erreichen. Mit der Anschaffung des Antragsgegenstandes wird die F\&E in diesem Bereich an der Hochschule nachhaltig unterstützt.

\section{Innovative Energiesysteme: Phase 2}

\begin{tabular}{|l|l|}
\hline Projektleiter & Prof. Dr. Siegfried Rolle \\
\hline Mittelgeber & Bund | BMWi | ZIM \\
\hline Projektvolumen & $263.491 €$ \\
\hline Laufzeit & $05 / 2016-04 / 2018$ \\
\hline
\end{tabular}

Die Entwicklung von Kompetenzen innovativer Engeriesysteme bis hin zu einem regenerativ-ambivalenten Kraftwerk auf der Basis regenerativer Energieerzeuger und Energiewandler in Verbindung mit neuen effizienten Speichereinheiten ist das Ziel des Netzwerkes aus Wirtschaft und Wissenschaft. Die Herausforderung in der gemeinsamen Arbeit liegt in der standortgerechten und verbrauchsorientierten Dimensionierung und Steuerung der Einzelkomponenten.

\section{W-NEA BOS BB - Demonstration Brennstoffzellen-USV im Behördenfunk}

Projektleiter

Mitarbeiter

Kooperationspartner

Mittelgeber

Projektvolumen

Laufzeit

Projekthomepage
Prof. Dr. Siegfried Rolle

Denny Ragusch, M. Eng.

Zentraldienst der Polizei des Landes Brandenburg, Projektorganisation Digitalfunk BOS BB

Bund | BMVBS, BMWi, BMBF, BMU | Nationales Innovationsprogramm Wasserstoff- und Brennstoffzellentechnologie

$471.200 €$

$06 / 2012-03 / 2016$

http://www.th-wildau.de/forschungsgruppen/ag-reg-energy0/ag-reg-energy/forschung

Projektgegenstand ist die wissenschaftliche Begleitung eines durch das Nationale Innovationsprogramm Wasserstoff- und Brennstoffzellen-technologie geförderten Projektes: Wasserstoff-Netzersatzanlagen der Behörden und Organisationen mit Sicherheitsaufgaben des Landes Brandenburg des Zentraldienstes der Polizei des Landes Brandenburgs Projektorganisation Digitalfunk BOS BB zur Erprobung von unterbrechungsfreier (Not-)Stromversorgung (USV) mittels Brennstoffzellen als Ersatz von wartungsintensiven und umweltproblematischen Diesel-generatoren im BOS-Digitalfunk. Die Projektorganisation BOS Digitalfunk koordiniert die landesweite Einführung eines bundesweiten Digitalfunknetzes für alle Behörden und Organisationen mit Sicherheitsaufgaben. Unter realen Bedingungen werden verschiedene Brennstoffzellen-USVs in statistisch signifikanter Stückzahl (116) im Flächenland Brandenburg über einen längeren Einsatzzeitraum von ca. 4 Jahren untersucht. Projektziele sind die Erprobung der Brennstoffzellen-USVs unter realen Bedingungen zum Nachweis der Praxistauglichkeit von schon heute verfügbaren Brennstoffzellen-USVs, die Marktvorbereitung und der Verifizierung der angebotenen Service- und Logistikkonzepte auf ihre Praxistauglichkeit. Der Schwerpunkt der technischen Untersuchungen liegt auf der Zuverlässigkeit der Brennstoffzellensysteme unter ständiger Einsatzbereitschaft. Für erweiterte Untersuchungen an einer Brennstoffzellen-USV sowie der Aus- und Weiterbildung von Studierenden und Interessierten wird ein "gläserner" Container an der Technischen Hochschule Wildau aufgebaut. 
HASA: Hocheffiziente Absorptionswärmepumpe mit skalierbarem Absorbens

Projektleiter

Prof. Dr. rer. nat. Franz-Xaver Wildenauer

Mittelgeber

Bund | BMBF

Projektvolumen

$272.376 €$

Laufzeit

$11 / 2016-10 / 2019$

Das Ziel ist die Entwicklung einer hocheffizienten Adsorptionswärmepumpe mit dem skalierbaren Sorptionsmaterial DAY Zeolith, optimiert für die Kälte- und Wärmebereitstellung in Industrie und Wirtschaft. Für das Adsorptionsmaterial ist die Entwicklung eines Herstellungsprozesses im Drehrohrofen für kurze Durchlaufzeiten vorzunehmen. Hierbei sollen die Materialparameter erzielt werden, die einer passgenauen Einstellung auf das neue Anlagenkonzept der Adsorptionswärmepumpe entsprechen.

RauchRei - Entwicklung eines neuartigen Rauchrohrkessels für Brennstoffe mit hohem Ascheanteil

\begin{tabular}{l|l|}
\hline $\begin{array}{l}\text { Projektleiter } \\
\text { Mittelgeber }\end{array}$ & Prof. Dr. rer. nat. Franz-Xaver Wildenauer \\
\hline Projektvolumen & $184.871 €$ \\
\hline Laufzeit & $09 / 2015-08 / 2016$ \\
\hline
\end{tabular}

In diesem Vorhaben soll ein Rauchrohrkessel entwickelt werden, der für die Verbrennung von Brennstoffen mit einem hohen Ascheanteil geeignet ist. Die Entwicklung zielt darauf ab, die Asche- und Partikelablagerungen an der rauchgasseitigen Rohrwand zu reduzieren und Stillstandszeiten des Kessels durch Reinigungsarbeiten zu minimieren. Im Fokus stehen aktive Maßnahmen zur Reduzierung von Partikelablagerungen und der Erhöhung des Kesselwirkungsgrades durch den Einsatz von strukturierten Rohren. 


\section{TABELLARISCHE ÜBERSICHT PUBLIKATIONEN}

\author{
Alarcón D, Mallareddy TT, Blaschke P (2016)
}

Blaschke P, Mallareddy TT, Alarcón D (2016)

Böhme A, Radke L, Schütze F, Schneider S, Liebscher T, Sauer S, Santo L, Quadrini F, Hummel M, Giese C, Frohme M, Foitzik A (2016)

Gatomski G, Nguyen HN, Quadrini F, Foitzik A (2016)

Herzog TH, Jänchen J (2016)

Kornejew E, Goering H, Herzog M (2016)

Kostova J, Schneider S, Sauer S, Böhme A, Casalboni M, Foitzik A (2016)

Liebscher T, Glös F, Böhme A, Birkholz M, Di Vona ML, Matteis F de, Foitzik A (2016)

Lietzau KH, Stollfuß C, Richetta M, Foitzik A (2016)

Lipinski R von, Reiff-Stephan J (2016)

Lipinski R von, Reiff-Stephan J, Buße D (2016)
Application of a 3D Scanning Laser Doppler Vibrometer on the Automatization of Modal Testing of Turbine Blades. In: 17. Nachwuchswissenschaftlerkonferenz ost- und mitteldeutscher Fachhochschulen (NWK 17), Fachhochschule Schmalkalden, Schmalkalden, pp 266-271

Anwendung eines skalierbaren, automatischen Modalhammers und eines 3D Scanning-Laser-Doppler-Vibrometers an Turbinenschaufeln. Application of a Scalable Automatic Modal Hammer and a 3D SLDV on Turbine Blades. In: VDI-Berichte 2259 - 4. VDI-Fachtagung „Schwingungsanalyse \& Identifikation“ 2016. VDI-Berichte. VDI Verlag GmbH, Düsseldorf, ISBN: 978-3-18-092259-1, pp 85-96

Miniaturized Flow-Through Bioreactor for Processing and Testing in Pharmacology. In: Materials Science Forum (Volume 879), pp 236-243. doi: 10.4028/www.scientific.net/MSF.879.236

Components of a Heart Catheter System for High Risk Patients. In: Materials Science Forum (Volume 879), pp 583-588. doi: 10.4028/www. scientific.net/MSF.879.583

Adsorption Properties of Modified Zeolites for Operating Range Enhancement of Adsorption Heat Pumps through the Use of Organic Adsorptive Agents. Energy Procedia 91:155-160. doi: 10.1016/j.egypro.2016.06.192

Optimierung von Epoxidharzsystemen für PE-Rohrinnenbeschichtungen als Sauerstoffsperrschicht. Wissenschaftliche Beiträge 2016 20:67-74. doi: 10.15771/0949-8214_2016_1_9

Novel Bioreactor-System for In Situ-Cultivation of Artificial Tissue. In: Materials Science Forum (Volume 879), pp 1002-1007. doi: 10.4028/www. scientific.net/MSF.879.1002

Affinity Viscosimetry Sensor for Enzyme Free Detection of Glucose in a Micro-Bioreaction Chamber. In: Materials Science Forum (Volume 879), pp 1135-1140. doi: 10.4028/www.scientific.net/MSF.879.1135

Experimental Bio-ESPI for Validation of Magnetic Induced Deformation on HeLa Cells. In: Materials Science Forum (Volume 879), pp 1141-1146. doi: 10.4028/www.scientific.net/MSF.879.1141

Energiedaten als Führungsgröße. Selbstadaptive Grenzwertsetzung hochenergetischer Prozesse. atp edition 58(9):32-41. doi: 10.17560/atp. v58i09.577

Vergleich von Implementierungsmöglichkeiten industrieller Energiemonitoringsysteme für KMU. Wissenschaftliche Beiträge 2016 20:59-65. doi: 10.15771/0949-8214_2016_1_8 
Speeding up the Learning Curve! An Approach to Foster Interpersonal and Intraorganisational Knowledge Sharing in Logistics Competence Development. In: Tomé E (ed). TAKE. E4 Conferences, Lisbon/Portugal, ISBN: 978-989-20-6806-0, pp 786-802

Reiff-Stephan J (2016)

Implementierungsansätze für verteilte Energiemanagementsysteme in der Produktion. In: VDE-Kongress 2016 - Internet der Dinge: Technologien/Anwendungen/Perspektiven. VDE VERLAG GmbH, Berlin·Offenbach, ISBN: 978-3-8007-4308-7

Reiff-Stephan J (2016)

Studieren und Forschen für die Zukunft an einer praxisorientierten Hochschule. Ingenieurwissenschaften - Elektro+Informationstechnik Deutschland 07(16):110-118

Reiff-Stephan J, Lipinski R von (2016)

Automatisierte und selbstadaptive Grenzwertsetzung in Produktionsprozesse auf Basis energetischer Daten. In: Automatisierung im Fokus von Industrie 4.0 : Tagungsband AALE 2016 ; 13. Fachkonferenz, Lübeck. Deutscher Industrieverlag, München, ISBN: 978-383-5673-12-0, pp 183-196

Ristić A, Furbo S, Moser C, Schranzhofer H, Lazaro A, Delgado M, Peñalosa C, Zalewski L, Diarce G, Alkan C, Gunasekara SN, Haussmann T, Gschwander S, Rathgeber C, Schmit H, Barreneche C, Cabeza L, Ferrer G, Konuklu Y, Padilla-Michel Y, Paksoy H, Rammelberg H, Munz G, Herzog TH, Jänchen J, del Barrio EP (2016)

Rogge C, Zinn S, Schneider S, Francini R, Prosposito P, Foitzik A (2016)

Schneider S, Beyer HJ, Lange K, Bohmeyer W, Casalboni M, Richetta M, Foitzik A (2016)

Stollfuß C, Lietzau KH, Richetta M, Foitzik A (2016)

A New Approach for the Spectroscopic Detection of Different pH-Values. In: Materials Science Forum (Volume 879), pp 1606-1611. doi: 10.4028/ www.scientific.net/MSF.879.1606

Miniaturized Laser Power Sensor via Rapid Phototyping. In: Materials Science Forum (Volume 879), pp 1721-1724. doi: 10.4028/www.scientific. net/MSF.879.1721

Novel ESPI Measurement Prototype for Analyzing Biological Samples from Cell Culture Technique. In: Materials Science Forum (Volume 879), pp 1859-1864. doi: 10.4028/www.scientific.net/MSF.879.1859

\section{FORSCHUNGSPREISE}

Prämierter Forschungsbeitrag bei der 17. Nachwuchswissenschaftlerkonferenz im Bereich „Angewandte Naturwissenschaften“
Erik Krumnow, B. Sc „Conception of a validation system for an experimental ESPI setup“ 
Verkehr und Logistik Transport and Logistics 


\section{Scandria2Act}

Prof. Dr.-Ing. Herbert Sonntag

PROJEKTMITARBEITER

KOOPERATIONSPARTNER

PROJEKTVOLUMEN

MITTELGEBER

LAUFZEIT
Philip Michalk

19 Partner aus Finnland, Norwegen, Schweden, Dänemark und Deutschland

$3.600 .000 €$

EU | Interreg BSR

05/2016-04/2019
Die Entwicklung einer gemeinsamen Infrastruktur- und Verkehrspolitik ist ein Thema, das die Europäische Kohäsion auch „physisch“ zum Leben erweckt und daher eine besondere Bedeutung für das Zusammenwachsen der Europäischen Union hat. Das Projekt Scandria2Act ist dabei eines von mehreren sogenannten Korridorprojekten, die Strategien und Anwendungen entlang der TEN-T-Korridore entwickeln, um die regionale Zusammenarbeit der europäischen Partner zu fördern. Scandria2Act beschäftigt sich mit einem Korridor, der vom Norden Schwedens über die ostdeutschen Bundesländer bis an die Adria reicht. Das Projekt fokussiert auf die skandinavischen Staaten und die Bundesländer Mecklenburg-Vorpommern, Brandenburg, Berlin und Sachsen. Der südliche Teil des Korridors soll im Fokus eines weiteren, bereits beantragten Projekts InterGreen stehen (ebenfalls unter Mitwirkung der TH Wildau).

Die FG Verkehrslogistik (FGVL) der TH Wildau erfüllt dabei mehrere Schlüsselrollen im Projekt: Zum einen wird die FGVL, basierend auf ihren reich-

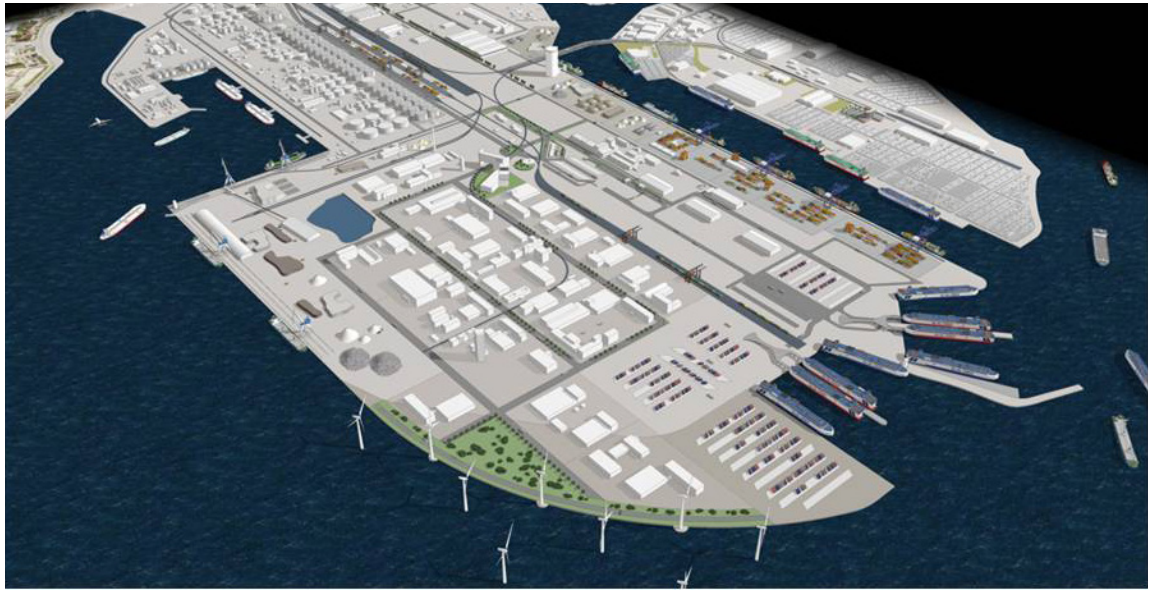

Abb. 1) Der Hafen Malmö in einer möglichen zukünftigen Ausbaustufe ist eines von mehreren Toren zum skandinavischen Markt (Quelle: Scandria.eu)

haltigen Erfahrungen im Bereich der Elektromobilität, an der Entwicklung einer gemeinsamen Harmonisierungsstrategie für elektromobile Anwendungen im Projektraum mitwirken. Zum anderen wird die FGVL die Arbeiten mehrerer Partner koordinieren, um erstmals ein umfassendes und detailliertes Bild der Verkehrsströme zwischen dem Nordosten Deutschlands und den skandinavischen Ländern zu erhalten. Zu diesen Partnern zählen insbesondere der Hafen Ros- tock, die Häfen der Region Skane und die schwedische Verkehrsverwaltung. Basierend auf diesen Arbeiten wird die FGVL dann an Strategien zur Entwicklung nachhaltiger Verkehre im Korridor mitwirken.

\section{PROJEKTWEBSEITE}

http://www.scandria-corridor.eu/ index.php/en/projects/scandria2-act

\section{KONTAKT}

philip.michalk@th-wildau.de

Gefördert durch:

\section{.01100 .010 terreg}

Baltic Sea Region

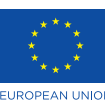

EUROPEAN 


\title{
TABELLARISCHE ÜBERSICHT LAUFENDER PROJEKTE
}

\author{
IwU KMU: Ausbau von Industrie-4.0-Aktivitäten zur wissenschaftlichen Unterstützung von regionalen KMU \\ \begin{tabular}{l|l} 
Projektleiter $\quad$ Prof. Dr.-Ing. Frank Gillert \\
\hline
\end{tabular} \\ Mittelgeber Land Brandenburg | MWFK | EFRE \\ \begin{tabular}{l|l} 
Projektvolumen & $73.500 €$
\end{tabular} \\ Laufzeit $\quad$ 02/2016-06/2017
}

Das Projekt dient der Erweiterung der Intralogistikumgebung der Hochschule hin zu einer geschlossenen Industrie 4.0-Umgebung. Damit soll angewandte Forschung zu Themen rund um Industrie 4.0 in Kooperation mit KMU gefördert werden. Dabei werden moderne Sensoriken und automatische Identifikationstechnologien genutzt, um Prozesse zu automatisieren und autonomen Betrieb zu ermöglichen.

\section{Vivantes - Planung zentrale Marktwirtschaft}

Projektleiter

Prof. Dr.-Ing. Frank Gillert

Kooperationspartner Vivantes Netzwerk für Gesundheit GmbH, Ressort Einkauf- Logistik- Apotheke (ELA)

\section{Mittelgeber Wirtschaft}

Laufzeit $\quad 04 / 2014-02 / 2016$

Die Vivantes AG plant ein Zentrallager im Stadtgebiet von Berlin einzurichten. Das Zentrallager soll seinen Betrieb nach sorgfältiger Planung und Standortauswahl Ende 2015 aufnehmen. Hierzu sollen in verschiedenen Planungsstufen Aspekte des Netzwerkes, der Lagerauslegung und Anforderungen der IT-Struktur geplant und umgesetzt werden.

\section{ELLI: Elektroantrieb für Leichtflugzeug Innovation}

\begin{tabular}{l|l} 
Projektleiter $\quad$ Prof. Dr.-Ing. Wolfgang Rüther-Kindel \\
\hline
\end{tabular}

Mittelgeber Bund | BMWi

\begin{tabular}{l|l} 
Projektvolumen & $499.600 €$
\end{tabular}

Laufzeit $\quad$ 01/2016-12/2017

Ziel des Vorhabens ELLI ist die Umsetzung eines Elktroantriebssystems für eine neue Generation eines hochinnovativen Leichtflugzeugs. 


\section{SAPODS - Smart Airborne Pollutants Detection System}

\begin{tabular}{|l|l|}
\hline Projektleiter & Prof. Dr.-Ing. Wolfgang Rüther-Kindel \\
\hline Kooperationspartner & BLIC (DE), Fluidtume (AT), Chaps (CZ) \\
\hline Mittelgeber & Bund I BMBF I FHprofUnt \\
\hline Projektvolumen & $324.000 €$ \\
\hline Laufzeit & $07 / 2013-06 / 2016$ \\
\hline
\end{tabular}

Die Aufgabe dieses Projektes ist die Weiterentwicklung der Messdrohne ATISS für den Einsatz unter extremen Umweltbedingungen und in großen Höhen zur Befliegung von Aschewolken aktiver Vulkane, sowie die Einrüstung einer speziellen Messtechnik zur Bestimmung von Partikelkonzentrationen und Schadstoffen des Kooperationspartners FH Düsseldorf. Abschließend ist eine Durchführung von Messkampagnen in Island zur Demonstration der Funktionstauglichkeit des Gesamtsystems geplant.

DISBUS - Betriebsoptimierung der Fernbus-Terminal durch ein Steuerungs- und Informationssystem

Projektleiter Prof. Dr.-Ing. Herbert Sonntag

Kooperationspartner BLIC (DE), Fluidtume (AT), Chaps (CZ)

Mittelgeber $\quad$ Bund | BMBF | Eurostars

\begin{tabular}{l|l} 
Projektvolumen $\quad 1.278 .900 €$
\end{tabular}

Laufzeit $\quad 12 / 2015-05 / 2018$

Die Liberalisierung des Busmarktes, hat vor allem in Deutschland aber auch in den Nachbarländern zu einem signifikanten Anstieg der Fernbusverkehre geführt. Die meist innerstädtisch gelegenen Busterminals können aber baulich kaum oder nur in sehr begrenztem Maße erweitert werden. Eine Lösung bietet die optimierte Nutzung der vorhandenen Ressourcen um mehr Verkehre ohne bauliche Veränderung abwickeln zu können. DISBUS entwickelt dazu einen IT-basierten Prototyp für die Optimierung von Betriebsabläufen in Fernbusterminals, einschließlich der Schnittstellen zu Fernbusbetreibern und zu Fahrgastinformationssystemen. Das Projekt zielt auf eine Markteinführung des Produktes, nach Abschluss der Forschungsphase ab.

Mini-Harvester - Entwicklung eines vollmechanisierten Ernteverfahrens zur Pflege von Jungbeständen

\begin{tabular}{l|l|}
\hline $\begin{array}{l}\text { Projektleiter } \\
\text { Mittelgeber }\end{array}$ & Prof. Dr.-Ing. Herbert Sonntag \\
\hline Projektvolumen & $148.845 €$ \\
\hline Laufzeit & $06 / 2015-01 / 2018$ \\
\hline
\end{tabular}

Ziel sind Entwicklung, Test und Bewertung eines funktionsfähigen vollmechanisierten Verfahrens für die Pflege junger Waldbestände mit Kleintechnik. Damit wird eine Verfahrenslücke zur Anwendung im kleinstrukturierten Wald und auf Waldumbauflächen geschlossen. Das wissenschaftliche Hauptziel ist die Erarbeitung von Grunddaten zur Bewertung eines spezifischen Pflege- und Bereitstellungsverfahrens als Beitrag im Bereich der forsttechnischen Forschung. 
PAXNet 2 - Netzwerk für einen multimodalen, öffentlichen Fernbusverkehr in der Donauregion

\begin{tabular}{|c|c|}
\hline Projektleiter & Prof. Dr.-Ing. Herbert Sonntag \\
\hline Mittelgeber & Bund | BMBF \\
\hline Projektvolumen & $21.881 €$ \\
\hline Laufzeit & $05 / 2015-02 / 2016$ \\
\hline
\end{tabular}

\section{Scandria 2 Act: Sustainable and Multimodal Transport Actions in the Scandinavian Adriatic Corridor}

Projektleiter

Mittelgeber

Projektvolumen

Laufzeit

Projekthomepage
Prof. Dr.-Ing. Herbert Sonntag

\section{EU | Interreg BSR}

$293.605 €$

05/2016-05/2019

http://www.scandria-corridor.eu/index.php/en/projects/scandria2-act

Scandria II Act ist ein gemeinsames Projekt von Regionen und Forschungseinrichtungen entlang des Kernnetz-Korridors von Skandinavien an die Adria (Scanmed). Es unterstützt regionale Entwicklungsmaßnahmen im Rahmen der Europäischen Transportpolitik. Schwerpunkte des Projekts liegen in den Bereichen „Alternative Antriebe“, "Multimodaler Transport" und „Trans-Governance“.

\section{SEEN-KV: Simulation des Einsatzes Elektrischer Nutzfahrzeuge im KV}

Projektleiter

Mittelgeber

Projektvolumen

Laufzeit
Prof. Dr.-Ing. Herbert Sonntag

Bund | BMVI

SEEN-KV: Simulation des Einsatzes Elektrischer Nutzfahrzeuge im KV

$10 / 2016-09 / 2018$

Entwicklung eines Simulationsansatzes zur Erforschung und Erprobung von vollelektrischen Fahrzeugflotten im Umschlag und im Nachlauf des kombinierten Verkehr.

\section{SMARTSET - Sustainable MARketdriven Terminal Solutions for Efficient freight transport}

\begin{tabular}{l|l}
$\begin{array}{l}\text { Projektleiter } \\
\text { Mittelgeber }\end{array}$ & EU I CIP / IEE \\
\hline Projektvolumen & $171.480 €$ \\
\hline Laufzeit & $05 / 2013-04 / 2016$
\end{tabular}

SMARTSET untersucht unter anderem den möglichen Betrieb eines City Terminals in Berlin-Tempelhof. Durch den Einsatz von elektromobilen Verteilerfahrzeugen soll der Innenstadtlage Rechnung getragen werden („letzte Meile“). Dadurch sollen Energie und Status nachhaltig gesenkt werden. Die TH Wildau wird zusammen mit dem Senat Berlin ein tragfähiges Geschäftsmodell entwickeln, sodass die Stadt Berlin bereits jetzt die Grundlage für zukünftige, innovative Logistiklösungen legt. 
Strategie zur gemeinsamen Entwicklung des Berliner Großmarktes und des Westhafens

Projektleiter

Prof. Dr.-Ing. Herbert Sonntag

Mittelgeber

BEHALA - Berlinder Hafen- und Lagergesellschaft mbH

Laufzeit

$05 / 2016-12 / 2016$

Drei Schwerpunkte der Strategieentwicklung wurden dem Projekt zu Grunde gelegt:

a) Entwicklung einer gemeinsamen Dachmarke

b) Indikator- und Benchmarkingsystem - Nachhaltigkeit

- Auswahl einer Zieldimension für den Nachhaltigkeitsindikator

c) Einbindung der Entwicklung der Gelände des Westhafens und des Großmarktes in den stadtplanerischen Kontext

- Erstellung einer Zielsystembeschreibung sowie einer Beschreibung der Wirkung von Trends für den stadtplanerischen Kontext

- GIS-Analyse im Nahbereich

- Beschreibung des Vorgehens für die strategische Entwicklung des Geländes“

Unterstützung der Ausarbeitung eines Angebots für die Siemens AG

Projektleiter Prof. Dr.-Ing. Herbert Sonntag

\begin{tabular}{l|l} 
Mittelgeber $\quad$ BEHALA Berliner Hafen- und Lagerhausgesellschaft mbH
\end{tabular}

Laufzeit $\quad$ 05/2016-05/2016

Unterstützung der Ausarbeitung eines Angebots für die Siemens AG - Power and Gas Division

a) Fortentwicklung des bereits entwickelten Hallenplans auf Basis der neuen Input-Werte der Firma Siemens

b) Erstellung eines groben Prozessplans für die Soll-Prozesse des geplanten BEHALA-Angebots

c) Kalkulation der möglichen Produktivitätssteigerung, basierend auf eingesparten Fahrzeug-Kilometern und internen Prozessverbesserungen

VARMA - Value added by optimal wood raw material allocation and processing

\begin{tabular}{l|l} 
Projektleiter Prof. Dr.-Ing. Herbert Sonntag & Pring
\end{tabular}

Mittelgeber Bund | BMEL | ERA-Net WoodWisdomNet+

\begin{tabular}{l|l} 
Projektvolumen & $122.270 €$
\end{tabular}

Laufzeit $\quad$ 03/2014-02/2017

Die Forst- und Holzwirtschaft steht vor der Herausforderung, dem stetig wachsenden Bedarf an Rohstoffen für eine breite Fülle an Nutzungspfaden zu begegnen und die Akteure wettbewerbsfähig aufzustellen. Dies ist auch mit der Aufgabe verbunden, Holzrohstoffe waldseitig versorgungssicher zu verteilen. VARMA greift die entstehenden Herausforderungen auf und hat das Ziel, z.T. grundlegend neue Modelle und Wertschöpfungsketten zu konzipieren. 


\section{TABELLARISCHE ÜBERSICHT PUBLIKATIONEN}

Neumann G, Masurat T (2016)

Samuylov VM, Pokrovskaya OD, Gashkova LV, Sonntag H (2016)
Speeding up the Learning Curve! An Approach to Foster Interpersonal and Intraorganisational Knowledge Sharing in Logistics Competence Development. In: Tomé E (ed). TAKE. E4 Conferences, Lisbon/Portugal, ISBN: 978-989-20-6806-0, pp 786-802

Objective Function Development Based on the Parameters of a Regional Terminal Network. Wissenschaftliche Beiträge 2016 20:75-79. doi: 10.15771/0949-8214_2016_1_10 
Management und Recht Management and Law 


\section{STAY IN TOUCH: MINTalent Relationship Management an der Technischen Hochschule Wildau}

Prof. Dr. rer. pol. Sandra Haas

PROJEKTMITARBEITER(INNEN) Prof. Dr. Dana Mietzner, Prof. Dr. Stefan Kubica, Daniela Schultz, Prof. Dr. Klaus-Martin Melzer, Dr. Anke Renger, Prof. Dr. Tippe

KOOPERATIONSPARTNER Forschungsinstitut für betriebliche Bildung f-bb Kompetenznetzwerk Metallverarbeitung und Umwelttechnik Eisenhüttenstadt e. V. (KoMU) Koordinatorin der Jugendsozialarbeit an Berliner beruflichen Schulen bei der Stiftung SPI Programmagentur: Anne Merfert

OSZ Oder Spree Fürstenwalde/OSZ

TIEM Berlin Spandau

Türkisches Generalkonsulat

PROJEKTVOLUMEN

$250.616 €$

MITTELGEBER

Land Brandenburg | MWFK | ESF

LAUFZEIT

$01 / 2016-12 / 2018$

Neue Wege gehen in der Erschließung neuer Zielgruppen:

Unter Anwendung eines Ansatzes aus dem betrieblichen Personalmarketing, des Talent Relationship Managements, beabsichtigt die Technische Hochschule Wildau, eine spezielle und bislang unzureichend berücksichtigte Gruppe von beruflich Qualifizierten, die versteckten MINT-Talente an Oberstufenzentren (=studierfähige beruflich Qualifizierte, die sich ihrer Studierfähigkeit nicht bewusst sind), als akademischen MINT-Nachwuchs für das Land zu gewinnen.

Das Projektvorhaben zielt auf eine frühzeitige Identifikation und Ansprache versteckter Talente im Hinblick auf eine Weiterentwicklung ihrer Studierfähigkeit und auf eine Bindung an die Technische Hochschule Wildau. Ein besonderes Augenmerk liegt dabei in der Entwicklung von versteckten Talenten aus bildungsfernen Haushalten und/oder mit Migrationshintergrund, wodurch diskriminierende Effekte abgebaut und Chancen auf höhere Bildungsrenditen verbessert werden sollen. Das Vorhaben fördert somit besonders die Umsetzung von Prinzipien der Bildungsgerechtigkeit, Chancengleichheit und Nichtdiskriminierung.

\section{KONTAKT}

sandra.haas@th-wildau.de

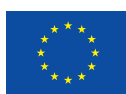

EUROPÄISCHE UNION Europäischer Sozialfonds

Investition in Ihre Zukunft!

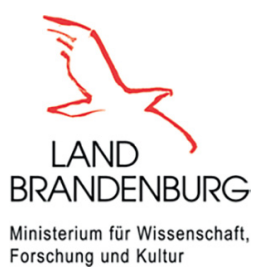




\section{\#talents - Digital Management-Talents Initiative}

Prof. Dr. Dana Mietzner

PROJEKTMITARBEITER(INNEN) Sandra Jakob, Bianca Baumann, Sabine Neumann

PROJEKTVOLUMEN

MITTELGEBER

LAUFZEIT
287.660 Euro

Land Brandenburg | MWFK | ESF

$01 / 2016-12 / 2018$
Digitale Kompetenzen sind heute nicht nur für Fachkräfte der IT grundlegend, sondern durch die Digitalisierung nahezu für alle Berufsgruppen. Aktuell etablieren sich zunehmend neue Berufsbezeichnungen auf dem Arbeitsmarkt, die u. a. technische und kaufmännische Fähigkeiten mit neuen digitalen Kompetenzen verknüpfen (z.B. SEO-, Content- oder Community Manager/innen).

Vor diesem Hintergrund ist auch für Brandenburger Unternehmen der Aufbau digitaler Managementkompetenzen strategisch bedeutsam. Allerdings gibt es eine strukturierte Ausbildung dieser Kompetenzen an deutschen

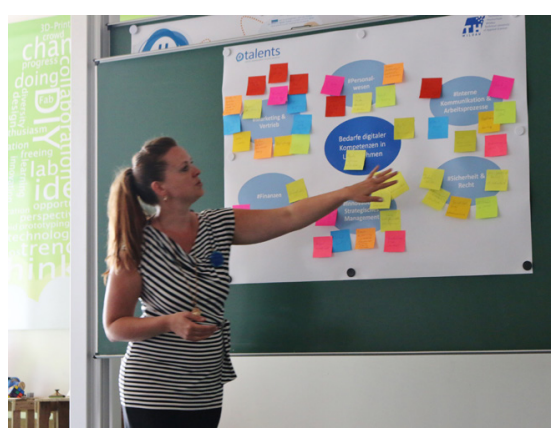

Abb. 1) Interaktive Informations- und Auftaktveranstaltung, "\#talents - meetup", mit Brandenburger Unternehmen und TH Wildau Alumni im ViNN:Lab

Hochschulen bis heute kaum. Das Projekt "\#talents - Digital ManagementTalents Initiative“ widmet sich dieser Problematik, indem es einen Beitrag leistet, diese Lücke insbesondere für Brandenburger Unternehmen und Studierende zu schließen.

Dabei fokussiert \#talents die Erforschung von Digital-Management Talents einerseits, die Aus- und Weiterbildung mit Praxisbezug von Studierenden andererseits: Studierende der TH Wildau erhalten in modularen Workshops digitales Knowhow und wenden dieses anschließend bei der Bearbeitung realer Unternehmensfallbeispiele an.

In der Begleitstudie werden zudem die neuen beruflichen Anforderungen im Zusammenhang mit digitalen Berufsbildern eruiert und analysiert. Neben der Bestandsaufnahme aktueller Berufsbezeichnungen und Kompetenzbedarfsanalysen von regionalen Unternehmen sollen auch Handlungsempfehlungen zur Kompetenzentwicklung von Studierenden für die Hochschule abgeleitet werden.

So trafen sich im Rahmen des Projekts erstmalig im Mai 2016 Brandenburger

Gefördert durch das Ministerium für Wissenschaft, Forschung und Kultur aus Mitteln des Europäischen Fonds für regionale Entwicklung und des Landes Brandenburg.

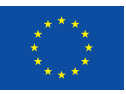

EUROPÄISCHE UNION Europäischer Sozialfonds

Investition in Ihre Zukunft!

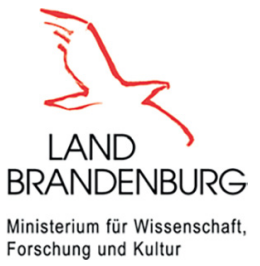

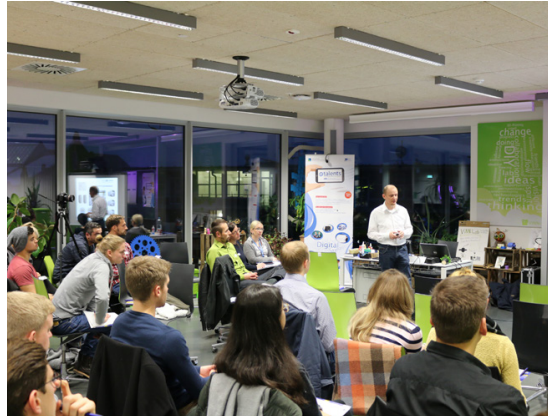

Abb. 2) \#talents - Kick-Off WiSe 2016/2017“: Das erste Zusammentreffen der teilnehmenden Unternehmen und Studierenden im Wintersemester 2016/2107 im ViNN:Lab

Unternehmen sowie Alumni der TH Wildau, um gemeinsam den Wandel digitaler Berufsanforderungen sowie digitale Aufgaben- und Problemfelder in Unternehmen zu reflektieren. Auf der Grundlage dieser interaktiven Veranstaltung wurden sowohl die studentischen Praxisprojekte als auch die inhaltlichen Themen der Workshops für den ersten Durchlauf im WS 16/17 generiert. Studierende besuchten die von externen Experten durchgeführten "Digital Skill Labs" zu den Themenkomplexen digitale Sicherheit, digitales Recht, digitale Etikette, digitales Projektmanagement sowie digitale Content-Strategie und werden ihre Ergebnisse zu den Fallbeispielen nach einer neun-tägigen Praxisphase (u. a. vor Ort bei den teilnehmenden Unternehmen) im Frühjahr 2017 vorstellen.

\section{PROJEKTWEBSEITE \\ www.th-wildau.de/digital-talents}

KONTAKT

digital-talents@th-wildau.de 


\title{
TABELLARISCHE ÜBERSICHT LAUFENDER PROJEKTE
}

\author{
Marketing Deceptions in German Practices
}

Projektleiter

Prof. Dr. iur. Katrin Blasek, Prof. Dr. rer. pol. Sandra Haas

Kooperationspartner Universität Oldenburg: Prof. Dr. Thomas Raabe

Laufzeit $\quad 01 / 2014-12 / 2017$

The interdisciplinary project „Marketing deceptions in German Practices“ focuses on: a) Providing a systematic review of pubilshed cases on false marketing practices in Germany by analyzing cases in terms of published users, using types as well as in terms of violations against $\S 5$ UCA or against the even more undesirable blacklisted per se bans that were introduced in 2008 to impelent EU regulations. b) Analyzing how marketing deceptions are presented within the German media ladscape.

ECMT+: Entrepreneurship and Communication in Multicultural Teams

\begin{tabular}{|c|c|}
\hline Projektleiter & Dr. Gregory Bond \\
\hline Mittelgeber & EU | Erasmus | KA2 Strategic Partnerships \\
\hline Projektvolumen & $56.000 €$ \\
\hline Laufzeit & 09/2016-08/2019 \\
\hline
\end{tabular}

Diese Projekt ist eine Kooperation von sieben europäischen Hochschulen. Das Projket hat drei Säulen: Zum ersten werden Studierende bei internationalen Workshops unternehmerisches Denken und interkulturelle Arbeit praktizieren. In einem begleitenden Forschungsprojekt werden Lehrmethoden für interkulturelles Unternehmertum entwickelt und getestet. Die dritte Komponente ist die Etablierung einer „Community of Practice“ unter Lehrenden.

Emoree - Online-Lernplattform für Schnell-Lesen mit softwarebasierten Schnell-Lesetechniken für Studenten und Berufstätige

\begin{tabular}{l|l} 
Projektleiter & Dipl.-Kauffrau Babette Grothe
\end{tabular}

Mittelgeber $\quad$ EU | Horizont 2020 | SME Instrument

Projektvolumen $\quad 125.000 €$

Laufzeit $\quad$ 07/2015-06/2016

Emoree bietet Cloud-basierte E-Learning-Inhalte für den Bereich Schnell-Lesen für Studenten und Berufstätige an. Die Teilnehmer werden nach neuestem wissenschaftlichen Erkenntnisstand gelehrt und stehen im Mittelpunkt. Die Vermittlung und Einübung neuer Lesetechniken erfolgt in einer virtuellen Lernumgebung, die einen deutlich verbesserten Lernerfolg erzielt: Die Merkfähigkeit wird bis zu 90\% gesteigert. Die Konzentrationsfähigkeit steigt und es kann in deutlich verkürzter Zeit eine 3 bis 5 mal schnellere Lesegeschwindigkeit erlernt werden. Die Kursdurchführung erfolgt durch einem virtuellen Klassenraum, der für alle Lerntypen geeignet ist. Hier entfaltet das Produkt seine Innovationskraft, indem die SchnellLesetechniken mit Hilfe von programmierter Schnell-Lesesoftware gelehrt werden sollen. Die Kursinhalte sind skalierbar, jederzeit aktualisierbar und können an den aktuellen Stand der Technik angepasst werden. Mit dem Einsatz geräteunabhängiger Technologien entscheidet man, wann, wie und wo gelernt wird. Die Eliminierung von acht Weiterbildungsbarrieren, eine intuitiv bedienbare Nutzeroberfläche, schneller Kursbuchbarkeit mit wenigen Klicks nach Zahlungseingang, hoher Kursverfügbarkeit und transparenten Lernfortschritt erzielen ein optimales Lernergebnis. 


\section{B-Watch - Entwicklung eines sensorbasierten Bewegungsanalysesystems}

Projektleiter

Kooperationspartner

Mittelgeber

Projektvolumen

Laufzeit
Prof. Dr. phil. Bertil Haack, Prof. Dr. rer. nat. Thomas Goldmann

Charité Berlin, DreiF Informationstechnologie GmbH, SATIS INFORMATION GmbH

Bund | BMWi | ZIM

$174.220 €$

$07 / 2014-06 / 2017$

Im Rahmen der sensormotorischen Behandlung von Patienten mit Parkinson-Syndromen, Schlaganfall und anderen neurologischen Erkrankungen ist es erforderlich, Bewegungen präzise, objektiv und ohne hohen technischen bzw. zeitlichen Aufwand zu untersuchen. Beabsichtigt ist die Entwicklung eines sensorbasierten Systems zur Bewegungsanalyse im Prototypen insbesondere für die klinische Anwendung bei Parkinson- und Schlaganfall-Patienten, jedoch mit der Erweiterungsoption auf weitere Anwendungsbereiche.

KVR - Aufbau und Durchführung des Bachelor- Studienganges Kommunales Verwaltungsmanagement und Recht

\begin{tabular}{l|l} 
Projektleiter Prof. Dr. phil. Bertil Haack & Pros
\end{tabular}

Mitarbeiter Fr. Anne Herrmann, Hr. Dr. Alfred Krause

Kooperationspartner Brandenburgische Kommunalakademie (BKA)

Mittelgeber Brandenburgische Kommunalakademie

Projektvolumen $\quad 1.755 .000 €$

Laufzeit $\quad$ 09/2009-09/2017

Es ist geplant, den Studiengang „Kommunales Verwaltungsmanagement und Recht“ seitens der TH Wildau in Kooperation mit der Brandenburgischen Kommunalakademie in Potsdam zu konzipieren und umzusetzen. Dieser Studiengang wird als Bachelor-Studiengang im Fachbereich Wirtschaft, Verwaltung und Recht der TH Wildau integriert sein. Er wird unter Leitung und Führung der TH Wildau sowohl an der TH Wildau, als auch bei der Brandenburgischen Kommunalakademie in Potsdam in enger Anlehnung an die Praxis und die dortige Ausbildung zum Verwaltungsfachwirt (analog gehobener Dienst) durchgeführt. Die Semester 1-3 des Studienganges werden an der BKA, die Semester 4-6 an der TH Wildau realisiert. Gemäß Plan werden KVR-Studierende zum SomSem 2011 ihr Studium an der TH Wildau aufnehmen.

\section{STAY IN TOUCH: MINTalent Relationship Management an der TH Wildau}

\begin{tabular}{|c|c|}
\hline Projektleiter & Prof. Dr. rer. pol. Sandra Haas \\
\hline Mittelgeber & Land Brandenburg | MWFK | ESF \\
\hline Projektvolumen & $250.616 €$ \\
\hline
\end{tabular}
Laufzeit
$01 / 2016-12 / 2018$

Unter Anwendung des betrieblichen Talent Relationship Management Ansatzes werden versteckte MINT-Talente an den Oberstufenzentren (= sudierfähige beruflich Qualifizierte, die sich ihrer Studierfähigkeit nicht bewusst sind) als akademischer MINT-Nachwuchs erschlossen. Ein besonderes Augenmerk liegt dabei in der Entwicklung von versteckten Talenten aus bildungsfernen Haushalten und/oder mit Migrationshintergrund. 
\#talents: Digital Management-Talents Initiative

Projektleiter

Prof. Dr. rer. pol. Dana Mietzner

Mittelgeber

Land Brandenburg | MWFK | ESF

Projektvolumen $287.660 €$

Laufzeit

$01 / 2016-12 / 2018$

Der Aufbau digitaler Management-Kompetenzen ist für brandenburger Unternehmen von strategischer Bedeutung. Eine strukturierte Ausbildung dieser Kompetenzen an Hochschulen gibt es hier jedoch kaum. Das Vorhaben „Digital Management-Talents Initiative“ leistet einen Beitrag zur Schließung dieser Lücke, indem es Anforderungen an Digital Management-Talents erforscht und ein Programm aufsetzt, das die Entwicklung der Digital Management-Talents an der Schnittstelle zwischen Studium und Beruf zum Gegenstand hat.

Auf Schienen: EXIST-Gründerstipendium

Projektleiter Prof. Dr. rer. pol. Dana Mietzner

Mittelgeber $\quad$ Bund | BMWi | ESF | EXIST

\begin{tabular}{l|l} 
Projektvolumen $\quad 105.000 €$
\end{tabular}

Laufzeit $\quad 12 / 2016-11 / 2017$

Auf Schienen standardisiert und automatisiert mit einer Software im Internet, einem dazugehörigen Dokumentationssystem und einem während des EXIST-Ptrogramms fertig zu entwicklenden Algorithmus die Vermittlung von Personal und weiterer Ressourcen zwischen Unternehmen innerhalb der Bahnbranche. Die Ergebnisse aus dem EGS-Projekt sollen in ein künfitges technologieorientiertes Dienstleistungsunternehmen der Bahnbranche einfließen.

Coaching:Pilot: Coaching Pilot für den Berufseinstieg von Studierenden im Land Brandenburg

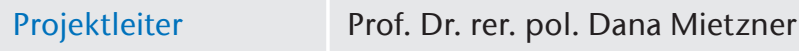

Mittelgeber Land Brandenburg I MWFK | ESF

Projektvolumen $\quad 290.660 €$

Laufzeit $\quad$ 01/2016-12/2018

Das Projekt beinhaltet die Konzipierung, Umsetzung und Evaluierung eines neuen Coaching-Modells, um den Berufseinstieg von Studierenden zu unterstützen. Im Rahmen des Modells werden Studierende und Unternehmen/Coaches in einem strukturierten Prozess gewonnen. Nach einem Pre-Matching von Coaches und Trainees und einem vorbereitenden Elevator Pitch entwickeln Coaches und Trainees gemeinsam mit Unterstützung von Hochschulmitarbeitern innovative Projekte, die in den Unternehmen bearbeitet werden.

Cross.Inn: Entwicklung von labbasierten methodischen Ansätzen für die Umsetzung von Cross-Industry-Innovation

\begin{tabular}{l|l}
\hline $\begin{array}{l}\text { Projektleiter } \\
\text { Mittelgeber }\end{array}$ & Prof. Dr. rer. pol. Dana Mietzner \\
\hline Projektvolumen & $99.800 €$ \\
\hline Laufzeit & $02 / 2016-01 / 2017$ \\
\hline
\end{tabular}

Mit dem Vorhaben soll eine technische Infrastruktur aufgebaut werden, die das Kreativlabor der TH Wildau (ViNN:Lab) erweitert und die Umsetzung von Cross Industry-Innovation unterstützt. Weiterhin soll die Möglichkeit geschaffen werden, das noch junge Forschungsfeld der Cross Industry-Innovation durch neue methodische Ansätze zu stärken und für den Einsatz im unternehmerischen Kontext zu professionalisieren. 
Local OI: Entwicklung und Testen nutzerzentrierter Innovationsmethoden

Projektleiter

Prof. Dr. rer. pol. Dana Mietzner

Mittelgeber

Land Brandenburg I MWFK | EFRE

Projektvolumen

$77.360 €$

Ziel des Vorhabens ist es, eine komplexe technische und räumliche Infrastruktur aufzubauen, mit welcher der Ansatz Local Open Innovation methodisch strukturiert unterstützt und forschungsseitig begleitet werden kann. Hierbei kann das Vorhaben bereits auf sehr gute räumliche Voraussetzungen zurückgreifen, die im Rahmen der Entwicklung eines FabLabs an der TH Wildau geschaffen wurden.

PROKOM 4.0 - Kompetenzmanagement für die Facharbeit in der High-Tech-Industrie: Implementierung eines Foresightprozesses und Analyse regionaler Umsetzungsbedingung

Projektleiter Prof. Dr. rer. pol. Dana Mietzner

Mittelgeber

Bund | BMBF

Projektvolumen

$287.031 €$

Laufzeit

$01 / 2015-12 / 2017$

Ziel des Verbundprojektes ist es, aufzuzeigen, welche Entwicklungen auf der Ebene der Facharbeit in welcher Form forciert werden müssen, damit der demografische Wandel, der Wandel hin zu „Industrie 4.0“ und die Energiewende erfolgreich gemeistert werden können. Ziel des Teilvorhabens ist es, mögliche Zukünfte der Industrie 4.0 herauszuarbeiten, um Anforderungen an die Facharbeit und entsprechende Kompetenzen wissenschaftlich begründet ableiten zu können. In diesem Zusammenhang wird auch die These geprüft, ob und inwieweit das Konzept Industrie 4.0 neue Möglichkeiten für Cross Industry Innovation eröffnet und in welchem Maße Open Innovation-Ansätze erforderlich sind, um Kompetenzen in Unternehmen und Netzwerken aufzubauen, damit Industrie 4.0 nachhaltig implementiert werden kann. Darüber hinaus ist beabsichtigt, Foresightmethoden mit neuen Elementen anzureichern. Ein weiteres Ziel besteht in der Aufklärung der Funktion regionaler Strukturen als Entwicklungsbedingungen für die Industrie 4.0.

START LEAN - Integrierter Gründungservice an der Technischen Hochschule Wildau [FH]

\begin{tabular}{l|l}
\hline $\begin{array}{l}\text { Projektleiter } \\
\text { Mittelgeber }\end{array}$ & Prof. Dr. rer. pol. Dana Mietzner \\
\hline Projektvolumen & $447.105 €$ \\
\hline Laufzeit & $01 / 2015-12 / 2017$
\end{tabular}

START LEAN Gründungsförderung an der Technischen Hochschule Wildau Projekt im Rahmen der gemeinsamen Richtlinie des Ministeriums für Arbeit, Soziales, Frauen und Familie und des Ministeriums für Wissenschaft und Europaangelegenheiten zur Förderung von Qualifizierungs- und Coachingmaßnahmen bei Existenzgründungen im Land Brandenburg 2015. 
Studienstart 2.0 - mobile Beratung für beruflich Qualifizierte

\begin{tabular}{l|l}
\hline Projektleiter & Dr. Andreas Preiß \\
\hline Mittelgeber & Land Brandenburg I MWFK I ESF \\
\hline Projektvolumen & $212.434 €$ \\
\hline Laufzeit & $05 / 2015-02 / 2018$ \\
\hline
\end{tabular}

Mit diesem Projekt wird der geringen Studienneigung beruflich Qualifizierter entgegengewirkt. Für diese äußerst heterogene Zielgruppe ist es nicht leicht, den Weg an die Hochschule zu finden. Als eine Ursache lassen sich Informationsdefizite identifizieren. Bedenkt man darüber hinaus die vergleichsweise höheren beruflichen- und/oder familiären Verpflichtungen beruflich Qualifizierter, zielt das Projekt auf die Erprobung passgenauer, mobiler Beratungsmöglichkeiten.

AQUSIS - Ausbau der Qualifizierungs- und Unterstützungsangebote für internationale Studierende

\begin{tabular}{l|l}
\hline Projektleiter & Rouven Sperling, M. A. \\
\hline Mittelgeber & Land Brandenburg I MWFK | ESF \\
\hline Projektvolumen & $177.654 €$ \\
\hline Laufzeit & $05 / 2015-04 / 2018$ \\
\hline
\end{tabular}

Das Projekt hat das Ziel, ausländische Studierende zu fördern, um ihre Integrationsfähigkeit zu erhöhen. Dabei wird die Strategie der TH Wildau hinsichtlich der Eingliederung von ausländischen Studierenden in den Brandenburger Arbeitsmarkt und dementsprechende Angebote weiterentwickelt. Es wird an Ansätze und Erfahrungen angeknüpft, die in dem Projekt Integration ausländischer Hochschulabsolventinnen und Hochschulabsolventen in den regionalen Arbeitsmarkt" bereits erarbeitet wurden.

Einbeziehung Studierender in das Projekt „Welcome Center“

\begin{tabular}{l|l|}
\hline Projektleiter & Prof. Dr. rer. nat. Ulrike Tippe \\
\hline Mittelgeber & DAAD \\
\hline Projektvolumen & $19.800 €$ \\
\hline Laufzeit & $07 / 2016-12 / 2016$ \\
\hline
\end{tabular}

Zur Unterstützung des im Juni 2016 neu gegründeten „Welcome Centers“ für Geflüchtete an der TH Wildau wurde mit Mitteln des DAAD im Juli 2016 das „Welcome Team“ gegründet, welches aus internationalen Bachelor- und Masterstudierenden besteht. Es soll studentisches Engagement für Geflüchtete in der Umgebung aufbauen, die TH Wildau bei Geflüchteten bekannt machen und der Integration Geflüchteter und internationaler Studierender in die TH Wildau dienen.

Profilgebundene WissensChecks

\begin{tabular}{l|l}
\hline $\begin{array}{l}\text { Projektleiter } \\
\text { Mittelgeber }\end{array}$ & Prof. Dr. rer. nat. Ulrike Tippe \\
\hline Projektvolumen & $66.916 €$ \\
\hline Laufzeit & $01 / 2016-06 / 2018$ \\
\hline
\end{tabular}

Das Projekts ist ein Verbundprojekt der BTU Cottbus-Senftenberg, der TH Wildau, der Hochschule für nachhaltige Entwicklung Eberswalde und der FH Brandenburg. "Profilgebunde WissensChecks" sollen an der TH Wildau in MINT-Fächern erstellt und allen Studieninteressierten für die Entscheidung über die Studienwahl und zur Unterstützung des Studienvortschritts in der Studieneingangsphase zur Verfügung gestellt werden. 
SOS - Strukturierung und Optimierung des Selbststudiums

Projektleiter

Prof. Dr. rer. nat. Ulrike Tippe

Mitarbeiter

Birgit Sellmer, Jacqueline Pudör, Xenia Jeremias, Christian Rabe

Mittelgeber

Bund | BMBF

Projektvolumen

$1.180 .000 €$

Laufzeit

$10 / 2011-09 / 2016$

Projekthomepage

www.th-wildau.de/selbststudium

Ziel des Projekts ist es, Materialien und Unterstützungsangebote für das Selbststudium der Studierenden an der TH Wildau in den Bereichen Mathematik und Rechnungswesen zur Verfügung zu stellen. Wir erproben dabei verschiedene Varianten von E-Learning. Dies umfasst u.a. die Gestaltung von strukturierten Kursräumen auf der Moodle-Lernplattform, online gestützte Materialsammlungen, (Self-)Assessments sowie Online-Tutoring. Eine umfassende Bestandsaufnahme stellt sicher, dass die Materialien die Bedarfe der Studierenden treffen und auch aus Sicht der Lehrenden kompatibel mit den entsprechenden Lehrveranstaltungen sind.

SOS - TEAM: Strukturierung und Optimierung des Selbststudiums - Tutoring, E-Assessment, Mathematik

Projektleiter

Mittelgeber

Projektvolumen

Laufzeit
Prof. Dr. rer. nat. Ulrike Tippe

Bund | BMBF

$1.086 .271 €$

$10 / 2016-12 / 2020$

In der ersten Förderperiode wurden vom Projekt SOS - Strukturierung und Optimierung des Selbststudiums OnlineKursräume und E-Assessments für Mathematik und Rechnungswesen entwickelt, um die Leistungen der Studierenden zu verbessern. In Mathematik war es dafür notwendig, zunächst die Vorbereitungsangebote neu zu konzipieren und im Blended-Learning-Format umzusetzen. In beiden Fachrichtungen wurde allen Studierenden eine tutorielle Unterstützung angeboten. Für E-Assessments wurden die technischen und strukturellen Voraussetzungen geschaffen sowie ein Fragenpool mit insgesamt über 1800 Fragen aufgebaut. Ziele für die zweite Förderperiode sind - der Ausbau des Unterstützungsangebots in Mathematik (erweitert auf Statistik) durch passgenauere, anwendungsbezogene Online-Angebote und Beratung,

- die überfachliche Unterstützung des Selbststudiums,

- der Aufbau eines hochschulweiten Präsenz- und Online-Tutoriensystems und

- die systematische Heranführung der Lehrenden aller Fachgebiete an qualitätsgesicherte E-Assessments.

Die Mathematikmaterialien und E-Assessments sollen für mobile Endgeräte angepasst und zusätzlich in englischer Sprache angeboten werden. Ein Fokus liegt dabei auf der nachhaltigen Einbindung in die Lehre durch Kooperation mit Lehrenden und Struktureinheiten der Hochschule.

TH College: Studienvorbereitung und Studienverlauf - Aufbau des TH Colleges

\begin{tabular}{l|l}
$\begin{array}{l}\text { Projektleiter } \\
\text { Mittelgeber }\end{array}$ & Prof. Dr. rer. nat. Ulrike Tippe \\
\hline Projektvolumen & $411.137 €$ \\
\hline Laufzeit & $01 / 2016-12 / 2018$ \\
\hline
\end{tabular}

Durch den Ausbau der Studienvorbereitung und Studienbegleitung sowie durch Einrichtung einer Koordination zur Vernetzung aller Aktivitäten in den Bereichen Studienorientierung, Studienvorbereitung und studienbegleitung hat das Projekt die Steigerung der Studierfähigkeit und die Erhöhung des Studienerfolgs insbesondere von beruflich Qualifierten, Berufstätigen und Menschen mit Migrationshintergrund zum Ziel. 
Welcome@TH-Wildau: Durchführung des „Welcome@TH-Wildau“-Programmes für Geflüchtete

Projektleiter

Prof. Dr. rer. nat. Ulrike Tippe

Mittelgeber

DAAD

Projektvolumen

$31.500 €$

Laufzeit

10/2016-12/2016

Das im Juni 2016 neu gegründete „Welcome Center“ für Geflüchtete möchte ab Oktober 2016 ein neues Studienvorbereitungsprogramm für Geflüchtete aufbauen und für mindestens 2 Jahre durchführen, um zu einer langfristigen Integration qualifizierter und studienfähiger Geflüchteter beizutragen bzw. diese als zukünftige Studierende für die TH Wildau zu gewinnen und sie optimal auf ein Studium an der TH Wildau vorzubereiten.

BIDS 2015- 2017 - Betreuungsinitiative Deutsche Auslands- und PartnerSchulen

\begin{tabular}{l|l} 
Projektleiter Dipl.-Wirtsch.infor. (FH) Carolina Winkler & D
\end{tabular}

Mittelgeber DAAD

Projektvolumen $\quad 90.000 €$

Laufzeit $\quad 02 / 2015-12 / 2017$

Seit dem Jahr 2002 verfolgt die TH Wildau die Strategie, gezielt Kooperationen mit Deutschen Schulen in Lateinamerika aufzubauen. Diese wurden 2008-2010 im Rahmen des BIDS-Programms vom DAAD gefördert, so dass erhebliche Qualitäts- und Quantitätssprünge in der Betreuung und Akquise lateinamerikanischer Studenten erreicht wurden. Zur Zeit bestehen Kooperationen mit 16 Schulen in Lateinamerika. 


\section{TABELLARISCHE ÜBERSICHT PUBLIKATIONEN}

Althaus M (2016)

Althaus M (2016)

Althaus M (2016)

Althaus M (2016)

Althaus M (2016)

Althaus M (2016)

Althaus M (2016)

Althaus M (2016)

Althaus M (2016)

Althaus M (2016)

Althaus M (2016)

Althaus M, Busch-Janser F (2016)

Althaus M, Busch-Janser F (2016)
Eleanor Roosevelt - Hillarys Idol. Marco Althaus über die linksliberale Ikone der US-Demokraten. Politik \& Kommunikation 14(3):54-56

Evaluation und lose Enden. Leistungsbewertung im Public Affairs Management. In: Holenweger M (ed) Anwendungsgebiete und Grundlagen Strategischer Kommunikation. Nomos, Baden-Baden, pp 58-109

Evitas Affäre mit dem Volk. Politik \& Kommunikation 14(1):70-72

Grundsätze der Politikberatung für die kommunale Jugendlobby. In: W. Lindner WP (ed) Kommunale Jugendpolitik. Beltz Juventa, Weinheim, ISBN: 978-3779934639, pp 252-269

Grundsätze der Politikberatung in der Umsetzung kommunaler Jugendpolitik. In: W. Lindner WP (ed) Kommunale Jugendpolitik. Beltz Juventa, Weinheim, ISBN: 978-3779934639

Politikberatung und Lobbying. In: Rheinland-Pfalz L (ed) Praxisentwicklungsprojekt (PEP) Jugendarbeit. Sozialministerium und Landesjugendamt Rheinland-Pfalz, Mainz

Regierungskommunikation als Herausforderung für die Politikberatung. In: Raupp J, Kocks JN, Murphy K (eds) Regierungskommunikation und staatliche Öffentlichkeitsarbeit im Wandel. Springer VS, Wiesbaden

Rien n'est perdu - nichts ist verloren. Marco Althaus über Charles de Gaulles eigenwilligen Führungsanspruch. Politik \& Kommunikation $14(2): 66-68$

Telexnetz im Nachrichtenrausch. Politik \& Kommunikation 14(4):82-84

Vom Verbands-Trainee bis zum HGF. Personalentwicklung bei Verbänden. In: F. Busch-Janser MA (ed) Karriereguide Verbandsmanagement. Polisphere, Berlin, ISBN: 9783945145005, pp 15-34

Vorwort. In: Politische Kampagnen auf Facebook. Ein Leitfaden für Politiker und Amtsträger, Berlin

Einleitung: Wegweiser durch das Arbeitsfeld Verbände. In: F. BuschJanser F \& Althaus M (eds) Karriereguide Verbandsmanagement. Polisphere, Berlin, ISBN: 9783945145005, pp 7-14

Karriereguide Verbandsmanagement. Polisphere, Berlin, ISBN: 9783945145005 
Baetge D (2016)

Baetge D (2016)

Baetge D (2016)

Baetge D (2016)

Baetge D (2016)

Baetge D (2016)

Baetge D (2016)

Baetge D (2016)

Baetge D (2016)

Baetge D (2016)

Baetge D (2016)
Gewöhnlicher Aufenthalt und Personalstatut von Flüchtlingen. Das Standesamt (StAZ) 69(10):289-295

Kommentierung von $\S 1$ UKlaG (Unterlassungs- und Widerrufsanspruch bei AGB). In: Junker M, Beckmann R, H. Rüßmann H (eds) Juris Praxiskommentar BGB, 8th edn. Juris, Saarbrücken, ISBN: 978-386330-153-8, Rn. 1-40

Kommentierung von § 13 UKlaG (Auskunftsanspruch der anspruchsberechtigten Stellen). In: Junker M, Beckmann R, H. Rüßmann H (eds) Juris Praxiskommentar BGB, 8th edn. Juris, Saarbrücken, ISBN: 978-386330-153-8, Rn. 1-13

Kommentierung von $\S 13 a$ UKlaG (Auskunftsanspruch sonstiger Betroffener). In: Junker M, Beckmann R, H. Rüßmann H (eds) Juris Praxiskommentar BGB, 8th edn. Juris, Saarbrücken, ISBN: 978-3-86330153-8,Rn. 1-11

Kommentierung von § 1a UKlaG (Unterlassungsanspruch wegen Beschränkung der Haftung bei Zahlungsverzug). In: Junker M, Beckmann R, H. Rüßmann H (eds) Juris Praxiskommentar BGB, 8th edn. Juris, Saarbrücken, ISBN: 978-3-86330-153-8,Rn. 1-11

Kommentierung von § 2 UKlaG (Ansprüche bei verbraucherschutzgesetzwidrigen Praktiken). In: Junker M, Beckmann R, H. Rüßmann H (eds) Juris Praxiskommentar BGB, 8th edn. Juris, Saarbrücken, ISBN: 978-3-86330-153-8, Rn. 1-32

Kommentierung von $\S 2 \mathrm{a}$ UKlaG (Unterlassungsanspruch nach dem Urheberrechtsgesetz). In: Junker M, Beckmann R, H. Rüßmann H (eds) Juris Praxiskommentar BGB, 8th edn. Juris, Saarbrücken, ISBN: 978-386330-153-8, Rn. 1-9

Kommentierung von § $2 \mathrm{~b}$ UKlaG (Missbräuchliche Geltendmachung von Ansprüchen). In: Junker M, Beckmann R, H. Rüßmann H (eds) Juris Praxiskommentar BGB, 8th edn. Juris, Saarbrücken, ISBN: 978-386330-153-8, Rn. 1-21

Kommentierung von $\S 3$ UKlaG (Anspruchsberechtigte Stellen). In: Junker M, Beckmann R, H. Rüßmann H (eds) Juris Praxiskommentar BGB, 8th edn. Juris, Saarbrücken, ISBN: 978-3-86330-153-8, Rn. 1-21

Kommentierung von § 3a UKlaG (Anspruchsberechtigte Verbände nach § 2a). In: In: Junker M, Beckmann R, H. Rüßmann H (eds) Juris Praxiskommentar BGB, 8th edn. Juris, Saarbrücken, ISBN: 978-386330-153-8, Rn. 1-10

Kommentierung von § 4 UKlaG (Qualifizierte Einrichtungen). In: Junker M, Beckmann R, H. Rüßmann H (eds) Juris Praxiskommentar BGB, 8th edn. Juris, Saarbrücken, ISBN: 978-3-86330-153-8, Rn. 1-19

Kommentierung von $\S 4 \mathrm{a}$ UKlaG (Unterlassungsanspruch bei innergemeinschaftlichen Verstößen). In: Junker M, Beckmann R, H. Rüßmann $\mathrm{H}$ (eds) Juris Praxiskommentar BGB, 8th edn. Juris, Saarbrücken, ISBN: 978-3-86330-153-8, Rn. 1-12 

Hochschulen. In: Lehren und Lernen von Mathematik in der Studieneingangsphase. Konzepte und Studien zur Hochschuldidaktik und Lehrerbildung Mathematik. Springer Fachmedien, Wiesbaden, ISBN: 978-3-658-10260-9, pp 115-129. doi: 10.1007/978-3-658-10261-6_8 satzfunktionen und Rabattarten. Wissenschaftliche Beiträge 2016 20:81-87. doi: 10.15771/0949-8214_2016_1_11

\section{Haack B (2016)}

Wie ihr bei einem Burgenbauprojekt erfolgreich sein könnt. In: Schlaurier T (ed) Wir gehen studieren. Wildau Verlag $\mathrm{GmbH}$, Wildau, ISBN: 978-3-945560-06-8, pp 93-114

Haack B, Attrey A, Barr J, Meghnagi M, Brandenburger B (2016)

Haack B, Müller-Trabucchi M (2016)

Haack B, Müller-Trabucchi M (2016)

Haack B, Müller-Trabucchi M (2016)

Haas S, Schmidt L (2016)

Haas S, Schmolke T (2016)

Hantel P (2016)

Hantel P (2016)

Hantel P (2016)

Hartmann F, Lahr M, Mietzner D (2016)
Boosting Job Creation Project - The Brandenburg Review. OECD.

Best of Agile - Neupositionierung der TD zwischen Information Management und „Neccessary Overhead“. In: pp 401-403

Beyond Zeitmanagement. Agile Methoden als Moderatoren der Beschleunigung. In: tcworld, pp 121-123

Wege aus der Zeitfalle. technische kommunikation 38(2):18-26

What Drives the Success of Pop-Up Stores? Wissenschaftliche Beiträge 2016 20:89-95. doi: 10.15771/0949-8214_2016_1_12

Die Abo-Commerce Landschaft in Deutschland: Eine angebotsbezogene Untersuchung. Wissenschaftliche Beiträge 2016 20:97-102. doi: 10.15771/0949-8214_2016_1_13

Europäisches Arbeitsrecht. Mit zahlreichen Beispielsfällen aus der Rechtsprechung des EuGH. Springer, Berlin, Heidelberg. ISBN: 978-3662-46893-7. doi: 10.1007/978-3-662-46894-4

Öffentliche Auftragsvergabe und unionsrechtliche Mindestarbeitsbedingungen. Zeitschrift für euroäisches Sozial- und Arbeitsrecht 15(4):159-164

Unionsrechtliche Voraussetzungen und Grenzen für den Ausschluss von EU-Ausländern von Sozialhilfeansprüchen. Neue Justiz 70(4):133140

Maker Movement as a Path of Digital Transformation? Current Understanding and How It May Change the Social and Economic Environment. In: Athens Institute for Education and Research, Athen, ISBN: 978-960-598-077-1, pp 29-30 
Hartmann F, Mietzner D (2016)

Hartmann F, Mietzner D, Dinh H (2016)

Hartmann F, Mietzner D, Zerbe D (2016)

Hubert T (2016)

Hubert T (2016)

Hubert T (2016)

Kunkel C (2016)

Kunkel C (2016)

Kunkel C (2016)

Kunkel C (2016)

Kunkel C (2016)

Kunkel C, Kunkel O (2016)

Kunkel C, Kunkel O (2016)
Szenarien zur Transformation von Energieversorgungssystemen als Voraussetzung für die Ableitung von Anforderungen an zukünftige Kompetenzen. Technische Hochschule Wildau [FH]. doi: 10.15771/0949-8214_2016_1_14

Industrie 4.0 Affinität von Branchen und Regionen. Working paper zum Projekt PROKOM 4.0. In: Wildau. doi: 10.13140/RG.2.1.2801.1122

Die Maker Bewegung als neues soziales Phänomen - Ergebnisse einer qualitativen Inhaltsanalyse ausgewählter Massenmedien. doi: 10.13140/RG.2.2.32111.02727

Steuerneutrale Realteilung auch bei Ausscheiden eines Mitunternehmers aus einer Mitunternehmerschaft? StuB online 8:292-296

Unternehmenssteuern, 2. Auflage. Kompakt-Training Praktische Betriebswirtschaft. Kiehl, Herne. ISBN: 978-3-470-65452-2

Verlustanteile aus der Beteiligung an einer Personengesellschaft in den Bilanzen einer (anderen) Personengesellschaft. Erfassungsmethoden in Handels- und Steuerbilanz. StuB online 20:769-776

Keine Verletzung des Anspruchs auf faire Verfahrensgestaltung durch Versagung von Akteneinsicht gem. § 406e StPO, wenn mutmaßlich verletzte Strafnorm (hier: § 20a WpHG) keine drittschützende Wirkung hat. juris PraxisReport Compliance \& Investigations 3(3):Anmerkung 3

Rechtsfolgen der wirksamen Einziehung eines Geschäftsanteils. JurisPraxisReport Handels- und Gesellschaftsrecht 8(6):Anmerkung 5

Vertragsgestaltung. Eine methodisch-didaktische Einführung. Springer, Berlin, Heidelberg. ISBN: 978-3-662-48430-2. doi: 10.1007/978-3662-48431-9

Wirtschaftsrecht, 1st edn. Schriftenreihe des Privaten Intituts für Angewandtes Wirtschaftsrecht/Gesellschaftsrecht III. Neopubli, Berlin. ISBN: 978-3-7418-2470-8

Zur Ordnungsgeldsanktionierung gem. § 335 HGB bei verspäteter Offenlegung des Jahresabschlusses einer UG (haftungsbeschränkt). Juris-PraxisReport Strafrecht 10(4):Anmerkung 5

Gesellschaftsrecht I, 2nd edn. Schriftenreihe des Privaten Intituts für Angewandtes Wirtschaftsrecht. Neopubli, Berlin. ISBN: 9783741845123

Gesellschaftsrecht II, 2nd edn. Schriftenreihe des Privaten Intituts für Angewandtes Wirtschaftsrecht. Neopubli, Berlin. ISBN: 9783741845130 
Zur Vermögenslosigkeit einer GmbH i. S. d. § 394 Abs. 1 FamFG - ein Beitrag „de lege ferenda" und zugleich eine Besprechung von OLG Karlsruhe v. 21.08.2014, 11 Wx 92/13. Der Deutsche Rechtspfleger 124(7):381-385

Mietzner D, Schultz C (2016)

Mietzner D, Schultz C (2016)

Schultz C, Mietzner D, Hartmann F (2016)

Seeliger F (2016)
Collaborative Discovery of Technology-Driven Business Opportunities. In: FGF e.V, Leipzig

Nachgründungsphase - Mit systematischen Methoden strategische Entscheidungen treffen und Wachstum sichern. In: Siemon C, Müller K-D (eds) Methoden für die Gründungsqualifizierung. Update international: Bewährtes und Neues. tredition GmbH, Hamburg, ISBN: 978-3-7345-1865-2, pp 151-170

Action Research as a Viable Methodology in Entrepreneurship Research. In: Kuckertz ESCB\&A (ed) Complexity in Entrepreneurship, Innovation and Technology Research. FGF Studies in Small Business and Entrepreneurship. Springer International Publishing, Schweiz, ISBN: 978-3-319-27106-4, pp 267-283. doi: 10.1007/978-3-319-27108-8_13

Buchsicherung in Bibliotheken. In: N. Lushington WRLW (ed) Entwurfsatlas Bibliotheken. Birkhäuser, Basel, ISBN: 9783038216292, pp 114-119. doi: 10.1515/9783038216292-019

RFID und moderne technische Infrastruktur. In: Werner PH\&KU (ed) Praxishandbuch Bibliotheksbau. De Gruyter Saur, Berlin, ISBN: 9783110403183, pp 326-335. doi: 10.1515/9783110403183-024

\section{FORSCHUNGSPREISE}

Forschungsprofessur 2012-2017 der TH Wildau

Forschungsprofessur 2014-2019 der TH Wildau
Prof. Dr. rer. pol. Dana Mietzner

Prof. Dr. rer. nat. Margit Scholl

\begin{abstract}
„Innovations- und
Regionalmanagement"
\end{abstract}

"Ganzheitlicher Aufbau und partizipatives Management von Smart-Technologien des 21. Jahrhunderts“ 


\section{Technische Hochschule}

Wildau

Technical University

of Applied Sciences

Hochschulring 1

15745 Wildau

\section{Germany}

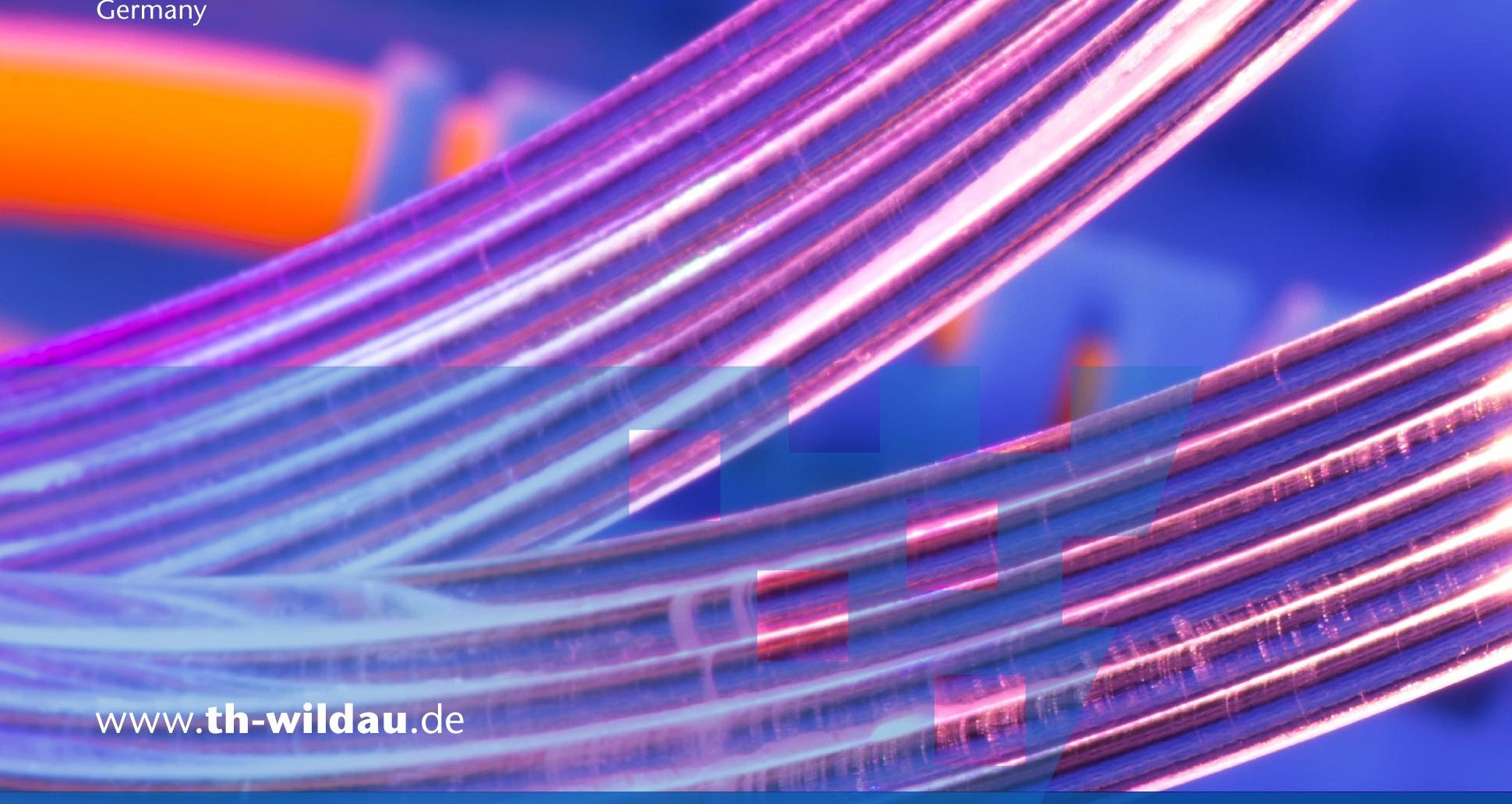

